Roberta Pacheco Damasceno

Uso de recursos alimentares e eletividades na dieta de uma assembléia de anuros terrícolas das dunas do médio Rio São Francisco, Bahia.

São Paulo

2005 
Roberta Pacheco Damasceno

\section{Uso de recursos alimentares e eletividades na dieta de uma assembléia de anuros terrícolas das dunas do médio Rio São Francisco, Bahia.}

Dissertação apresentada ao Instituto de Biociências da Universidade de São Paulo, para a obtenção de Título de Mestre em Ciências, na Área de Zoologia.

Orientador: Prof. Dr. Pedro L. B. da Rocha

\section{São Paulo \\ 2005}


Damasceno, Roberta

Uso de recursos alimentares e eletividades na dieta de uma assembléia de anuros terrícolas das dunas do médio Rio São Francisco, Bahia. $110 \mathrm{p}$.

Dissertação (Mestrado) - Instituto de Biociências da Universidade de São Paulo. Departamento de Zoologia.

1. Dieta 2. Anura 3. Caatinga I. Universidade de São Paulo. Instituto de Biociências. Departamento de Zoologia.

Comissão Julgadora:

$\operatorname{Prof}(a) . \operatorname{Dr}$ (a)

Prof(a). Dr.(a)

$\operatorname{Prof}(a) . \operatorname{Dr} .(a)$

Prof(a). Dr.(a)

Prof. Dr. Pedro L. B. da Rocha

Orientador 
Aos que sempre me apóiam e me permitem apenas dar passos em frente: meus pais, P. Luís e Hermes. 


\section{AGRADECIMENTOS}

Gostaria de agradecer imensamente a todos que da alguma maneira contribuíram para a realização desse trabalho, em especial:

A Fundação Boticário de Apoio à Natureza, CADCT/SEPLANTEC, CNPq, CAPES e FAPESB, pelos apoios financeiros concedidos; Ao Prof. Pedro Rocha, pela dedicação e pela disposição interminável para discutir o projeto; A meus pais, pelo apoio, generosidade e compreensão constantes; A Hermes S. Oliveira, por ter se envolvido tanto nesse projeto e pelo trabalho de diagramação;

Ao Prof. Miguel T. Rodrigues, pela atenção e apoio dispensados; Aos colegas do LVT, por formarem uma poderosa e prazerosa equipe de trabalho;

Aos colegas e amigos Sheila, Camila e Ricardo, por estarem presentes durante mais essa dura jornada;

A Wly, por ter tornado a estada em São Paulo tão divertida; Aos funcionários das Secretarias do Departamento de Zoologia e da PósGraduação da USP, pelo atendimento sempre prestativo e célere às minhas solicitações, feitas muitas vezes de longe. 


\section{SUMÁRIO}

Resumo

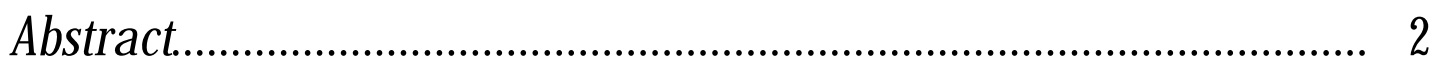

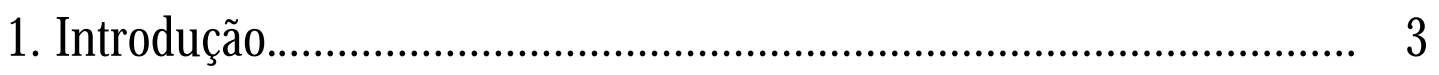

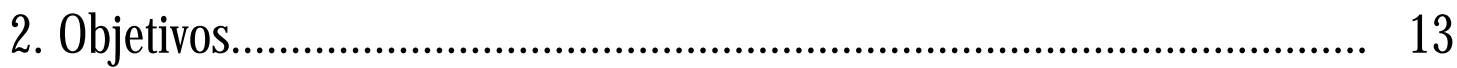

3. Material e Métodos.......................................................................... 15

4. Resultados............................................................................... 34

5. Discussão............................................................................ 46

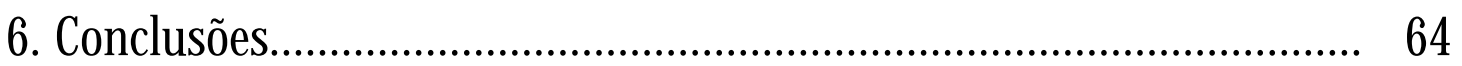

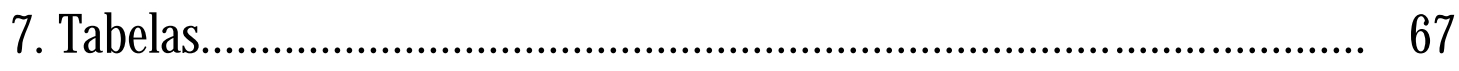

8. Figuras

9. Referências bibliográficas........................................................... 100 


\section{RESUMO}

A surpreendente descoberta de uma assembléia de anuros terrícolas extremamente abundante, sintópica à fauna peculiar de lagartos, serpentes e anfisbenas, numa localidade dos mares de areia do médio Rio São Francisco (estado da Bahia, Brasil) motivou: (1) o estudo do uso de alimento e eletividades na dieta dos anuros locais, (2) a investigação de evidências de adaptação na sua dieta ao ambiente desafiador das dunas e (3) a avaliação do possível impacto que os anuros causam na assembléia sintópica de Squamata anteriormente estudada. $\mathrm{O}$ uso de alimento e as eletividades na dieta das três espécies de anuros mais abundantes, assim como suas variações ontogenéticas, foram descritas e premissas sobre adequação das estimativas de uso e disponibilidade de recursos alimentares foram testadas. Evidências de adaptação nas dietas dos anuros às dunas foram feitas comparando-se sua dieta com as de espécies filogeneticamente próximas. As estimativas de uso e de disponibilidade utilizadas foram consideradas adequadas. Bufo granulosus apresentou eletividade positiva por formigas. Pleurodema diplolistris e Physalaemus albifrons apresentaram ambos eletividade positiva por besouros e eletividade negativa por cupins e por formigas, respectivamente. Não houve variação ontogenética nos tipos de presa consumidas por nenhuma das espécies estudadas e isso não pôde ser atribuído à avaliação de uma pequena extensão de tamanhos dos anuros. Variações ontogenéticas no tamanho das presas foram observadas apenas para B. granulosus e P. diplolistris. Não houve evidência de apomorfia na dieta de B. granulosus e não houve dados disponíveis suficientes para realizar essa análise para P. diplolistris. As apomorfias registradas na dieta de P. albifrons podem ser explicadas por interações competitivas com outros componentes da herpetofauna local. Os anuros não parecem causar impacto forte sobre a assembléia de Squamata sintópica, devido a divergências nas eletividades por alimento e nos horários de atividade entre a maioria deles e grande parte desse padrão divergente parece ter se estabelecido antes da formação dessa assembléia. A eletividade positiva por formigas de B. granulosus e do tropidurídeo Tropidurus psammonastes pode apontar interação competitiva contemporânea entre eles, devido a suas grandes abundâncias locais. No entanto, é necessário haver indícios de limitação de recursos para levantar tal hipótese, porque a divergência nos horários de atividade deles impede competição por interferência. Mas formigas são abundantes na área. 


\section{ABSTRACT}

The discovery of an extremely abundant anuran terrestrial assemblage, that is syntopic to a peculiar fauna of lizards, snakes, and worm snakes, in a locality at the sand dune fields of the Middle São Francisco River (Bahia state, Brazil) motivated: (1) the study of food use and electivities of local anurans, (2) investigations about evidences of adaptation in anurans' diet to the challenges of a semi-arid environment, and (3) the assessment of the impact caused by anurans on the Squamata syntopic assemblage already studied. Food use, food electivities, and ontogenetic variation in diet of the three most abundant anuran species were described, and premises about the adequacy of the used estimates of food use and food availability were tested. Evidences of adaptation in diet were assessed by comparison of the diet of anurans from the dunes and that of phylogenetically related species. Estimates of food use and availability were considered suitable. Bufo granulosus showed positive electivity for ants. Pleurodema diplolistris and Physalaemus albifrons had both positive electivities for beetles and negative electivities for termites and ants, respectively. No species changed the types of prey it consumed during ontogeny and this was not a spurious result of a narrow range of anurans size analyzed. B. granulosus and P. diplolistris ate bigger preys as they grew. There was no evidence of adaptation in B. granulosus diet and insufficient data precluded this analysis with $\mathrm{P}$. diplolistris diet. Apomorphies registered in P. albifrons diet can be explained by ecological contemporary interactions with local herpetofauna components. Anurans do not seem to cause a big impact on Squamata syntopic species, because in general anurans and squamates show divergent food electivities and/ or activity times. Moreover, most of this divergent pattern has probably evolved before the establishment of the current assemblage. Coincident positive electivities for ants of B. granulosus and the tropidurid Tropidurus psammonastes can be an indicative of contemporary competitive interactions between them, principally because they are very abundant at the dunes. But evidence of limiting resources is necessary to rise this hypothesis because divergent activity times preclude interference competition, moreover ants are very abundant at the dunes. 


\section{INTRODUÇÃO}

\subsection{Contexto Teónico}

Um dos principais objetivos da ecologia animal é avaliar especificamente os tipos de alimento e as variedades de hábitats que os animais utilizam (Johnson, 1980) e muitos estudos se preocupam em avaliar tais aspectos no sentido de determinar preferências ou eletividades. Por preferência (sensu Johnson, 1980), entende-se a probabilidade que um recurso seja escolhido se oferecido em quantidade igual a outros e por eletividade (sensu Lawlor, 1980), a preferência e/ ou habilidade relativa na utilização de um recurso. Segundo Winemiller e Pianka (1990), os padrões de uso de recursos constituem uma propriedade fundamental dos sistemas ecológicos.

No contexto da ecologia de comunidades, estudos sobre o padrão de uso de recursos geralmente têm a intenção de elucidar as causas e processos que organizam as comunidades biológicas, principalmente no sentido de verificar a importância relativa das interações ecológicas contemporâneas e da história (restrições) dos táxons e/ ou das áreas sobre a estrutura e a organização de nichos das comunidades (Cadle e Greene, 1993; Ricklefs e Schluter, 1993; Losos, 1996). Toft (1985) critica o fato de muitos trabalhos concentrarem-se na descrição do padrão de uso, sem tentar descobrir as causas do padrão detectado, apesar de admitir ser uma árdua tarefa atingir os dois objetivos num mesmo estudo. De fato, a única maneira de fazêlo adequadamente seria através de experimento (manipulativo ou não) delineado especificamente para testar o efeito do processo de interesse no padrão de uso. Estudos de descrição de padrão podem, no máximo, levantar hipóteses sobre suas causas, hipóteses essas a serem testadas posteriormente com dados independentes dos que geraram as mesmas. 
Via de regra, análises que objetivam diferenciar o papel desses dois fatores (restrições históricas e interações ecológicas) no padrão de uso de recursos exigem informações de ecologia e filogenia. Esse tipo de análise para Anura, no entanto, apresenta dificuldades, pois as propostas de filogenia para o grupo são raras (Ford e Cannatella, 1993) e restringem-se às relações de parentesco entre famílias. Exceto para Dendrobatidae (Toft, 1995; Caldwell, 1996), estudos sobre as relações de parentesco entre gêneros e espécies de Anura são pouco encontradiços.

Em assembléias recém-estabelecidas, por exemplo, padrões de uso de recursos pelas espécies podem representar principalmente habilidades plesiomórficas de utilização herdadas de suas respectivas linhagens. 0 mesmo pode acontecer em comunidades formadas por espécies de ampla distribuição geográfica, pois o fluxo gênico entre populações submetidas a diferentes pressões seletivas (por exemplo, diferentes comunidades competitivas) pode limitar a diferenciação genética local (Endler, 1977). Por outro lado, a organização de nichos de uma assembléia pode ser majoritariamente influenciada pelas interações ecológicas contemporâneas.

Estudos com assembléias de Anura e Squamata há muito contribuem ativamente para o crescimento do corpo teórico, empírico e metodológico da ecologia de comunidades e esses organismos têm sido utilizados como modelos nos estudos de uso de recursos (Toft, 1985; Cruz, 2003).

Há consenso acerca da afirmação de que descrições adequadas do uso de recursos devam incorporar nas análises informações sobre a disponibilidade dos recursos (e.g. Colwell e Futuyma, 1971; Pianka, 1973, 1986; Pertraitis, 1979; Johnson, 1980; Toft, 1980a, b, 1981; Strüssman et al., 1984; Wheater, 1986; Winemiller e Pianka, 1990; D onnelly, 1991; Simon e Toft, 1991; Vitt e Caldwell, 1994; Flowers e Graves, 1995; Arthur et al., 1996; Whiting et al., 
1997; Lima, 1998; Measy, 1998; Vitt e Zani, 1998; Parmelee, 1999; RodríguezRobles e Greene, 1999; Rocha e Rodrigues, no prelo), pois, do contrário, corre-se o risco de descrever e comparar características do organismo juntamente com as do ambiente (o que é revelado conjuntamente pelo padrão de uso de recursos) e não apenas as dos organismos (suas eletividades) (Lawlor, 1980). Lawlor (1980) chega a argumentar que o uso de recursos pode ser considerado um caráter fenotípico, enquanto que as eletividades são mais próximas de características genotípicas e essas últimas devem provavelmente refletir melhor as mudanças evolutivas, devendo ser preferidas na investigação das similaridades no uso de recursos. No entanto, alguns trabalhos partem da premissa improvável de que a disponibilidade dos diferentes recursos é igual no ambiente (por exemplo, Pianka, 1975; Vitt, 1995) ou simplesmente não levam a disponibilidade de recursos em consideração (por exemplo, Caldwell, 1996 e Maneyro et al., 2004).

Alguns autores discutem os métodos para estimar disponibilidade (Pertraitis, 1979; Christian, 1982) e para compará-la com o uso por animais, apontado suas dificuldades (Strauss, 1979; Johnson, 1980; Winemiller e Pianka, 1990). Uma boa estimativa de disponibilidade dos recursos pode tornar-se bastante difícil de acessar se partirmos do referencial teórico de Johnson (1980) que, embora bastante coerente, define a disponibilidade (quantidade de recursos acessível a um animal num certo período de tempo) como algo diferente da abundância (quantidade de recursos no ambiente).

Muitos dos trabalhos sobre dieta de lagartos e sapos que estimam a disponibilidade 0 fazem com base em coletas de artrópodes diretamente do ambiente, por vários métodos de amostragem, o que a rigor não passa de uma estimativa da abundância das presas no ambiente. Além disso, o sucesso de captura de artrópodes coletados por armadilhas de queda, um método comumente utilizado (Heyer et al., 1994) é reconhecidamente um índice misto 
de abundância local e do grau de atividade dos indivíduos (van der Aart e Smeenk-Enserink, 1975; Adis, 1979; Greenberg et al., 1994; Cornish et al., 1995).

Uma saída proposta para esse problema é a utilização do total de recursos consumido pela comunidade como uma estimativa da disponibilidade dos mesmos (Lawlor, 1980; Pianka, 1986; Winemiller e Pianka, 1990), pois, apesar de ser menos intuitiva que os métodos de estimativa de abundância, a dieta total parece ser a grandeza que melhor representa a quantidade dos recursos tal qual percebida pelo consumidor.

A dieta total é uma estimativa freqüentemente utilizada na literatura de ecologia de Anura e Squamata por alguns autores (por exemplo, Pianka, 1986; Vitt e Caldwell, 1994; Rocha e Rodrigues, no prelo ) e seu viés está associado principalmente ás preferências dos indivíduos e espécies utilizados na estimativa (D onnelly 1991, 1994; Rocha e Rodrigues, no prelo). Ademais, a disponibilidade dos recursos é um fator que varia no tempo, no espaço e entre consumidores (Winemiller e Pianka, 1990).

Pelo fato de ambas as estimativas apresentarem vieses, um procedimento adequado para avaliar sua qualidade seria compará-las, aplicado-as na amostragem de recursos numa mesma área e ao mesmo tempo, e discutir suas diferenças e respectivas tendências. Rocha e Rodrigues (no prelo) realizaram procedimento semelhante ao descrito acima para análise de dados oriundos de uma área de dunas interiores na Caatinga, e encontraram resultados bastante similares nas duas estimativas comparadas, com a seguinte diferença: categorias alimentares de baixa mobilidade foram mais bem amostradas na dieta total dos lagartos e categorias de alimento com defesas químicas foram mais bem amostradas pelas armadilhas de queda. Os autores concluem que tais diferenças devem-se à ineficiência das armadilhas de queda em capturar 
itens pouco móveis e à evitação de presas com defesas químicas pelos lagartos estudados por eles. Tal resultado levou-os a utilizar uma estimativa mista da disponibilidade. Tinoco (2004), analisando comunidades de lagartos e anuros de uma paisagem fragmentada de Mata Atlântica no extremo-sul da Bahia, encontrou resultados semelhantes e adicionalmente detectou que as armadilhas de queda amostraram menos artrópodes voadores. Com base nesses resultados, adotou também uma estimativa mista de disponibilidade.

O utro aspecto relacionado à disponibilidade de recursos é a escala temporal adequada para a questão e 0 sistema biológico em estudo. A maioria dos trabalhos de uso de recursos soma os dados de uma coleta, uma estação, um ano ou usa os dados totais para realizar as descrições e análises. Contudo, em certos sistemas, a renovação dos recursos ou alterações na sua disponibilidade, podem ser fatores que levam as análises a resultados espúrios (Jacobs, 1974; Arthur et al., 1996). Em um trabalho recente sobre dieta de Pleurodema diplolistris (Leptodactylidae) nas dunas do médio Rio São Francisco, Santos e colaboradores (2003) sugerem que variações no consumo de térmites pelos anuros provavelmente estão associadas à incidência de chuvas fortes e esse é um fenômeno que pode variar no período de um dia.

A utilização de armadilhas de queda (pitfall traps) sem líquidos conservantes na coleta de animais para análises de dieta baseia-se na premissa implícita de que 0 eventual consumo de alimento nas armadilhas não tem influência importante na dieta dos predadores. Apesar de ser uma premissa de fácil verificação, há apenas um registro de tal procedimento ter sido realizada em estudos com herpetofauna. Rocha e Rodrigues (no prelo) encontraram que os artrópodes consumidos pelos lagartos das dunas de Ibiraba tiveram atividade noturna (com base em coletas de artrópodes em armadilhas de queda), enquanto que a maioria dos lagartos teve atividade diurna, e interpretaram esse resultado como um indicador de que os lagartos não se alimentaram nas 
armadilhas de queda. Caldwell (1996) refere-se à importância de avaliar a qualidade da informação sobre uso de recursos, principalmente em trabalhos de contexto evolutivo.

Investigações acerca da dieta de anuros envolvem poucos táxons e o grupo é tido, em geral, como predador oportunista de artrópodes, cujas proporções de consumo são semelhantes às proporções de alimento no ambiente (D uellman e Trueb, 1986). Tal padrão pode ser resultado de estudos feitos sem se considerar a disponibilidade de recursos no ambiente, ou negligenciando-se variações diárias da disponibilidade de recursos (utilização de dados totais), ou ainda, desconsiderando-se diferenças de dieta entre animais de diferentes classes de tamanho na amostra, o que pode obscurecer as preferências. Segundo Toft (1981), os Bufonidae são considerados consumidores especializados em formigas e os Leptodactylidae, consumidores especializados em "não-formigas".

Vários autores registram mudanças ontogenéticas na dieta de anuros (Strüssmann et al., 1984; Weather, 1986; D onnelly, 1991; Simon e Toft, 1991; Flowers e Graves, 1995; De Bruyn et al., 1996; Evans e Lampo, 1996; Giaretta et al., 1998; Lima, 1998; Lima e Magnusson, 1998; Parmelee, 1999; Lima et al., 2000). No entanto, muitos outros analisam a dieta desses animais somando dados de várias classes de tamanho diferentes. Tal procedim ento pode esconder diferenças no uso e nas eletividades das diferentes classes de tamanho (Flowers e Graves, 1995). Nesse sentido, descrições adequadas do uso de recursos por anuros têm de investigar variações na dieta relacionadas ao tamanho do sapo, pois os fatores "tamanho" e "espécie" do sapo podem ter efeitos diferentes e independentes no padrão de uso de recursos (Lima e Magnusson, 1998). Além disso, tanto o tipo quanto os tamanhos das presas na dieta podem variar com a ontogenia e modificações no tipo de presa podem 
ser apenas um epifenômeno da escolha por presas maiores (Lima e Moreira, 1993; Lima, 1998; Lima e Magnusson, 1998; Lima et al., 2000).

\subsection{Antecedentes}

O domínio morfoclimático das caatingas ocupa uma área aproximada de $800.000 \mathrm{~km}^{2}$ e, embora seja um dos mais bem conhecidos quanto à fauna de répteis e anfíbios se comparado aos outros biomas do país, esse nível de conhecimento ainda é insatisfatório. Rodrigues (2003) defende que estudos sobre a história, ecologia e evolução da fauna das caatingas são extremamente necessários para auxiliar no entendimento dos padrões de distribuição das espécies no bioma.

Atualmente, acreditzse que a fauna das caatingas não seja meramente um subconjunto da fauna presente no grande cinturão diagonal de áreas abertas que vai desde 0 Chaco até 0 nordeste brasileiro, como suposto anteriormente. Há espécies endêmicas no bioma, mesmo desconsiderando-se a fauna de ambientes florestados encravados nas caatingas. Nesse contexto, a região do campo de dunas do Rio São Francisco caracteriza-se por ser a área de endemismos mais importante desse domínio, o que, somado à sua limitada extensão (cerca de 1\% da área da caatinga - Ab'Saber, 1980) e ao padrão, lá encontrado, de espécies vicariantes em lados opostos do rio, torna a área um dos centros de diferenciação mais importantes (com relação à fauna adaptada a ambientes arenosos) da América do Sul cisandina (Rodrigues, 2003).

Na região, há uma herpetofauna bastante diversificada, marcadamente psamófila, e grande número de espécies de Squamata endêmicas. Lá são registradas 61 espécies de lagartos, serpentes e anfisbenas, das quais 20 são endêmicas (Rodrigues, 1996; 2003), e 12 espécies de Anura: Bufo granulosus, B. paracnemis (Bufonidae), Scinax x-signatus, H yla sp. nov. (Hylidae), Pleurodema 
diplolistris, Physalaemus albifrons, L eptodactylus ocellatus, L . podicipinus, L. fuscus, L. caatingae (Leptodactilydae), Dermatonotus mulleri e Elachistodeis ovalis (Microhylidae) (Heyer e Juncá, 2003; Rocha e Rodrigues, no prelo ; F.A.Juncá, comunicação pessoal). Todas essas espécies de anuros têm ampla distribuição no bioma das caatingas (Rodrigues, 2003), à exceção de H yla sp. nov que é aparentemente endêmica das dunas.

Uma série de estudos de ecologia, comportamento e evolução vem sendo realizada nessa região (por exemplo, Cruz, 2000; Freitas et al., 2003; Santos et al., 2003; Mendes et al., 2004; Neves, 2004; Rocha et al., 2004; Santos, J.W.A. 2004; Santos, D.T.V. 2004; Gomes, 2005; Lima e Rocha, submetido; Rocha e Rodrigues, no prelo; D amasceno e Rocha, em preparação; Fonseca et al. (em preparação) e muito deles foram, e estão, sendo desenvolvidos no sentido de avaliar as causas dos padrões de organização de comunidades herpetológicas.

Gomes (2005), Rocha e Rodrigues (no prelo), Fonseca et al. (em preparação) e Damasceno e Rocha (em preparação) realizaram estudos com assembléias de lagartos, serpentes e anfisbenas presentes em uma localidade de dunas com morfologia típica (a vila de Ibiraba). Lá coexistem sintopicamente 17 espécies de lagartos (incluindo anfisbenas) e essa diversidade local é alta quando se considera a homogeneidade estrutural do ambiente das dunas. Os trabalhos de Rocha e Rodrigues (no prelo) e D amasceno e Rocha (em preparação) detectaram que há diferenças marcantes entre as dimensões do nicho das espécies estudadas e Damasceno e Rocha (op.cit.) determinaram que os padrões de uso e eletividade de recursos, para a maioria das espécies, são semelhantes aos de espécies filogeneticamente próximas, o que sugere que as eletividades detectadas refletem 0 padrão plesiomórfico das respectivas linhagens. Fonseca et al. (em preparação), por outro lado, encontraram resultados diversos, indicando não ser plesiomórfico o padrão de uso de alimento pelas espécies de lagartos de médio porte m 
localidade. Gomes (2005) testou e refutou a hipótese de que o padrão diferencial de uso por essas últimas espécies pode ser explicado por competição contemporânea, sugerindo que 0 padrão deriva de ação de competição pretérita.

Diferentemente das espécies de Squamata (Rodrigues, 1996, 2003) e uma de Rodentia (Rocha, 1995) endêmicas das dunas, a maior parte da fauna de anuros até 0 momento detectada na área é composta de espécies de mais ampla distribuição, à exceção da espécie nova citada acima. No entanto, ainda assim são modelos biológicos adequados para estudos de evolução e ecologia, porque espécies de ampla distribuição podem fornecer informações relevantes para a elucidação da história de formação da caatinga e sua fauna (Rodrigues, 2003).

D urante a realização de seu trabalho com lagartos, Rocha e Rodrigues (no prelo ) coletaram uma quantidade surpreendente de anuros terrícolas nas dunas de Ibiraba. As espécies mais abundantes foram Pleurodema diplolistris, Physalaemus albifrons (Leptodactylidae) e Bufo granulosus (Bufonidae). Ainda que não pareçam utilizar as dunas para reprodução (P.L.B.Rocha, comunicação pessoal), por causa do tipo de solo e a topografia que impedem completamente a formação de poças de água, e não sejam ativas durante a época de clímax da seca, as populações de anuros são muito abundantes, superando em freqüência e em biomassa as populações sintópicas de lagartos, durante o clímax das chuvas. Este fato potencialmente seria capaz de gerar impacto sobre a utilização dos recursos alimentares (artrópodes) compartilhados com os lagartos sintópicos. Durante as chuvas, período do ano em que as espécies de anuros e lagartos estão ativas e são mais abundantes, há uma alteração de dieta dos últimos que passam a consumir em grande quantidade larvas de insetos (Rocha e Rodrigues, no prelo). Apesar dessa possível interação entre elementos da herpetofauna, a ampla distribuição 
das espécies de anuros encontradas na área e o regime de baixa previsibilidade de incidência de chuvas nas dunas tornam esperado um padrão plesiomórfico de uso de recursos por esses animais. 


\section{OBJETIVOS}

Motivada pelo contexto teórico e pelos antecedentes apresentados, nesse trabalho enfoquei três tópicos principais:

(1) A assembléia de anuros das dunas do São Francisco representa o último grupo expressivo da herpetofauna local que não foi sujeito a análises ecológicas detalhadas, impedindo uma síntese global a respeito da influência dos fatores ecológicos e históricos sobre padrão de uso de recursos alimentares nessa fauna. Qual o padrão de uso e de eletividades por recursos alimentares pelas espécies sintópicas mais abundantes de anuros terrícolas das dunas? É possível refutar a hipótese de que o padrão encontrado deriva das características intrínsecas das linhagens? Q uais os possív eis impactos da presença dessas espécies sobre a disponibilidade de recursos alimentares para as demais espécies da herpetofauna local?

(2) A influência do tamanho dos anuros sobre a qualidade das presas consumidas tem sido negligenciada na literatura, e raramente os trabalhos são capazes de distinguir os efeitos do tipo e do tamanho da presa sobre a dieta. Como o tamanho dos anuros terrícolas das dunas influencia suas eletividades por tipos e tamanhos distintos de presas? As possíveis variações ontogenéticas nas eletividades por tipo de presa são apenas um epifenômeno de mudanças no tamanho das presas consumidas causadas pelo crescimento dos anuros?

(3) Os índices de uso e disponibilidade de alimento normalmente utilizados na literatura específica apresentam limitações potenciais e premissas que, via de regra, são 
negligenciadas na interpretação das análises e que, no entanto, podem modificar substancialmente os resultados encontrados. Quais as principais premissas dos índices de uso e disponibilidade utilizados nesse trabalho? Q uais são os vieses das estimativas de uso e disponibilidade dos recursos alimentares utilizadas? 


\section{MATERIAL E MÉTODOS}

\section{1 Área de estudos}

As dunas fixadas do médio Rio São Francisco localizam-se na região noroeste do estado da Bahia, aproximadamente entre as longitudes $41^{\circ} 00^{\prime}$ e $43^{\circ} 30^{\prime}$ O este e as latitudes $09^{\circ} 00^{\prime}$ e $11^{\circ} 00^{\prime}$ Sul (Figura 1). Uma grande porção de sua área, o campo de dunas de Xique-Xique, localiza-se na margem oeste do Rio São Francisco, nos municípios de Barra e Pilão Arcado, sendo delimitada a oeste pela Serra do Estreito. As dunas incluem ainda, na mesma margem do rio, o campo de dunas de Casa Nova e, na margem oposta, manchas de areia na Lagoa de Itaparica, em Vacaria e em Santo Inácio (cuja mancha de areia não está representada no mapa). Esse conjunto constitui um corredor de áreas arenosas ao longo rio, adjacente à sua planície aluvial que, a partir daqui, será referido como "mares de areias" (sensu McKee, 1982) (Figura 2).

Os mares de areias do médio Rio São Francisco compreendem uma superfície de cerca de $7.000 \mathrm{Km}^{2}$ (Barreto, 1996), o que corresponde a cerca de 1\% da área total do Domínio Morfoclimático das Caatingas (Ab'Saber, 1980), onde estão inseridos. Os solos da área são do tipo areno-quartzoso distrófico, de granulometria muito fina a média, apresentando teores de argila inferiores a 15\%, com drenagem alta a excessiva (Bahia-SEPLANTEC, 1978; Barreto, 1996).

As dunas encontram-se em uma faixa de climas semi-áridos que se estende desde o Raso da Catarina (onde ocorrem 9 a 11 meses de seca por ano) em direção sudoeste, ao longo do vale médio do Rio São Francisco. Nesta faixa, a temperatura anual é a maior do estado, ultrapassando a marca de $26,0^{\circ} \mathrm{C}$ (Bahia-SEPLANTEC, 1978). 
Alguns autores enquadram setores da caatinga brasileira na categoria de climas semi-áridos rústicos e até de climas desérticos em função de sua escassez de precipitações, altos níveis de temperatura média e forte incidência de anos secos de periodicidade variável (Ab'Saber, 1980). Ainda que atualmente os mares de areia não constituam precisamente uma região desértica, há fortes evidências de que essa era a situação ao final do período glacial Würm-Wisconsin (Tricart, 1974; Barreto, 1993), há cerca de 12.000 anos (Rodrigues, 1991).

O clima local é classificado segundo Köppen (Leal, 1970) como Bswh': quente e semi-árido, com grande estação de seca que se estende por 7 a 8 meses. O período de chuvas dá-se entre outubro e março, sendo os meses de maior precipitação os três últimos (Nimer, 1979). A precipitação anual média não ultrapassa os $900 \mathrm{~mm}$ e as temperaturas anuais médias ficam entre 24 e 27 ${ }^{\circ} \mathrm{C}$ (INMET, 2000). 0 posto meteorológico de Barra (o mais próximo da localidade de estudo, a Vila de Ibiraba) registra temperatura média anual de 26,2 C e precipitação anual média de 692,0 mm (Nimer, 1979).

A vegetação local predominante é a caatinga, podendo ser arbustiva nas porções mais próximas ao Rio São Francisco, ou arbórea, semelhante a uma transição entre vegetação de caatinga e de floresta caducifólia, que ocorre extensivamente sobre os depósitos eólicos. Finalmente, margeando o Rio São Francisco, encontra-se a floresta ciliar de carnaúba e ao longo dos tributários e em baixadas interdunares ocorre vegetação típica de veredas (Jacomine et al., 1976).

A vila de Ibiraba $\left(10^{\circ} 48^{\prime} \mathrm{S}, 42^{\circ} 50^{\prime} \mathrm{W}\right)$, pertencente ao município de Barra, na margem oeste do rio, é a localidade de estudo do presente trabalho (Figura 3). Ela está incluída na Área de Proteção Ambiental (APA) das Dunas e 
Veredas do Baixo médio Rio São Francisco, no campo de dunas de XiqueXique (na margem oeste).

Nesta localidade, as dunas apresentam relevo acentuado, com uma sucessão de setores de vale, patamar, talude e cume (Figuras 4). Análises preliminares baseadas em medições elétricas ao longo do Rio Icatu (corpo d’água mais próximo das dunas de Ibiraba) sugerem que a profundidade máxima do substrato das dunas varia entre $50 \mathrm{~m}$ e $150 \mathrm{~m}$ (Barreto, 1996).

Em estudo realizado por Rocha e colaboradores (2004) nessa localidade, foram detectadas 86 espécies vegetais. A vegetação local, caracteristicamente xeromórfica, é baixa e esparsa, deixando exposta grande proporção do solo arenoso (Figura 5). O estrato arbóreo-arbustivo é formado predominantemente por indivíduos com altura entre 1,5 e 2,0 m e sua densidade é baixa, 1.083 indivíduos/ ha. As lenhosas mais freqüentes incluem uma nova espécie de E ugenia (Mirtaceae), endêmica da área (34,1\% das lenhosas), e Copaifera coriacae (Leguminosae, 14,8\%). Não há um estrato herbáceo conspícuo, apenas cerca de $15 \%$ do substrato é coberto por plantas nãolenhosas e baixas, agrupadas em touceiras formadas principalmente por Bromelia antiacantha (Bromeliaceae) e T acinga inamoena (Cactaceae) (Figura 6). A flora das dunas de Ibiraba é composta principalmente por espécies típicas de áreas arenosas da caatinga. Ademais, diferentemente da vegetação de caatinga circundante, nas dunas há uma produção constante de folhas e frutos pelas plantas, mesmo na época seca. Ainda segundo os autores (Rocha et al., 2004), o hábitat possui estrutura bastante simples e homogênea e dois gradientes ambientais são capazes de descrever a maior parte de sua variação: um gradiente de densidade de lenhosas e outro de aumento de Bromelia antiacantha e T acinga inamoena em direção aos vales, o que determina dois tipos de microhábitats protegidos para a fauna cursora de pequeno porte. 
O Rio Icatu é o corpo d'água permanente mais próximo da localidade de coleta (aproximadamente a 300 metros de distância); contudo, os anuros utilizam-se de poças temporárias, formadas pelo acúmulo da água da chuva numa local restrito na base de uma das dunas, para fins de reprodução (P.L.B.Rocha, comunicação pessoal) (Figura 7). Segundo Rodrigues (2003), os Bufonidae, Hylidae e Microhylidae encontrados nas dunas de morfologia típica de Ibiraba desovam em ambientes lênticos, e os Leptodactylidae desovam em ninhos de espuma.

\subsection{Coleta de dados em campo}

Os anuros utilizados nesse estudo foram coletados em cinco excursões ao campo de dunas de Ibiraba: fevereiro-março/ 96, fevereiro-março/ 97 (auge da estação chuvosa), setembro/ 96 (auge da estação seca), dezembro/ 96 (início da estação chuvosa), com duração aproximada de 16 dias consecutivos de coleta cada (Licença do IBAMA \# 3451/93-13-AC), e em dezembro/2003fevereiro/ 2004 (início e auge da estação chuvosa), com 13 dias nãoconsecutivos de coleta (Licença do IBAMA Processo \# 02006.004179/ 03-11). As coletas de 1996 e 1997 foram as mesmas do trabalho de Rocha e Rodrigues (no prelo).

Os animais foram coletados em armadilhas de queda (pitfall traps) (Heyer et al., 1994), organizadas em grade, com linhas e colunas distando de sete metros cada (Figura 8). Esta distância se mostrou adequada por não corresponder às distâncias entre os patamares, taludes, cumes e vales sucessivos das dunas, contemplando todos esses setores com armadilhas (Rocha e Rodrigues, no prelo ) nas excursões de 1996 e 1997. Na excursão de 2003-2004, as grades contemplaram apenas os vales e os taludes, de modo que as armadilhas não contemplaram os cumes. 
As armadilhas consistiram de um balde plástico (de $25 \mathrm{~cm}$ de diâmetro x 30 cm de altura ou 30 de diâmetro x $40 \mathrm{~cm}$ de altura) enterrado, de modo que a sua borda se posicionasse um pouco abaixo do nível do solo, acoplado a três cercas de direcionamento (drift fenœes) plásticas de 1,5 m de comprimento e 0,4 $\mathrm{m}$ de altura (dos quais cinco centímetro ficavam enterrados no solo) (Figura 9). Armadilhas com pelo menos $21 \mathrm{~cm}$ de altura parecem ser adequadas para a coleta de anuros terrícolas, dado o pequeno número de fugas (Brown, 1997). Não foram adicionadas às armadilhas quaisquer substâncias fixadoras ou iscas. Tais armadilhas serão chamadas, de agora em diante, de armadilhas de anuros. Nas excursões dos anos de 1996 e 1997, foi montada uma grade com 100 ou 120 armadilhas, alternando-se baldes de dimensões diferentes. A cada excursão, a grade era montada a pelo menos 250 metros de distância daquela da excursão anterior.

Com base no resultado das coletas de 1996 e 1997 e no sentido de maximizar as chances de coletar anuros das espécies terrícolas mais abundantes numa mesma noite, na excursão de 2003-2004, foram coletados apenas os animais capturados nas armadilhas em dias de chuva forte, quando há um maior sucesso de captura de anuros. Nesta excursão, foram utilizadas 200 armadilhas de queda, distribuídas em oito grades (de 50 armadilhas cada), todas concentradas nos vale e taludes. A cada dia, 40 armadilhas diferentes eram sorteadas (cinco em cada grade), para coleta dos anuros, de modo que não houvesse repetição das armadilhas em dias consecutivos, embora tenha havido repetição de algumas em dias não-consecutivos. Em todas as excursões, as armadilhas foram visitadas duas vezes por dia: no início da manhã, quando os anuros capturados foram coletados e no final da tarde, quando todos os vertebrados e artrópodes capturados foram retirados das armadilhas e libertos nas suas proximidades. 
Após a eutanásia dos anuros, realizada por anestesia seguida de morte, por banho em solução de álcool a 20\% (Caramaschi, 1987), procedi à fixação em solução de formalina a 10\%, durante três dias, ao armazenamento em solução de álcool a 70\% (Heyer et al., 1994) e ao tombamento na coleção do Museu de Zoologia da Universidade Federal da Bahia. O intervalo entre a coleta dos anuros nas armadilhas e a eutanásia foi de no máximo três horas, exceto para um dos dias (18/ 02/ 2004), quando os animais foram mantidos em geladeiras de isopor por até 48 horas após o momento da coleta, devido ao grande número de animais coletados naquele dia. Caldwell (1996) defende que 0 tempo entre coleta e eutanásia pode mudar drasticamente os resultados de análise de dieta, portanto o tempo demasiado longo entre coleta e eutanásia no dia 18/ 02 pode ter tido influência sobre o resultado das análises (o que foi averiguado).

Armadilhas de queda são amplamente utilizadas em diferentes estudos de vários segmentos da fauna, devido à sua capacidade de capturar uma variedade de vertebrados e invertebrados com sucesso, por exemplo: invertebrados de solo (van der Aart et al., 1975; Adis, 1979; Cornish et al., 1995; Hódar et al., 1996), anuros terrícolas (Brown, 1997), componentes da herpetofauna (G reenberg et al., 1994) e pequenos vertebrados terrestres (Mengak e Guynn, 1987). Por conta disso, estudos de dieta que utilizam animais capturados em armadilhas de queda têm como premissa que a eventual alimentação dos animais nos baldes não interfere significativamente na sua dieta. No sentido de testar tal premissa, comparei a dieta de animais da mesma espécie, de mesmo tamanho, coletados em mesmas noites por dois diferentes métodos: armadilhas de queda e coleta ativa. Na excursão de 2003-2004, coletei por procura ativa, durante a noite, anuros nas redondezas das grades de armadilhas de queda. Em cada noite, num período de 1,5 hora foram 
percorridos dois transectos, que passavam sempre pelos diferentes setores das dunas (cume, talude, patamar e vale) e seguiam por onde era possível o acesso.

Uma decisão metodológica desse trabalho foi a de utilizar a dieta total da assembléia de anuros estudada como a estimativa de disponibilidade de alimento. Considerei essa estimativa como uma amostra randômica das presas disponíveis para os anuros terrícolas (Pianka, 1986).

Apesar de ter julgado a estimativa baseada na dieta total a mais adequada para avaliar eletividades, não perdi de vista que qualquer estimativa tem vieses. Nesse sentido, comparei essa estimativa (baseada na dieta) com outra amplamente utilizada e feita independentemente, com 0 intuito de discutir suas diferenças no cálculo das eletividades. Na excursão de 2003-2004, coletei artrópodes em armadilhas de queda diferentes das utilizadas para capturar anuros. Tais armadilhas, chamadas a partir de agora de armadilhas de artrópodes, consistiram de frascos plásticos de $750 \mathrm{~mL}$ de capacidade, enterrados de modo que sua borda ficasse a aproximadamente um centímetro abaixo do nível do solo. As armadilhas não continham substâncias fixadoras nem iscas. Um total de 40 armadilhas de artrópodes foi montado (cinco em cada grade de armadilhas de anuros) e, para cada dia de coleta, nove armadilhas eram sorteadas (Figuras 10 e 11). As armadilhas eram visitadas duas vezes ao dia: pela manhã, todos os artrópodes capturados nas nove armadilhas sorteadas eram coletados e à tarde todas as armadilhas tinham seu conteúdo esvaziado. Julguei adequado coletar apenas os artrópodes de atividade noturna, porque esse é o horário de atividade dos anuros (detectado por Rocha e Rodrigues, no prelo). 


\subsection{Coleta de dados em laboratório}

Registrei o comprimento rostro-cloacal (CRC) de todos os exemplares de anuros coletados das espécies mais abundantes. Essa medida corresponde à distância entre as extremidades mais anterior (ponta do focinho) e mais posterior (orifício cloacal) do corpo do animal, quando em decúbito ventral. O sexo dos animais foi determinado por análise das gônadas e os indivíduos sem gônadas conspícuas foram considerados jovens.

As análises de dieta basearam-se em dados de triagem do conteúdo estomacal dos anuros. Agrupei os itens alimentares em categorias de presa no nível de Ordem e registrei o número de itens de cada categoria de presa (freqüência) e a massa seca total de cada categoria (precisão de 0,0001g) em cada conteúdo estomacal. Procedi de tal maneira, pois acredito ser a massa a grandeza mais adequado para estimar a contribuição das categorias de alimento na dieta, em oposição ao volume das presas e aos vieses associados a seus métodos de medida (Magnusson et al., 2003), amplamente utilizados em estudos de dieta. A massa das categorias foi medida após os itens terem sido secos em estufa a $60^{\circ} \mathrm{C}$, por duas horas, e mantidos em temperatura ambiente por cerca de sete dias em placas de Petri plásticas. Tal procedimento foi adotado no sentido de remover a solução de álcool utilizada para conservar os conteúdos e promover uma medida de massa 0 mais acurada possível. Às categorias alimentares cujas massas foram menores que o poder de leitura da balança $(0,0001 \mathrm{~g})$, atribui o valor de massa 0,00001g. Esse procedimento, além de registrar a presença da categoria alimentar na dieta (valor de massa diferente de zero), é suficientemente pequeno para não alterar as contribuições percentuais das categorias mais importantes na dieta.

Os itens foram classificados em três categorias, a depender do seu estado de conservação no estômago. Os itens que se mantinham íntegros e 
completos foram tidos como "intactos"; os que estavam desarticulados, mas com todas as partes íntegras e passíveis de identificação no estômago foram tidos com "desarticulados" e os itens cujas partes não foram todas identificadas ou encontradas no estômago, foram tidos como "incompletos". Medi a maior dimensão de todos os itens alimentares (precisão $0,1 \mathrm{~cm}$ ) dos conteúdos estomacais. Essa medida correspondeu geralmente ao comprimento do item alimentar: a distância entre as extremidades mais anterior e mais posterior do item, excluindo-se os apêndices quando no caso de artrópodes. Os itens desarticulados e incompletos foram medidos após suas partes terem sido agrupadas de forma a simular sua forma original. Tal prática levou a uma superestimação da maior dimensão dos itens desarticulados e, naturalmente, à subestimação dos itens incompletos.

Os procedimentos de triagem dos invertebrados coletados nas armadilhas de artrópodes, coletados para compor uma estimativa de abundância das presas no ambiente, foram semelhantes aos adotados na triagem dos itens alimentares, com relação a contagem e aferição de massa.

\subsection{Análise de dados}

\subsubsection{Uso e eletividades por recursos alimentares}

O índice de uso de alimento (dieta) utilizado foi a contribuição percentual em massa das categorias alimentares nos conteúdos estomacais. Estimativas diárias de dieta de cada espécie foram feitas com base nos conteúdos estomacais de três indivíduos das três espécies de anuros mais abundantes (Pleurodema diplolistris, Physalaemus albifrons e Bufo granulosus) coletados num mesmo dia, em baldes diferentes. Os dias em que foram coletados três indivíduos de apenas duas das três espécies mais abundantes também foram incluídos nas análises. 
A utilização de apenas um animal por armadilha por dia foi feita para minimizar o problema da pseudo-repetição (sensu Hurlbert, 1984), assim como a utilização de animais coletados em dias não-consecutivos. Animais capturados numa mesma armadilha provavelmente não fornecem informações independentes sobre dieta, pois o consumo de um indivíduo deve interferir no consumo dos outros indivíduos ativos na área de ação de uma mesma armadilha (pela alteração da disponibilidade de alimento local), partindo do pressuposto que a área de ação da armadilha de queda é proporcional ao comprimento das cercas de direcionamento utilizadas $(1,5 \mathrm{~m})$ e que os sapos forrageavam na área de ação das armadilhas onde foram capturados.

Calculei as porcentagens de contribuição em massa (\%M) e freqüência $(\% \mathrm{~F})$ das categorias alimentares na dieta de cada indivíduo e calculei a média dessas contribuições para descrever a dieta das três espécies. Esse procedimento evita vieses relacionados ao tamanho dos sapos (Evans e Lampo, 1996) e à massa dos conteúdos estomacais, dando igual importância a todos os exemplares (Smith et al., 2004). Calculei também o número de indivíduos que consumiram cada categoria alimentar (registrado como "O corrência") e a sua porcentagem (\%0) com relação ao total de indivíduos analisados de cada espécie.

Categorias alimentares que tiveram contribuição percentual média em massa maior ou igual a 20\% foram consideradas importantes na dieta. Como a contribuição em massa na dieta total da espécie é a média das contribuições nas dietas dos indivíduos, a medida de porcentagem de ocorrência influenciou o resultado desse cálculo. Dessa forma, apenas categorias com grande contribuição em massa e que foram consumidas por uma porcentagem razoável dos indivíduos puderam ser consideradas importantes na dieta. 
Comparei o uso de recursos alimentares pelas espécies e a disponibilidade de alimento, calculando as eletividades na dieta. $O$ índice de disponibilidade de recursos alimentares foi a contribuição porcentual em massa (\%M) das categorias alimentares na estimativa de disponibilidade de alimento baseada na dieta total dos anuros. Diferenças absolutas maiores ou iguais a 20 entre a contribuição percentual em massa na dieta e na disponibilidade de alimento (\%M consumo - \%M disponibilidade) foram interpretadas como eletividades: diferenças positivas representam eletividades positivas e diferenças negativas, eletividades negativas. Esse procedimento evita a superestimação de

eletividades por itens raros ou consumidos por poucos indivíduos da população. A fórmula utilizada para calcular as eletividades equivale ao índice linear de seleção de alimento de Strauss (1979). A escolha desse índice de eletividade foi feita com base na simplicidade de sua interpretação, a despeito das críticas levantadas a ele por Pearre (1982). Pearre (1982), assim como Strauss ao propor o índice, discute as fraquezas e os vieses do índice linear, quando são realizados testes de significância, mas esse procedimento não foi adotado no presente trabalho. Pearre (1982) ainda comenta que o índice de Strauss comportou-se bastante bem nas análises com dados sintéticos que ele realizou e que sua simplicidade de cálculo o torna atraente.

\subsubsection{Teste de premissa sobre a qualidade da estimativa de uso de recursos utilizada}

No sentido de avaliar se a eventual alimentação dos anuros nas armadilhas de queda modifica sua dieta, comparei a dieta de animais coletados por essas armadilhas (passivamente) com a de anuros coletados ativamente. Os indivíduos utilizados nessa análise foram diferentes daqueles utilizados na descrição do uso e eletividades por recursos alimentares. Todos os anuros coletados passivamente foram capturados em armadilhas de queda distintas 
(apenas um indivíduo por armadilha por dia foi utilizado) e diferentes daquelas nas quais anuros utilizados nas outras análises foram capturados. Para evitar confusão do tamanho dos anuros nas análises, utilizei apenas indivíduos de mesmo tamanho (mesma amplitude total de comprimento rostro-cloacal para indivíduos coletados ativa e passivamente) e para excluir 0 efeito de diferenças na disponibilidade de alimento em diferentes dias, foram utilizado anuros coletados pelos dois métodos de coleta nas mesmas noites.

Realizei uma análise de similaridades [ANOSIM - A nalysis of similarities (Clarke e Warwick, 2001; McCune e Grace, 2002)] de dois fatores cruzados (ANO SIM 2-way crossed) para comparar as dietas dos dois grupos de anuros (programa utilizado: PRIMER 5 for $\mathrm{W}$ indows). Um dos fatores representou os tratamentos (os tipos de coleta utilizados), e o outro fator representou os blocos (os diferentes dias de coleta). ANO SIM é um teste multivariado que procura diferenças entre grupos com base nas diferenças dos postos (rankings) das distâncias entre os objetos de um mesmo grupo e de grupos diferentes e gera níveis de significância por métodos de randomização (Clarke e Warwick, 2001). A escolha dessa análise em detrimento de outras mais amplamente utilizadas (como análise de variância multivariada - MANOVA) baseia-se no fato da ANOSIM não ter como premissas normalidade multivariada dos dados, nem homogeneidade de variâncias (Clarke e Warwick, 2001; McCune e Grace, 2002). A matriz na qual se baseou o teste tinha como linhas os indivíduos (objetos), como colunas, as categorias alimentares de contribuição maior ou igual a 10\% em percentual de massa na dieta (variáveis) e as células foram preenchidas com os valores de contribuição percentual em massa das categorias na dieta (atributos) de cada animal.

O teste calcula a estatística $R$, que varia de -1 a 1 . Valores próximos a -1 indicam grupos pouco coesos, situação em que os postos das distâncias entre objetos de mesmo grupo são sempre maiores que os das distâncias entre 
objetos de diferentes grupos. Valores de R próximos a zero indicam que os valores dos postos das distâncias entre objetos de diferentes grupos são semelhantes aos das distâncias entre objetos de mesmo grupo e valores de $\mathrm{R}$ próximos a 1 indicam grupos muito coesos, situação na qual os postos das distâncias entre objetos de mesmo grupo são sempre menores que os das distâncias entre o bjetos de grupos diferentes (Clarke e Warwick, 2001).

ANOSIM de dois fatores testa duas hipóteses: (1) a de diferença entre blocos de um mesmo tratamento e (2) a de diferença entre tratamentos, sem prever interação entre blocos e tratamentos. 0 teste de significância é feito com base em permutações dos objetos nos diferentes tratamentos dentro de um mesmo bloco (teste de hipótese 1) e em permutações dos objetos de um mesmo tratamento nos diferentes blocos (teste de hipótese 2). As permutações geram distribuições nulas dos valores de $\mathrm{R}$ e o $\mathrm{R}$ calculado no teste é comparado com a distribuição. Utilizei como medida de similaridade 0 coeficiente de Bray-Curtis (McCune e Grace, 2002). Julguei essa medida de distância mais adequada, porque ela equivale à soma dos módulos das diferenças (entre objetos) de contribuição de todas as categorias de dieta. A matriz utilizada para a análise estava padronizada por objeto, pois continha a contribuição percentual das categorias alimentares na dieta, e isso fez com que a análise desse peso às proporções e não aos valores absolutos das categorias alimentares, um aspecto desejado. Os grupos tinham o mesmo número de objetos (12 cada).

Para avaliar com detalhe eventuais diferenças entre os tratamentos, comparei graficamente as contribuições das categorias alimentares dos dois grupos. 
3.4.3 Teste de premissa sobre qualidade da estimativa de disponibilidade utilizada - avaliação dos vieses

Comparei a estimativa de disponibilidade baseada na dieta total dos anuros terrícolas com uma estimativa de abundância baseada em coleta de artrópodes em armadilhas de queda, no intuito de discutir suas diferenças. O riginalmente havia planejado usar o ANOSIM para testar diferenças entre as estimativas, utilizando os dias de coleta como os objetos na matriz da análise, no entanto 0 número reduzido de objetos impediu esse procedimento. Por conta disso, analisei graficamente as contribuições percentuais das categorias de presa nas duas estimativas.

\subsubsection{Variações ontogenéticas na dieta}

Averigüei a existência de mudanças no tipo e/ ou no tamanho das presas consumidas pelos anuros, usando regressão simples (Zar, 1999) entre as eletividades da dieta e o tamanho dos anuros e entre o tamanho da maior presa consumida e o tamanho dos anuros, separadamente para cada espécie. Como uma modificação no tipo de presa pode ser um epifenômeno da escolha de presas maiores (Lima e Moreira, 1993; Lima, 1998; Lima e Magnusson, 1998; Lima et al., 2000), avaliei também a relação entre as eletividades por tipo de presa e o tamanho dos sapos, retirando da análise 0 efeito do tamanho da maior presa consumida.

Os eventos de consumo de diferentes categorias alimentares por anfíbios não são independentes entre si (Manly et al., 1993; Smith et al., 2004), 0 consumo de uma interfere negativamente no consumo de outras (Lima et al., 1997). Ademais a "dieta” é uma variável composta (Santos et al., 1996) ou multivariada (Manly et al., 1993). Uma análise adequada de dieta, portanto, deve levar em consideração toda a complexidade do fenômeno sem, no 
entanto, aumentar as chances de se encontrar resultados espúrios (principalmente erros do tipo I) e as técnicas multivariadas de análise parecem portanto ser as mais adequadas para algumas questões ecológicas que envolvem dieta.

As eletividades por tipo de alimento foram representadas por uma variável composta (NMD S-eletividades) resultado da redução de dimensionalidade das matrizes de eletividades das espécies de anuros, por escalonamento multidimensional não-métrico (NMD S - N on-M etric M ultidimensional Scaling). 0 NMD S é uma técnica iterativa que tem como resultado um mapa dos objetos em estudo que representa, com o máximo de fidedignidade, as distâncias ou similaridades entre os referidos objetos, num certo número de dimensões, de modo que objetos similares fiquem mais próximos entre si que objetos dissimilares (Kachigan, 1982; Jongman et al., 1995; Clarke e Warwick, 2001; McCune e Grace, 2002). Essa técnica (ao contrário de outros métodos de ordenação como análise de componentes principais - PCA) pode ser utilizada com qualquer medida de distância (similaridade ou dissimilaridade), não exige relações lineares entre as variáveis e é muito competente na recuperação de gradientes com dados simulados (Clarke e Warwick, 2001; McCune e Grace, 2002), o que levou ao seu emprego nesse trabalho. Uma desvantagem dessa técnica é o risco de não se chegar à melhor solução possível (Clarke e Warwick, 2001; McCune e Grace, 2002), por causa de sua natureza iterativa, mas isso pode ser minorado ao se realizar a rotina várias vezes (Clarke e Warwick, 2001; McCune e Grace, 2002). A avaliação da qualidade do resultado da ordenação por NMDS passa pela comparação da matriz de distâncias entre objetos nas dimensões originais e da matriz de distâncias entre objetos na configuração em poucas dimensões, por teste de goodness-of-fit (análise de stress) e por análise de correlação (teste de Mantel) (McCune e Grace, 2002). 
As matrizes originais utilizadas nessa análise continham as eletividades na dieta, calculadas para cada indivíduo, separadamente para cada espécie. Estimei a disponibilidade de recursos no ambiente para cada dia de coleta utilizado nas análises e calculei as eletividade de cada indivíduo com base na disponibilidade do dia em que o mesmo foi coletado, pois acredito que possa ter havido variação na disponibilidade de recursos nos diferentes dias. As linhas das matrizes foram os indivíduos e as colunas, as categorias alimentares. Utilizei o programa Ginkgo 1.4.1 do pacote estatístico VegAna para gerar matrizes de distância entre os objetos e reduzi-las a uma dimensão. Esse foi 0 único programa ao qual tive acesso que dispõe da medida de distância mais adequada para esse procedimento (distância de Manhattan) e realiza reduções em uma dimensão. Utilizei configurações iniciais aleatórias nas análises.

A qualidade da redução foi avaliada por teste de regressão de Mantel. Esse procedimento estatístico avalia a congruência entre duas matrizes de mesma dimensão levando em conta a não-independência dos pontos (=medidas de distância entre objetos) (McCune e Grace, 2002). Utilizei esse teste para avaliar a robustez com que a matriz de distâncias entre os objetos no eixo reduzido (uma dimensão) se relaciona com a matriz das distâncias originais entre os objetos (n dimensões). Tais análises foram feitas com o programa PC-ORD versão 4.25 e 0 método de avaliação da estatística foi o de randomizações.

Analisei a regressão linear simples (Zar, 1999) entre o maior tamanho da maior presa consumida e o tamanho dos anuros. Utilizei a maior medida do maior item consumido, pelo fato de crer que o aumento dessa medida reflita um aumento da capacidade de consumir presas maiores pelo sapo. Lima e colaboradores (observações não publicadas apud Lima et al., 2000) acreditam que sapos ingerem suas presas na mesma direção em que elas são agarradas pela língua e essa direção corresponde àquela em que a maior dimensão da 
presa fica paralela à abertura da boca. Nessa análise utilizei apenas as medidas dos itens "intactos" e "incompletos"; para evitar a superestimação dos tamanhos das presas (o que aconteceu com os itens "desarticulados"). Aos anuros que tinham apenas itens desarticulados nos seus estômagos, atribuí como valor da maior presa consumida a média da distribuição dos valores de tamanho dos itens "intactos" e "incompletos", da espécie, utilizados na análise.

Para as espécies em que foi detectada variação nas eletividades por tipo de presa e no tamanho da maior presa consumida com relação ao tamanho dos anuros, realizei análise de regressão múltipla do eixo reduzido das eletividades por tipo de alimento (NMD S-eletividades) com o tamanho dos anuros e 0 tamanho da maior presa. As regressões foram feitas pelo programa Systat versão 8.

\subsubsection{Avaliação de evidências de adaptação nas eletividades da dieta}

As eletividades na dieta dos anuros das dunas foram comparadas com as de populações alopátridas das mesmas espécies ou espécies filogeneticamente próximas às espécies das dunas, no sentido de averiguar evidências de adaptação na dieta. Esse procedimento assemelha-se ao proposto por Brooks e McLennan (1991) para levantar hipóteses sobre adaptação.

Com base nas informações disponíveis na literatura, estabeleci o padrão geral de eletividades dos gêneros estudados aqui e diferenças nas eletividades das espécies das dunas em relação ao padrão geral foram interpretadas como evidências de novidade evolutiva (apomorfia) nas eletividades, ocorrida após 0 estabelecimento da assembléia de anuros das dunas. Como uma apomorfia coincidente com uma mudança de regime seletivo pode ser interpretada como 
uma evidência de adaptação (Brooks e McLennan, 1991; Harvey e Pagel, 1991), então apomorfias nas eletividades da dieta dos anuros das dunas serão tidas como evidências de adaptação ao ambiente das dunas. A manutenção de um padrão plesiomórfico nas eletividades, indica, por outro lado, que contingências evolutivas (G ould, 2002) têm um papel preponderante na dieta dos anuros.

Comparei as eletividades das espécies das dunas com o padrão do gênero ou família, porque propostas de filogenia que incluam os anuros das dunas não estão disponíveis e, embora a rigor uma proposta de filogenia fosse necessária, mesmo informações mínimas sobre filogenia (Losos, 1996) permitem uma análise ampla como essa.

Embora a lógica desse procedimento resida na comparação de eletividades, dados desse tipo são escassos na literatura de ecologia de anuros (ver resultados), de modo que tais comparações tiveram de ser feitas também com dados de uso de recursos. Em tese, isso traz os problemas de se misturar características do ambiente (disponibilidade de alimento) com características das espécies (eletividades), o que se revela no uso (Lawlor, 1980). Entretanto, acredito que um padrão concordante de uso de alimento baseado na reunião de informações de dieta de espécies filogeneticamente próximas, em diferentes ambientes, é suficientemente redundante para informar principalmente sobre características dos gêneros ou famílias, e não sobre os ambientes em que vivem.

\subsubsection{Sobre a interpretação das análises}

Pelo fato de ter realizado vários testes com um mesmo conjunto de dados e de desejar manter o nível de significância global do trabalho em 0,05, o alfa de cada teste foi corrigido para 0,004 (total de 13 análises realizadas com um 
mesmo conjunto de dados). Tal medida torna 0 trabalho bastante conservativo e aumenta o risco de ocorrência do erro tipo II, pois apenas os efeitos mais fortes serão considerados significativos. A interpretação das análises, portanto, foi sempre ponderada pela avaliação de gráficos que tinham como eixos as grandezas envolvidas nas análises, no sentido de tornar as interpretações mais adequadas. 


\section{RESULTADOS}

\subsection{Assembléia de anuros temícolas}

O esforço de coleta total despendido nas cinco excursões (Fev-Mar/96, Dez/ 96, Set/ 96, Fev-Mar/ 97 e D ez/ 2003-Fev/ 2004) foi de 151.032 hora x pitfall. Na excursão de setembro de 1996 (auge da estação seca) não foi capturado nenhum anuro. 0 esforço de coleta ativa foi de 4,25 hora x homem numa noite e 6,33 hora x homem na outra (total de 10,6 hora x homem).

Os resultados das coletas revelaram que a assembléia de anuros terrícolas das dunas de topografia marcada de Ibiraba é formada por nove espécies: L eptodactylus fuscus, L. ocellatus, L. podicipinus, Physalaemus albifrons, Pleurodema diplolistris (Leptodactylidae), Bufo granulosus, B. schneideri (Bufonidae), D ermatonotus müelleri (Microhylidae) e Scinax x-signatus (Hylidae). A tabela 1 traz o sucesso de captura das espécies de anuros. Pleurodema diplolistris, Physalaemus albifrons (Figura 12) e Bufo granulosus foram as espécies com maior número de capturas, com 706, 274 e 248 indivíduos coletados, respectivamente. Esses números foram muito superiores aos das outras espécies (pelo menos uma ordem de grandeza). Apesar do sucesso das coletas por armadilhas de queda ser proporcional à abundância das populações e ao seu grau de atividade conjuntamente (van der Aart e Smeenk-Enserink, 1975; Adis, 1979; Greenberg et al., 1994; Cornish et al., 1995), julguei que há evidências suficientes para considerar que essas três espécies foram as mais abundantes da área. 


\subsection{Uso e eletividades por recursos alimentares}

As análises de dieta foram feitas apenas para as espécies mais abundantes Pleurodema diplolistris, Physalaemus albifrons e Bufo granulosus - para as quais houve o número mínimo de indivíduos coletados por dia. A expressão "anuros das dunas", a partir de agora, referir-se-á apenas a essas três espécies. Uma pequena parte dos dados da dieta de Physalaemus albifrons e Pleurodema diplolistris analisados aqui estão apresentados em Cruz (2000) e publicados em Santos e colaboradores (2003), respectivamente.

Analisei um total de 141 estômagos: 39 de B. granulosus, 54 de P. diplolistris e 48 de P. albifrons. Um total de 2.597 itens foi triado, somando 2,337 $\mathrm{g}$ de material dos conteúdos estomacais. 1.289 itens (massa total=0,4849 g) foram triados dos estômagos de B. granulosus, 522 itens (1,3996 g) de P. diplolistris e 786 itens $(0,4528 \mathrm{~g})$ de P. albifrons. Os B. granulosus apresentaram em média 33,0 itens alimentares no estômago, o maior valor das três espécies. A menor média foi de P. diplolistris, com 9,7 itens/ estômago e P. albifrons tinha em média 16,4 itens/ estômago.

Um número grande de categorias alimentares (total de dezenove) foi utilizado pelos anuros, embora nenhuma espécie tenha consumido todas as categorias e suas contribuições na dieta tenham variado bastante (Tabela 2). Os leptodactilídeos consumiram um maior número de categorias (14 por P. diplolistris e 16 por P. albifrons) que o bufonídeo (nove categorias).

A categoria "Outros Hymenoptera" incluiu todos os Hymenoptera exceto as formigas, "Arthropoda não-identificados" reuniu todos os itens que não puderam ser identificados no nível de Ordem e "Miscelânea" representou material em estágio avançado de digestão que não pôde ser identificado em nenhum nível. 
Julguei inadequado incluir as categorias "Arthropoda não-identificado" e "Miscelânea" nas análises, porque elas reúnem itens consumidos de muitos táxons e não traz informações de mesma qualidade que a de outras categorias alimentares. E, apesar de ter encontrado tecidos vegetais em mais de $50 \%$ dos indivíduos analisados (ver tabela 2), não considerei esse material como alimento. Assumi, com base em Evans e Lampo (1996) e Anderson e colaboradores (1999), que o consumo desse tipo de material pode se dar acidentalmente, em decorrência da estratégia de apreensão do alimento, baseado na projeção da língua pegajosa, ou ainda de forma incidental, pois esse material pode facilitar a redução física do exoesqueleto dos artrópodes, a expulsão de parasitas intestinais e atuar como uma fonte adicional de água, sem que haja, no entanto, qualquer ganho energético no seu consumo. Daqui para frente, esse material não mais constará nas análises nem nos gráficos; as contribuições percentuais da tabela 2 já foram calculadas excluindo-se essas três categorias.

As categorias alimentares importantes na dieta das três espécies foram Formicidae e Coleoptera. A primeira categoria teve $\% \mathrm{M}=68,01 \%$ e $\% \mathrm{O}=100 \%$ na dieta de Bufo granulosus, $\% \mathrm{M}=47,86 \%$ e $\% \mathrm{O}=87,04 \%$ na dieta de Pleurodema diplolistris e $\% \mathrm{M}=23,14 \%$ e $\% \mathrm{O}=83,33 \%$ na dieta de Physalaemus albifrons. A segunda categoria teve $\% \mathrm{M}=24,39 \%$ e $\% \mathrm{O}=74,36 \%$ na dieta de $\mathrm{B}$. granulosus, $\% \mathrm{M}=31,74 \%$ e $\% \mathrm{O}=72,22 \%$ na dieta de $\mathrm{P}$. diplolistris e $\% \mathrm{M}=42,06 \%$ e $\% \mathrm{O}=87,50 \%$ na dieta de $\mathrm{P}$. albifrons .

A massa total das categorias "Isoptera" e "Chilopoda" foram grandes se comparadas à massa total dos conteúdos estomacais de P. diplolistris, no entanto sua contribuição percentual foi bastante reduzida, devido ao fato de poucos indivíduos terem consumido uma grande massa dessas categorias. 0 mesmo ocorreu para "Isoptera" na dieta de P. albifrons. A maior parte dos cupins consumidos pelos anuros foi de indivíduos alados. 
B. granulosus apresentou eletividade positiva por formigas (índice de preferência de Strauss, L =0,234). P. albifrons apresentou eletividade positiva por besouros $(L=0,190)$ e negativa por formigas $(L=-0,214)$ (Tabela 3). P. diplolistris não apresentou eletividade por nenhuma categoria alimentar, mas isso pode ser apenas efeito de sua maior contribuição na estimativa de disponibilidade de alimento. A massa total da dieta de P. diplolistris foi de cerca 1,4 g, a de B. granulosus de 0,5 g e a de P. albifrons, 0,4 g. Por conta disso, considerei que P. diplolistris apresenta eletividade positiva por Coleoptera $(L=0,087)$ e negativa por Isoptera $(L=-0,102)$, seus dois maiores valores de eletividade em módulo.

Os maiores itens alimentares consumidos pelas três espécies de anuros tiveram, em sua maioria, tamanhos variando de 2,5 a 10,0 milímetros (Figura 13). Os B. granulosus consumiram presas de até $7,5 \mathrm{~mm}$ de comprimento, à exceção de um indivíduo. Além de consumirem, em sua maioria, itens menores, os bufonídeos consumiram também presas com os menores tamanhos relativos (tamanho da presa/ tamanho do sapo) (Figura 14). A amplitude de tamanhos relativos de presa foi maior para os leptodactilídeos que para o bufonídeo, que consumiu presas em sua maioria com tamanho relativo entre 0,1 e 0,2 .

\subsection{Teste de premissa sobre a qualidade da estimativa de uso de recursos utilizada}

O planejamento dessa análise previa que as duas estimativas de uso comparadas fossem feitas com dados da dieta das três espécies mais abundantes de anuros, no entanto isso não foi possível por causa da falta de sucesso na coleta ativa de B. granulosus e P. albifrons. D esse modo os resultados 
da comparação foram feitos com base na dieta de P. diplolistris e as conclusões foram tidas como válidas para as outras duas espécies.

A ANOSIM 2-way crossed que comparou estimativas de uso de alimento por Pleurodema diplolistris coletados ativa e passivamente revelou não haver diferença entre os grupos $(R=0,096, p=0,10)$ (12 objetos por grupo, dos quais nove de um bloco e três de outro). Também não foi detectada diferença entre os dias de coleta $(R=-0,102, p=0,77)$. As distribuições nulas dos valores de $R$ com a localização do R's calculados são apresentadas na figura 15. 0 resultado da ANOSIM com 9.999 permutações (apresentado aqui) foi semelhante ao encontrado quando as análises foram feitas realizando todas as permutações possíveis (243.099 para o fator tipo de coleta e 48.400 para 0 fator dia de coleta).

A análise da figura $\mathbf{1 6}$ revela diferenças sutis entre as duas estimativas: três anuros coletados passivamente consumiram formigas numa proporção maior que qualquer outro anuro coletado ativamente e dois anuros coletados ativamente consumiram larvas numa proporção maior que qualquer outro anuro coletado pelas armadilhas de queda. Nos gráfico estão apresentadas apenas as categorias de presa que contribuíram com pelo menos $10 \%$ da massa total da dieta: Coleoptera, Formicidade, Larva de Arthropoda e Orthoptera. Tais categorias somaram, respectivamente, $92,5 \%$ e $95,6 \%$ da massa de artrópodes na dieta dos sapos coletados passivamente e ativamente. A categoria "Outros" corresponde à soma de todas as outras categorias de presa encontradas nos estômagos. 


\subsection{Teste de premissa sobre a qualidade da estimativa de disponibilidade de recursos utilizada - avaliação dos vieses}

Essa comparação foi originalmente planejada para ser feita com dados da dieta das três espécies mais abundantes, dos quatro dias em que foram coletados artrópodes em armadilhas de queda. No entanto, o sucesso insuficiente de capturas de P. albifrons não permitiu sua inclusão nessa análise, de modo que só houve indivíduos suficientes das outras duas espécies B. granulosus e P. diplolistris) para a análise com dados de três dias. Cada grupo (estimativas de disponibilidade) foi composto por três objetos de três blocos diferentes (dias): um objeto por grupo por bloco.

A comparação entre a estimativa de disponibilidade de alimento (baseada na dieta total da assembléia de anuros terrícolas) e de abundância de alimento (baseada na coleta de artrópodes em armadilhas de queda) revelou concordância nas estimativas de besouros, baratas, escorpiões e diferenças nas estimativas de diplópodes e formigas (Figura 17). Os Diplopoda foram subestimados pela estimativa de disponibilidade e os Formicidae, pela estimativa de abundância. Estão representadas no gráfico apenas as categorias de presa que tiveram contribuição percentual em massa maior ou igual a 10\% (Diplopoda, Coleoptera, Blattidae, Scorpionida e Formicidade) e elas somaram, 89,8\% em massa na estimativa de abundância dos artrópodes e 87,7\%, na estimativa de disponibilidade. A categoria "Outros" corresponde à soma de todas as outras categorias de presa.

\subsection{Variações ontogenéticas na dieta}

As distribuições dos valores dos tamanhos dos anuros (CRC) utilizados nessas análises demonstraram que uma amplitude de tamanhos adequada foi 
amostrada (Figura 18); para as três espécies, os maiores indivíduos tinham mais que 0 dobro do tamanho dos indivíduos menores. A diferença entre 0 maior e o menor tamanhos da distribuição em termos de porcentagem do menor tamanho [(maior tamanho-menor tamanho)/menor tamanho] foi de 123,0\% para B. granulosus, de 155,7\% para P. diplolistris e de 118,9\% para P. albifrons. D esse modo, a falta de relação entre tamanho dos anuros e tipo e/ ou tamanho das presas não pôde ser interpretada como resultado espúrio devido a uma pequena variação de tamanhos de anuros amostrada. Os resultados das análises para P. diplolistris, por outro lado, podem ter sido influenciadas pela maior freqüência de indivíduos com tamanhos grandes.

\subsubsection{Redução das eletividades}

A matriz original das eletividades dos anuros utilizada na redução por NMD S continha apenas as categorias para as quais pelo menos 10\% dos indivíduos tinham eletividade (independente do tipo, positiva ou negativa, para valores de eletividade $=0,20$ em módulo). Tomei essa medida com 0 intuito de incluir nas análises apenas as variáveis (colunas) que tinham significado para 0 fenômeno estudado. Em decorrência disso, a matriz original de eletividades de B. granulosus (39 objetos) tinha apenas duas colunas: as eletividades por Formicidae e por Coleoptera. A matriz original de P. diplolistris (54 objetos) tinha quatro colunas, eletividades por Formicidae, por Coleoptera, por Isoptera e por Araneae e a matriz de P. albifrons (48 objetos) tinha três colunas: eletividades por Formicidae, por Coleoptera e por Isoptera.

A redução das eletividades de B. granulosus em uma dimensão resultou numa configuração com stress final de 0,22. 0 número de iterações necessárias foi 18 e de passos (runs) foi 74. O teste de Mantel detectou que a configuração em uma dimensão representou 84,6\% da variação da matriz de distâncias originais 
(estatística padronizada de Mantel, $\mathrm{r}=0,920$ ) e das 1.000 randomizações realizadas, nenhuma apresentou valores de $\mathrm{Z}$ iguais ou maiores que 0 calculado com os dados reais $(p=0,001)$. A configuração em uma dimensão das eletividades de P. diplolistris apresentou um stress final de 0,33 (iterações necessárias $=42$, passos=34). 0 teste de Mantel calculou $r=0,81(65,1 \%$ da variação original representada no eixo reduzido) $\operatorname{com} p=0,001$. 0 eixo NMD S da redução das eletividades de P. albifrons teve stress final de 0,37 (iterações necessárias=17, passos=20) e o teste de Mantel apontou a representação de $53,5 \%$ da variação original $(r=0,732, p=0,001)$ em uma dimensão.

A análise dos gráficos de dispersão entre o eixo reduzido (NMDSeletividaes) e as eletividades por categorias alimentares da matriz original permitiram compreender quais categorias foram bem representadas após a redução. Houve um padrão recorrente de relação forte entre os eixos NMD Seletividades de todas as espécies de anuros e as eletividades por Formicidae e Coleoptera (Figura 19 a, b, c, d, e, f), justamente as categorias importantes na dieta de todas as espécies. Para P. diplolistris e P. abifrons houve relação negativa com formigas e positiva com besouros e, para o bufonídeo, 0 contrário: relação positiva com eletividade por formigas e negativa com besouros. Não houve relação forte entre os eixos NMD S-eletividades e as eletividades por Isoptera, nem por Araneae, para os dois leptodactilídeos (Figura 19 g, h, i) e os altos níveis de stress da redução das eletividades de P. diplolistris e P. albifrons provavelmente se devem à incapacidade da ordenação de preservar as distâncias entre os pontos com relação às eletividades por essas duas categorias. 
4.5.2 Variação ontogenética nas eletividades por tipo de presa

B. granulosus e P. albifrons não apresentaram variação ontogenética nas eletividades por tipo de presa (Figura 20 a, c). A regressão simples entre 0 eixo NMD S das eletividades e CRC dos anuros não foi significativa: $F=0,080$, $p=0,779, r^{2}=0,002$, para $B$. granulosus e $F=2,125, p=0,152, r^{2}=0,044$, para $P$. albifrons. Após excluir um caso considerado extremo (outlier) (resíduo Studentizado=-3.207), a análise de regressão com os dados de P. diplolistris apontou relação significativa entre as eletividades por tipo de presa e tamanho do sapo $(F=9.851, p=0,003)$. No entanto essa relação não foi forte, apresentando $\mathrm{r}^{2}=0,162$. A análise do gráfico de dispersão (Figura 20 b) indica ampliação dos possíveis espectros de eletividades da dieta em animais maiores que $30 \mathrm{~mm}$.

De fato, não houve relação entre CRC e as eletividades pelas categorias alimentares de B. granulosus, nem de P. albifrons e o mesmo pôde ser notado para a relação entre CRC e as eletividades por Isoptera e Araneae de P. diplolistris (Figura 21 a, c, d, f, g, h, i). No entanto, é possível notar uma certa orientação dos pontos nos gráficos de CRC de P. diplolistris pelas eletividades de formigas e de besouros (Figura 21b, e). Esse, por outro lado, pode ser um resultado espúrio que reflete apenas o efeito do maior número de P. diplolistris grandes na amostra; nos gráficos de dispersão da figura 21 (b, e) pode-se notar que a orientação da nuvem de pontos deve-se principalmente à ampliação da dispersão dos pontos na faixa entre aproximadamente 32,0 e $45,0 \mathrm{~mm}$ de CRC. 


\subsubsection{Variação ontogenética no tamanho das presas}

As maiores presas consumidas por B. granulosus e P. diplolistris aumentaram com um aumento do tamanho dos anuros (CRC) e essa relação não parece ser linear para o leptodactilídeo. Não houve modificação no tamanho das maiores presas consumidas por P. albifrons com relação ao tamanho do anuro (Figura 22). Não foi possível linearizar (por transformação logarítmica) a relação das variáveis para P. albifrons, porque há valores negativos de eletividade (podem variar de-1 a 1).

As análises de regressão entre tamanho do anuro (CRC) e maior tamanho das maiores presas consumidas apontaram valores extremos para todas as espécies, de modo que tive de retirar tais casos das análises. Houve um valor extremo nas distribuições de cada espécie e esses valores não estão representados nos gráficos. $O$ valor extremo da distribuição de B. granulosus tinha resíduo Studentizado de 11,906, o da distribuição de P. diplolistris tinha resíduo Studentizado=23,680 e na de P. albifrons, resíduo Studentizado=7,407.

A variação do tamanho (CRC) de B. granulosus explicou 52,3\% da variação nos tamanhos das maiores presas $(F=39,406, p<0,001)$, e a variação de tamanhos de P. diplolistris explicou apenas 17,1\% da variação dos tamanhos das maiores presas $(F=10,51, p=0,002)$. Não houve regressão entre CRC e 0 tamanho das maiores presas para $\mathrm{P}$. albifrons $(\mathrm{F}=0,429, \mathrm{p}=0,516)$.

Os maiores itens consumidos pelas três espécies foram formigas e besouros, em sua maioria. Formigas representaram $75 \%$ dos maiores itens consumidos por B. granulosus, 55\% dos maiores itens de P. diplolistris e $25 \%$ dos maiores itens de P. albifrons. Besouros corresponderam a 38\% das maiores presas consumidas por P. albifrons, a 30\% das maiores presas de P. diplolistris e a apenas 8\% das maiores presas consumidas por B. granulosus (Figura 23). 
4.5.4 Variação ontogenética nas eletividades por tipo de presa independente do tamanho da presa

O tamanho das maiores presas consumidas por P. diplolistris não apresentou relação com suas eletividades por tipo de presa (NMDS-eletividades), retirando-se 0 efeito do tamanho do sapo (parcial $p=0,110$, tolerância $=0.829$ ) (Figura 24). E, retirando-se o efeito do tamanho das presas, uma relação fraca e não-significativa, semelhante à revelada pela regressão simples das eletividades pelo tamanho do sapo, foi encontrada pela análise parcial, a despeito de sua baixa probabilidade de ocorrer por acaso (parcial $p=0,006$ ). Mais uma vez esse pode ser um resultado espúrio derivado do maior número de sapos grandes na análise.

A figura 25 traz um resumo esquemático das eletividades na dieta e das variações ontogenéticas na dieta das espécies de anuros terrícolas estudadas aqui.

\subsection{Avaliação de evidências de adaptação nas eletivi- dades da dieta}

Os padrões gerais de eletividades dos gêneros Bufo, Pleurodema e Physalaemus foram estabelecidos com base em 18 trabalhos (Tabela 4). Na verdade, foi levantado um número maior de trabalhos sobre a dieta de espécies desses gêneros, mas a análise envolveu apenas parte deles, porque alguns não disponibilizavam informações sobre as categorias mais importantes na dieta, nem eletividades. O trabalho de Duellman (1990) foi incluído na análise, porque relata a dieta de muitas espécies, mas só forneceu informações qualitativas sobre dieta e nenhuma informação sobre métodos de análise.

A dieta do gênero Bufo foi a melhor documentada, 13 espécies diferentes foram estudadas em 17 dos trabalhos analisados. As dietas de Physalaemus 
(total de cinco espécies em quatro trabalhos) e especialmente Pleurodema (uma espécie e um trabalho) estão pobremente representadas na literatura (os trabalhos de Santos e colaboradores [2003] e Cruz [2000] não foram utilizados na análise, porque relatam a dieta das mesmas populações estudadas aqui).

Parece ser plesiomórfico para o gênero Bufo a preferência por formigas e a importante contribuição de besouros na dieta, e esse foi o padrão encontrado na dieta de B. granulosus nas dunas. Cupins e formigas são recorrentemente importantes ou preferidos na dieta de espécies de Physalaemus e o padrão encontrado para P. albifrons nas dunas difere do padrão geral estabelecido aqui. Não houve dados suficientes para estabelecer o padrão de eletividades do gênero Pleurodema. 


\section{DISCUSSÃO}

\subsection{Sobre a composição da anurofauna das dunas de Ibiraba}

A herpetofauna dos mares de areia do São Francisco é reconhecidamente peculiar e destacase, principalmente, porque uma grande proporção das espécies de lagartos, serpentes e anfisbenas lá presentes: (1) é endêmica dos mares de areia; (2) forma pares de espécies filogeneticamente muito próximas com distribuição alopátrida nas duas margens do rio e (3) apresenta alto grau de aptação (sensu Gould e Vrba, 1982) ao ambiente arenoso (psamofilia). Por aptação, entende-se uma característica do organismo que, independente de ter sofrido seleção natural na sua origem, interage operacionalmente com algum fator do seu ambiente de modo a favorecer a sobrevivência e reprodução do indivíduo (Gould e Vrba, 1982). Ademais, (4) em comparação com herpetofaunas de outros ambientes áridos e mesmo florestados, as assembléias de Squamata de lá apresentam um número elevado de espécies sintópicas (Rodrigues, 1996).

Apesar de pouco explorada, a anurofauna das dunas também se revela bastante expressiva. Nove foram as espécies sintópicas amostradas nas dunas de topografia típica de Ibiraba (L eptodactylus fusaus, L . ocellatus, L. podicipinus, Physalaemus albifrons, Pleurodema diplolistris [Leptodactylidae], Bufo granulosus, B. schneideri [Bufonidae], Dermatonotus müelleri [Microhylidae] e Scinax x-signatus [Hylidae]). Em duas áreas adjacentes às dunas típicas, uma de mata de galeria e outra de dunas sem topografia marcada, foram levantadas também algumas espécies que parecem não habitar as dunas típicas. Na mata de galeria foram coletadas as espécies: Bufo granulosus, L eptodactylus ocellatus, L. podicipinus, L. fuscus, Physalaemus albifrons, Pleurodema diplolistris, E lachistodeis ovalis e uma nova 
espécie de leptodactilídeo, L eptodactylus caatingae e, nas dunas sem topografia marcada, foram coletados: Bufo granulosus, Physalaemus albifrons, Pleurodema diplolistris e Dermatonotus müelleri (P.L.B.Rocha e F.A.Juncá, comunicação pessoal; Heyer e Juncá, 2003). Esses números são muito superiores aos registrados por Rodrigues (2003) para essa localidade (quatro espécies) e como ele prevê, projetos que procuram maximizar a representação das comunidades de répteis e anfíbios na caatinga podem ainda revelar herpetofaunas deveras ricas.

As três espécies de anuros mais abundantes das dunas típicas foram Pleurodema diplolistris, Bufo granulosus e Physalaemus albifrons, em ordem decrescente de abundância. O gênero Pleurodema, exclusivamente sulamericano (Frost, 2004), tem sua história de radiação intimamente relacionada à dispersão de ambientes xéricos (Duellman e Veloso, 1977), embora P. diplolistris seja a única espécie presente na caatinga e em áreas abertas adjacentes (Cardoso e Arzabe, 1993). O gênero Bufo tem distribuição amplíssima e está presente em quase todos os continentes (Narvaes, 2003). Bufo granulosus é tido como típico de hábitats abertos das Américas do Sul e Central e, ainda que ocorra em áreas predominantemente florestadas, associase sempre a hábitats abertos nessas áreas (Narvaes, 2003). Physalaemus é um gênero exclusivamente americano, sua distribuição vai do México até a América do Sul, incluindo-a (Frost, 2004). Physalaemus albifrons distribui-se na Bahia e em Minas Gerais (Frost, 2004) e com base nos trabalhos de dieta analisados (da tabela 4), o gênero habita ambientes variados desde a caatinga até florestas úmidas. Pelo menos duas (B. granulosus e P. diplolistris) das três espécies mais abundantes de anuros terrícolas das dunas típicas são táxons reconhecidamente associados a ambientes abertos ou xéricos. 


\subsection{Sobre atividade sazonal}

O s resultados das coletas de Rocha e Rodrigues (no prelo) revelaram que, nas dunas típicas de Ibiraba, os anuros (os estudados aqui) suplantaram os lagartos (estudados por eles) em número de indivíduos e em massa. Também em coletas realizadas por P.L.B.Rocha e equipe em 2000, numa mata de galeria e numa área de dunas sem morfologia marcada, ambas adjacentes às dunas típicas, houve um maior sucesso de coleta de anuros que de lagartos, na época de chuvas (P.L.B.Rocha e F.A.Juncá, comunicação pessoal).

Esse é um padrão que pode ser tido como surpreendente, dado que anfíbios são muito susceptíveis às vicissitudes ambientais, por exemplo são ectotérmicos, possuem tegumento permeável, de maneira geral, necessitam de um ambiente úmido para reproduzir-se (Beuchat et al., 1984; Duelmann e Trueb, 1986; Preest e Pough, 1989; Brekke et al., 1991; Stebbins e Coen, 1995; Arzabe, 1999), e que a caatinga é um ambiente bastante desafiador pela sua aridez. Ainda assim, a caatinga é habitada por uma anurofauna rica em espécies e em estratégias de redução de perda de água (Rodrigues, 2003; Navas et al., 2004).

Na estação seca, entretanto, houve ausência completa de anuros, nas dunas de morfologia típica, até mesmo os lagartos tiveram uma redução de atividade (Rocha e Rodrigues, submetido), e esse é um padrão recorrente na biologia de anuros (D uellman e Trueb, 1986). Por exemplo, Seebacher e Alford (1999) relatam que uma população de Bufo marinus de uma ilha tropical emergiu em 90 a 100\% das noites no período de maior umidade e em nenhuma noite no período mais seco e relacionaram esse comportamento aos níveis da umidade do solo. Dodd (1994), num estudo sobre efeitos da seca na estrutura de populações de dois Bufonidae em ambiente xérico, notou que o número de capturas de sapos diminuía à medida que a seca se acentuava. Anderson e 
colaboradores (1999) descrevem a dieta de Bufo cognatus, Spea bombofrons e S. multiplicata, no ambiente semi-árido de Playas Wetlands (Southern Haigh Plains, Texas) e relatam que várias espécies de sapos da região emergem nas enchentes da primavera. Gibbons e Bennet (1974) num trabalho feito em duas lagoas vizinhas a uma área de plantação de Pinus encontraram correlação positiva entre atividade de anuros e chuvas, resultados concordantes com os encontrados por diversos trabalhos citados por eles.

A diminuição da atividade das espécies de anuros das dunas muito provavelmente tem correlação positiva com comportamento de enterrar-se. Durante as excursões de 1996 e 1997, alguns indivíduos de B. granulosus, P. diplolistris e P. albifrons foram mantidos em caixas de plástico com areia, em situação de semi-cativeiro, e observou-se que durante o dia eles permaneciam enterrados, emergindo apenas à noite (P.L.B.Rocha e J.W.A.Santos, comunicação pessoal). Segundo Duellman \& Trueb (1986), muitos bufonídeos, principalmente os que vivem em regiões áridas, têm o hábito de refugiar-se em tocas ou enterrar-se durante a estação mais seca. Arzabe e Almeida (1996) observaram o hábito semi-fossório de L eptodactylus troglodytes, numa localidade de caatinga, próxima a uma reserva florestal de mata secundária em Mamanguape, Pernambuco, e relatam outros dois trabalhos que detectaram o mesmo comportamento para a espécie na caatinga. Carvalho e Bailey (1948), em viagem pelo Rio São Francisco, registram os hábitos de Pleurodema diplolistris, dentre os quais está o de enterrar-se na areia em galerias (individuais ou de grupos) com profundidade de até $65 \mathrm{~cm}$. Arzabe (1999) comenta que o hábito fossório é comum em anuros de regiões áridas. 


\subsection{Sobre a atividade noturna}

O utro padrão marcante encontrado foi o da atividade exclusivamente noturna de todas as espécies (mesmo as menos abundantes) de anuros das dunas. Cascon (1987) e Gallardo (1965) também registram atividade noturna para Pleurodema diplolistris e D uellman (1990), num estudo sobre herpetofaunas de florestas úmidas, registra atividade noturna para Bufo granulosus, em Barro Colorado. Embora seja tentador criar uma explicação adaptacionista para esse comportamento, a atividade noturna de anuros não evoluiu no contexto da colonização da catinga (Navas et al., 2004), pois esse é um caráter extremamente difundido entre espécies de anuros de vários táxons.

Vários trabalhos relatam atividade noturna para espécies de Bufo, em diversos ambientes, desde florestas úmidas até áreas abertas (por exemplo, Vitt e Cadlwell [1994], para B. typhonius; D uellman [1963]; Strüssmann et al. [1984]; Seebacher e Alford [1999], para Bufo marinus; D uellman [1963], para B. valliceps valliceps; Anderson et al. [1999], para Bufo cognatus e Rappi et al. [2000], para Bufo variegatus). Duellman (1990), no entanto, registra atividade diurna para várias espécies de Bufo nas florestas que estudou. Espécies do gênero Physalaemus podem ter atividade somente à noite ou durante o dia e a noite, em áreas florestadas ou de transição de mata e áreas mais abertas (D uellman, 1990; Vitt e Cadlwell, 1994; Caldwell e Vitt, 1999).

Navas e colaboradores (2004), numa avaliação preliminar de aspectos da fisiologia e comportamento de anuros na caatinga, encontraram resultados conflitantes com os do presente trabalho sobre atividade de Bufo granulosus, B. paracnemis e Pleurodema diplolistris. Os autores encontraram ativos indivíduos das três espécies durante a estação seca e durante o dia, embora não especifiquem seus métodos, nem a(s) localidade(s) de estudo, e argumentam que indivíduos jovens das duas espécies de Bufo evitam a desidratação, ao comportarem-se de 
forma oportunista, recolhendo-se em abrigos quando o solo se torna muito seco. Tais discrepâncias poderiam dever-se a diferenças etárias dos indivíduos analisados nos dois trabalhos, mas esse não parece ser o caso, pois no presente estudo indivíduos jovens e adultos foram analisados. Ao discutirem seus resultados, Navas e colaboradores (2004) argumentam que apesar da estivação ser um comportamento comum em anuros de regiões áridas, essa não parece ser a norma para sapos de caatinga, devido à atividade de algumas espécies na época da seca. Contrariamente, a estivação é provavelmente uma estratégia importante para os sapos das dunas, pois durante a estação seca eles extinguiram completamente sua atividade e provavelmente mantiveram-se enterrados.

O s autores concluem que as adaptações dos anuros ao ambiente da caatinga envolvem uma complexa gama de traços fisiológicas e comportamentais, que muitas vezes incluem estratégias contrastantes e de difícil interpretação (Navas et. al., 2004). Tal quadro, por outro lado, pode ser facilmente explicado pela imprevisibilidade climática característica da caatinga e uma conseqüente falta de pressões seletivas direcionais por um tempo suficiente para selecionar traços adaptativos a esse ambiente (Mares et al., 1985).

\subsection{Sobre as estimativas de uso}

Apesar de não ter havido diferenças entre as dietas de P. diplolistris coletados ativa e passivamente, pode-se notar diferenças sutis nas proporções de consumo de formigas e larvas (ver figura 16). Tais diferenças podem ser resultado do tempo longo decorrido entre a captura e a eutanásia de alguns animais coletados por armadilhas de queda no dia 18 de fevereiro de 2004. Larvas são, dentre os artrópodes consumidos, provavelmente as formas com menores teores de quitina e, portanto de mais rápida digestão. Formigas, do 
contrário, são muito quitinosas e de digestão lenta. 0 indivíduo que apresentou o maior consumo de formigas (100\%) tinha apenas um item alimentar no estômago, uma formiga.

\subsection{Sobre as estimativas de disponibilidade}

A estimativa de disponibilidade de recursos no ambiente utilizada nesse trabalho foi feita com base na dieta total da assembléia de anuros estudada. Tal estimativa é defendida por Lawlor (1980) e Winemiller e Pianka (1990), como sendo uma estimativa adequada do conjunto de presas disponíveis para o predador, e tem sido aplicada em estudos sobre dieta de sapos e lagartos (por exemplo, Vitt, 1991; Vitt e Caldwell, 1994; Vitt e Zani, 1996, 1998; Caldwell e Vitt, 1999; Parmelee, 1999; Rocha e Rodrigues, submetido). Além disso, essa parece ser a estimativa que melhor representa a disponibilidade (sensu, Johnson, 1980). Tal estimativa, no entanto é criticada, com razão, por não ser independente da dieta dos animais estudados (Winemiller e Pianka, 1990; Manly et al., 1993).

Por outro lado, a dieta total não parece ser mais tendenciosa que outras estimativas de abundância de alimento, consideradas mais diretas, que são utilizadas como estimadoras da disponibilidade de recursos no ambiente. De fato, a disponibilidade efetiva de qualquer recurso deve variar no tempo, no espaço e de consumidor para consumidor, a depender de seu comportamento e de diferenças no seu horário de atividade e 0 de suas presas, como argumentam Winemiller e Pianka (1990). Portanto, seria ingênuo imaginar que a disponibilidade de recursos, tal qual percebida pelo predador, é facilmente estimada (Hódar et al., 1996) ou que algum método de amostragem não apresenta tendências. Johnson (1980 e referências citadas lá) e Winemiller e Pianka (1990) apontam as dificuldades em estimar a disponibilidade e 
assumem que esse é um processo arbitrário, pois conclusões a respeito de um recurso ser "preferido" ou "evitado" podem depender do que o pesquisador considera disponível para o predador.

Muitos dos trabalhos de dieta de lagartos e sapos estimam a disponibilidade de recursos no ambiente por métodos chamados "diretos", porque a disponibilidade (=abundância, sensu Jonhson, 1980) das presas (geralmente artrópodes) é estimada diretamente do ambiente, sem intermédio do consumidor (por exemplo, Labanick, 1976; Christian, 1982; Strüssmann et al., 1984; Galatti, 1992; Lima e Moreira, 1993; Flowers e Graves, 1995; Hódar et al., 1996; Lima, 1998). A princípio esses métodos parecem objetivos (em oposição a subjetivos), por não envolverem escolhas do pesquisador sobre que categorias de presa estão disponíveis para os predadores, nem informações da dieta dos organismos estudados. Armadilhas de queda, de cola, amostras de solo e folhiço processadas em funil de Berlese ou amostradores por sucção (D e-vac suction sampler) são, via de regra, utilizados para amostrar artrópodes disponíveis.

Ainda que a princípio esses métodos não pareçam tendenciosos, todos eles subestimam ou superestimam algum tipo de recurso e terminam por ser arbitrários na maneira como estimam a disponibilidade. As armadilhas de queda são as mais freqüentemente utilizadas para estimar disponibilidade, no entanto subestimam abundâncias de artrópodes pouco móveis (Cornish et al., 1995; Tinoco, 2004; Rocha e Rodrigues, submetido) e, segundo Adis (1979), seus resultados devem ser interpretados com cautela. Amostras de solo precisam ser coletadas e processadas nos funis de Berlese, com muito cuidado, pois do contrário apenas uma pequena porcentagem dos artrópodes é efetivamente coletada (Toft e Levings, 1979 apud Lima, 1998). Galatti (1992) comenta que armadilhas de cola podem estimar as abundâncias das presas de 
maneira tendenciosa. Flowers e Graves (1995) apontam a ineficiência das armadilhas D e vac na coleta de dípteros.

A estimativa de disponibilidade baseada na dieta total resolve uma parte dos problemas associados à arbitrariedade com que as categorias alimentares são consideradas disponíveis, pois não há dúvida quanto ao fato de todos as categorias alimentares consumidas estarem disponíveis. Mas, uma vez que nem todos as categorias disponíveis são de fato consumidas, devido às preferências dos consumidores, há subestimação das eletividades negativas de itens não consumidos. Além disso, há certa circularidade envolvida na comparação do uso e da disponibilidade (Winemiller e Pianka, 1990).

Acredito que uma estimativa de disponibilidade imune a muitas dessas críticas seria baseada na dieta total da assembléia estudada com base nos conteúdos estomacais de indivíduos diferentes dos utilizados para calcular eletividades, porém coletados no mesmo período de tempo e na mesma área. Esse procedimento não foi adotado nesse trabalho por conta de um número insuficiente de anuros coletados das três espécies em mesmos dias.

As diferenças encontradas entre a estimativa de disponibilidade e de abundância eram esperadas, embora, para a maioria das categorias alimentares, as duas estimativas tenham concordado. Houve diferenças nas estimativas de Diplopoda e Formicidae: a primeira foi subestimada pela dieta total e a segunda, pelas armadilhas de queda. Diplópodos são animais com defesas químicas que provavelmente são evitados pelos sapos e as formigas, apesar de também terem defesas químicas, são geralmente muito bem toleradas por anuros (várias famílias são especialistas em formigas - Toft, 1995; Caldwell, 1996) e foram importantes na dieta de todas as espécies analisadas. Além disso, armadilhas de queda podem subestimar a abundância de formigas pelo 
fato delas muitas vezes serem capazes de escapar das armadilhas (observação pessoal).

Os resultados desse trabalho e de Rocha e Rodrigues (submetido) são muito diferentes dos encontrados por Schoener (citados como comunicação pessoal por Winemiller e Pianka, 1990), que ao coletar artrópodes de folhiço não foi capaz de detectar nem 10\% dos artrópodes consumidos pelos lagartos que estudou. Tinoco (2004) encontrou concordância entre estimativas de abundância baseadas em armadilhas de queda e na dieta de uma assembléia de lagartos e anuros para vários grupos de artrópodes, numa localidade de mata atlântica. No entanto, encontrou diferenças entre métodos nas estimativas de artrópodes muito móveis, melhor estimados por armadilhas de queda; de itens pouco móveis, melhor amostrados pela dieta e de artrópodes com defesas químicas, subestimados pela dieta.

A subestimação dos diplópodes pela estimativa de disponibilidade refletiuse numa subestimação das eletividades negativas dos anuros por essa categoria. Além disso, essa subestimação pode ter reflexo também nas eletividades pelas outras categorias alimentares, porque a eletividade é calculada com base na contribuição percentual das categorias alimentares. Provavelmente os valores das eletividades positivas estão todos superestimados e os valores das eletividades negativas estão subestimados. Apesar disso, a ordem crescente (ou decrescente) das eletividades provavelmente não foi alterada.

\subsection{Sobre variações ontogenéticas na dieta}

Nenhuma das espécies de anuros das dunas modifica as eletividades por tipo de presa à medida que cresce e o tamanho das maiores presas consumidas por B. granulosus e P. diplolistris aumentam com o crescimento do sapo. A falta de 
relação entre tamanho e dieta para $\mathrm{P}$. albifrons não pôde ser atribuída à pequena variação de tamanhos do sapo nas análises. Apesar de a princípio ter se revelado uma relação fraca entre tamanho do sapo e eletividade por tipo de presa para P. diplolistris, ao se retirar o efeito do tamanho da presa nas eletividades por tipo, a relação mostrou-se não-significativa. A avaliação dos gráficos parciais da análise de regressão múltipla revela que de fato não há relação entre as duas variáveis. A baixa probabilidade desse resultado ocorrer por acaso $(p=0,006)$ provavelmente deve-se ao número maior de animais de tamanho grande (entre 32,0 e 45,0 mm de CRC) na análise (ver Figura 24).

Esse é um resultado em parte inesperado, porque a literatura prevê uma modificação ontogenética nos tipos de presa consumidas por anuros, ainda que esse fenômeno seja apenas um efeito passivo do aumento do tamanho das presas consumidas (Lima e Moreira, 1993; Flowers e Graves, 1995; Lima, 1998; Lima e Magnusson, 1998). Modificações tanto no tamanho quanto no tipo de presa foram relatadas para algumas espécies de Bufo e alguns leptodactilídeos (por exemplo: Peña et al., 1994; Flowers e G raves, 1995; Lima, 1998; Lima e Magnusson, 1998; Maneyro et al., 2004; Rappi et al., 2000). Por outro lado, ao analisar a dieta de três espécies sintópicas (Bufo cognatus, Spea bombifrons e S. multiplicatus), Anderson e colaboradores (1999) surpreenderamse ao encontrar uma dieta menos diversa para o bufonídeo que para as outras espécies, pois o tamanho maior do Bufo fez com que eles esperassem que sua dieta pudesse incluir um maior espectro de tamanhos e conseqüentemente de tipos de presas. No entanto, um mais amplo espectro de tamanhos de presa pode não vir acompanhado de um maior espectro de tipos de presa, como encontrado aqui para B. granulosus e P. diplolistris. 


\subsection{Sobre eletividades na dieta}

O eixo NMD S-eletividades, resultado da análise que reduziu a dimensionalidade das eletividades na dieta, teve uma relação inversa com as eletividade por formigas e besouros para todas as espécies (ver figura 19). No entanto, tal variação não é explicada por diferenças no tamanho do sapo, como visto anteriormente. A que se deve então tal variação?

D ois outros fatores que podem explicar tais diferenças nas eletividades são o sexo dos sapos e os diferentes dias em que os animais foram coletados. Com 0 intuito de levantar hipótese sobre 0 efeito desses fatores nas eletividades dos anuros, avaliei se animais de diferentes sexos se organizavam com relação ao eixo NMD S-eletividades, através de um gráfico de dispersão (Figura 26) e se havia organização dos dias de coleta com relação ao mesmo eixo (Figura 27). Não pareceu haver, no entanto, qualquer relação clara entre os fatores e as eletividades. Esse quadro poderia mudar, caso um outro método de sexagem fosse utilizado, pois os animais que não estavam sexualmente maduros foram classificados como jovens. Apesar da categoria "jovens" poder ter obscurecido um padrão de diferenças na dieta entre os sexos, a comparação dos dados de macho e fêmeas revela que tal diferença é muito improvável. Hipóteses, portanto, acerca do efeito desse fatores nas eletividades são fracas heuristicamente.

\subsection{Sobre os possíveis impactos que os anuros causam na assembléia de lagartos, serpentes e anfisbenas sintópicos}

Os anuros das dunas típicas estão em sintopia com pelo menos 15 espécies de Squamata (10 espécies de lagartos, 4 de serpentes e 1 de anfisbena) e, na época de chuva, aqueles são mais numerosos que esses. Estudos sobre diferença na 
dieta entre lagartos e sapos são escassos (por exemplo, Vitt e Caldwell, 1994; Caldwell e Vitt, 1999; Lima et al., 2000), embora não o devessem, pois, pelo fato de freqüentemente serem artropodívoros e habitarem sintipocamente 0 folhiço, é grande a possibilidade de interação ecológica entre eles. Ademais, acredito ser legítimo incluir mesmo algumas serpentes em tais estudos, o que é defendido por Losos (1996), como por exemplo os Scolecophidia, serpentes pequenas, fossórias e que geralmente se alimentam de formigas (Webb e Shine, 1993; Webb et al., 2000).

Estudos ecológicos sobre a assembléia de Squamata sintópica aos anuros analisados aqui foram realizados por Rocha e Rodrigues (submetido), para lagartos de médio e pequeno porte, e por Damasceno e Rocha (em preparação), para anfisbenas, lagartos ápodes fossórios e serpentes fossórias. No sentido de discutir os possíveis impactos que os anuros causam na assembléia de lagartos, comparei os hábitos dos dois grupos.

Das sete espécies de lagartos analisados por Rocha e Rodrigues (submetido), apenas duas, Calyptommatus leiolepis (Gymnophthalmidae) e Briba brasiliana (Gekkonidae) têm atividade preferencialmente noturna. Todas as serpentes estudadas por Damasceno e Rocha (em preparação) têm atividade noturna e não foi possível determinar os horários de atividade das outras espécies. Uma coincidência nos horários de atividade poderia indicar a possibilidade de interferência entre os elementos da herpetofauna, mas 0 hábito fossório das serpentes e de Calyptommatus leiolepis e provavelmente fortemente arborícola de Briba brasiliana (Rocha e Rodrigues, submetido) não apontam interferência entre eles e os anuros.

As categorias mais importantes na dieta dos anuros foram formigas e besouros (ver tabela 2). Os dois leptodactilídeos apresentaram eletividade positiva por besouros e o bufonídeo teve eletividade positiva por formigas. P. 
diplolistris teve eletividade negativa por cupins e P. albifrons, por formigas (ver tabela 3). D as 15 espécies de Squamata sintópicas, apenas duas apresentaram eletividades por formigas: o lagarto Tropidurus psammonastes (Tropiduridae), por formigas adultas, e a serpente Typhlops amoipira (Typhlopidae), por larvas de formigas. Formigas adultas foram importantes apenas na dieta dos tropidurídeos e besouros não tiveram participação expressiva na dieta dos lagartos estudados por Rocha e Rodrigues (submetido). Para esses lagartos, larvas de insetos foram os itens mais importantes na dieta. Para os fossórios, as categorias mais importantes na dieta variaram: as Colubridae (A postolepis gaboi e Phimophs scriptorcibatus) consumiram principalmente vertebrados. Larvas e cupins foram importantes na dieta das anfisbenas e a categoria mais importante na dieta de Thyphlops amoipira foi larvas de formigas.

D e maneira geral, há pouca similaridade entre as dietas de sapos e lagartos e as divergências não parecem ter surgido como um resultado de interação entre os grupos, após o estabelecimento de simpatria entre eles (interações ecológicas passadas). Ademais, parece pouco provável que interações ecológicas contemporâneas entre sapos e lagartos tenham efeito forte na organização da assembléia. O s anuros não parecem , portanto, causar grande impacto na disponibilidade de presas consumidas ou preferidas pelos lagartos, serpentes e anfisbenas sintópicos. A eletividade positiva por formigas de Bufo granulosus e do tropidurídeo Tropidurus psammonastes pode apontar a existência de interação ecológica contemporânea entre eles. Muito embora seja fundamental haver indícios de limitação de recursos na área para levantar tal hipótese (pois a divergência nos horários de atividade dos sapos e dos tropidurídeos exclui competição por interferência). Por outro lado, formigas são muito abundantes nas dunas, o que foi detectado por Rocha e Rodrigues (no prelo) com duas diferentes estimativas de abundância, e diferenças no tamanho entre os sapos e os tropidurídeos consumidores de formigas podem 
ser responsáveis por diferenças no tamanho e mesmo tipo de presa (morfoespécies de formigas) que eles consomem.

Em geral, as formigas foram mais importantes na dieta dos sapos que na dos lagartos e houve pouca coincidência nos itens preferidos na dieta dos dois grupos. Esse resultado concorda com os trabalhos de Vitt e Caldwell (1994), Caldwell e Vitt (1999) e Lima e colaboradores (2000) e esses autores discutem possíveis mecanismos causadores de tal padrão, como por exemplo a possível origem alimentar das toxinas presentes na pele de muitos anuros.

\subsection{Sobre apomorfias na dieta}

O gênero Bufo tem ampla distribuição geográfica, agrupa muitas espécies (Duellman e Trueb, 1986; Duellman e Schulte, 1992; Narvaes, 2003) e, surpreendentemente, há uma grande homogeneidade nas preferências de dieta das espécies (Tabela 4). Por exemplo, B. marinus, uma espécie de tamanho relativamente grande e capaz de consumir até mesmo pequenos vertebrados (Weber, 1938; Werren, 1993), não deixa de incluir formigas na dieta.

Se por um lado é surpreendente a concordância entre espécies do gênero, por outro, não é de se esperar que a população de B. granulosus das dunas apresente apomorfias na dieta. A ampla distribuição geográfica da espécie (Narvaes, 2003) provavelmente resulta em fluxo gênico entre populações sujeitas a diferentes pressões seletivas, 0 que limita 0 surgimento de diferenciações genéticas locais (Endler, 1977). Contingências evolutivas exercem um papel prevalecente na dieta de Bufo granulosus, e provavelmente na dieta do gênero Bufo, e tal fato pode estar associado a uma restrição fisiológica relacionada à necessidade de consumo de formigas para a produção de toxinas pelo sapo, embora só haja evidência forte dessa relação para os dendrobatídeos (Caldwell, 1996; Caldwell e Vitt, 1999; Lima et al., 2000). 
Physalaemus albifrons apresentou eletividades divergentes daquelas estabelecidas aqui como o padrão geral para o gênero, o que aponta, segundo a lógica desse trabalho, apomorfia na dieta dessa população. A literatura aponta formigas como uma categoria importante na dieta de espécies do gênero Physalaemus e cupins como a categoria alimentar preferida.

Há mesmo uma tendência diametralmente oposta com relação às formigas na dieta de P. albifrons: o padrão geral indica essa categoria como importante e P. albifrons das dunas apresentou sua maior eletividade negativa por essa categoria. Tal divergência na preferência pode ser resultado de competição (atual ou passada) entre essa espécie e outros componentes da herpetofauna local, inclusive pelo fato de P. albifrons ser a espécies menos abundante das três estudadas aqui e das formigas serem importantes na dieta de todas as espécies de anuros e de dois lagartos sintópicos. Mais uma vez, esse pode não ser 0 caso, dada a grande abundância de formigas no local.

O exame da tabela 2 revela que os cupins contribuíram com aproximadamente metade da massa do conteúdo estomacal total desse leptodactilídeo e tiveram a maior massa dentre as categorias alimentares. Essa categoria, no entanto, não é importante na dieta de P. albifrons, porque foi muito consumida por um número reduzido dos sapos analisados e pouco ou não consumida pela maior parte deles, 0 que se refletiu na contribuição percentual média baixa da categoria. Os trabalhos consultados (tabela 4) negligenciaram informações sobre a freqüência de ocorrência dos cupins, de modo que sua importância na dieta pode ser menor do que a apresentada.

Dos cupins consumidos por P. albifrons, a maioria foi de formas aladas. Como, há concordância entre revoadas de cupins e chuvas fortes (Pianka, 1986; Cloudsley-Thompson, 1991) e entre atividade de anuros e chuva (Gibbons e Bennet, 1974; D uellman e Trueb, 1986; D odd, 1994; Anderson e 
colaboradores, 1999; Seebacher e Alford, 1999), então uma otimização do sucesso de coletas de anuros, em dias de chuvas fortes, pode levar a um viés na estimativa de uso de cupins alados. Apesar de tudo, um procedimento de otimização de coleta de anuros foi aplicado nesse trabalho e não estão disponíveis nos trabalhos consultados se os cupins registrados na dieta são formas aladas. Com base nisso, concluo que P. albifrons apresenta apomorfia na dieta, porque, diferentemente do padrão geral, apresenta eletividade negativa por formigas e cupins não são importantes na sua dieta. Ademais, P. albifrons das dunas tem eletividade positiva por besouros e isso levanta hipótese sobre adaptação dessa espécie ao ambiente das dunas.

A apomorfia detectada na dieta de P. albifrons poderia ser explicada como resultado de interações competitivas com anuros ou lagartos sintópicos, no entanto esse não parece ser o caso, porque cupins não são importantes na dieta da herpetofauna local e coleópteros são preferidos por uma espécie de anuro e duas espécies de lagartos da herpetofauna local. Por outro lado, interações competitivas com outros elementos da herpetofauna poderiam explicar a mudança na eletividade por formigas, pois elas são preferidas ou importantes na dieta das outras espécies de sapos e para duas espécies de lagartos sintópicas, apesar das formigas serem muito abundantes nas dunas.

Só foi possivel adquirir um trabalho, dos dois levantados, que relatou a dieta de uma espécie do gênero Pleurodema: 0 trabalho de Pincheira-Donoso (2002), com dieta de P. bufonina no Chile. Há concordância entre a dieta aqui descrita e a de P. bufonina, devido à grande contribuição percentual de formigas em ambas, no entanto os dados disponíveis não permitem discutir sobre evidências de apomorfias na dieta de P. diplolistris. Santos e colaboradores (2003), numa comparação mais ampla, concluem que as a dieta de $\mathrm{P}$. diplolistris nas dunas é similar àquela registrada para vertebrados artropodívoros e anuros de muitas regiões. 
Estudos ecológicos em assembléias herpetológicas têm encontrado diferentes evidências e levantado hipóteses sobre os processos organizadores das comunidades, mas de maneira geral têm concluído que tais mecanismos estão longe de ser esclarecidos (Caldwell, 1996; Vitt e Zani, 1996, 1998; Caldwell e Vitt, 1999; Lima et al., 2000; Vitt et al., 2003; Rocha e Rodrigues, submetido). A assembléia de anuros terrícolas estudada não é exceção a esse padrão, pois aqui também a história dos táxons e as interações ecológicas parecem interagir de maneira complexa na organização dos nichos. 


\section{CONCLUSÕES}

O s resultados e discussões apresentados aqui permitem concluir que:

1. As espécies de anuros terrícolas mais abundantes das dunas de relevo marcado de Ibiraba são Pleurodema diplolistris, Bufo granulosus e Physalaemus albifrons (em ordem decrescente de abundâncias) e que duas delas são típicas de áreas abertas ou xéricas (Bufo granulosus e Pleurodema diplolistris);

2. Formigas e besouros são as categorias alimentares mais importantes na dieta das três espécies de anuros estudadas (Bufo granulosus, Pleurodema diplolistris e Physalaemus albifrons);

3. Bufo granulosus tem eletividade positiva por formigas, Pleurodema diplolistris tem eletividade positiva por besouros e negativa por cupins, Physalaemus albifrons apresenta eletividade positiva por besouros e negativa por formigas;

4. A estimativa de uso de recursos utilizada para descrever a dieta foi adequada, pois a eventual alimentação de P. diplolistris nas armadilhas de queda utilizadas para capturá-los não modificou a composição da sua dieta;

5. A comparação da estimativa de disponibilidade de alimento utilizada no trabalho (dieta total) com uma estimativa de abundância de artrópodes revelou concordância para quase todos os grupos de artrópodes, à exceção de Diplopoda, cuja disponibilidade foi subestimada;

6. A análise de ordenação das eletividades na dieta dos anuros revelou haver, para todas as espécies, um gradiente de variação inversa 
das eletividades por formigas e besouros. Num extremo do gradiente são registradas eletividades positivas por formigas e negativas por besouro e, no outro extremo, o contrário, e essas foram as categorias mais importantes na dieta dos anuros;

7. Nenhuma das espécies de anuros estudadas modifica suas eletividades na dieta à medida que cresce, ou seja, não há variação ontogenética nos tipos de presa consumidas por nenhuma das espécies estudadas;

8. Há variação ontogenética associada aos tamanhos das maiores presas consumidas por Bufo granulosus e Pleurodema diplolistris, à medida que crescem essas duas espécies consomem presas maiores;

9. P. albifrons não apresenta qualquer modificação ontogenética na dieta e isso não pode ser atribuído à avaliação de uma pequena extensão de tamanhos desse anuro;

10. Não há evidência de apomorfias na dieta da população de Bufo granulosus das dunas típicas: a eletividade positiva por formigas é um padrão recorrente no gênero, e provavelmente plesiomórfico para ambos, espécie e gênero;

11. Não houve dados disponíveis suficientes para avaliar evidência de apomorfias na dieta de Pleurodema diplolistris;

12. Há evidência de apomorfia na dieta de Physalaemus albifrons das dunas típicas; o padrão geral de eletividades do gênero é de preferência por cupins e formigas e, nas dunas, P. albifrons teve eletividade po sitiva por besouros e negativa por formigas. E essa variação pode ser explicada por interações competitivas com outros componentes da herpetofauna local, embora não pareça provável; 
13. Os anuros não parecem ter potencial para causar impacto forte sobre a assembléia de lagartos, serpentes e anfisbenas sintópica, devido a divergências nas eletividades por alimento e nos horários de atividade entre a maioria deles e esse padrão não parece ter se estabelecido após a formação dessa assembléia. A eletividade positiva por formigas de Bufo granulosus e do tropidurídeo Tropidurus psammonastes pode apontar a existência de interação ecológica contemporânea entre eles, muito embora seja fundamental haver indícios de limitação de recursos na área para levantar tal hipótese, pois a divergência nos horários de atividade deles impede competição por interferência. No entanto, formigas são muito abundantes nas dunas. 


\section{TABELAS}


Tabela 1 - Total de anuros terrícolas coletados por armadilhas de queda (pitfall traps) nas dunas com morfologia típica de Ibiraba, Bahia, nas quatro excursões em que foram coletados anuros. Na excursão de setembro de 1996 (auge da estação seca) não foi capturado nenhum anuro. 0 esforço de coleta foi diferente entre al gumas das excursões.

\begin{tabular}{|c|c|c|c|c|c|}
\hline Espécies & Fev-Mar/96 & Dez/96 & Fev-Mar/97 & Dez/03-Fev/04 & TOTAL \\
\hline \multicolumn{6}{|l|}{ Leptodactylidae } \\
\hline Leptodactylus fuscus & 0 & 0 & 1 & 0 & 1 \\
\hline Leptodactylus ocellatus & 0 & 0 & 3 & 0 & 3 \\
\hline Leptodactylus podicipinus & 0 & 0 & 5 & 1 & 6 \\
\hline Physalaemus albifrons & 129 & 3 & 114 & 28 & 274 \\
\hline Pleurodema diplolistris & 20 & 13 & 255 & 418 & 706 \\
\hline \multicolumn{6}{|l|}{ Bufonidae } \\
\hline Bufo granulosus & 123 & 9 & 44 & 72 & 248 \\
\hline Bufo schneideri & 2 & 0 & 0 & 0 & 2 \\
\hline \multicolumn{6}{|l|}{ Microhylidae } \\
\hline Dermatonotus muelleri & 1 & 0 & 18 & 4 & 23 \\
\hline \multicolumn{6}{|l|}{ Hylidae } \\
\hline Scinax $x$-signatus & 0 & 0 & 1 & 0 & 1 \\
\hline TOTAL & 275 & 25 & 441 & 523 & 1264 \\
\hline
\end{tabular}


Tabela 2 - Dieta das espécies de anuros terrícolas mais abundantes das dunas do Rio São Francisco (BA) . "N"= número de estômagos analisados; "Freqüência"= número de itens de cada categoria nos estômagos e contribuição percentual média; "Massa"= massa em gramas e contribuição percentual média; "Ocorrência" = número de estômagos não-vazios analisados em que ocorreram as categorias alimentares e a porcentagem em relação ao total de estômagos analisados. "Outros Hymenoptera" inclui todos os Hymenoptera exceto Formicidae e "Miscelânea" inclui tudo o que não pôde ser identificado em nenhum nível. Em negrito as categorias importantes na dieta. Os percentuais foram calculados excluindo-se as categorias "Arthropoda não-identificado", "Tecidos Vegetais" e "Miscelânea".

\begin{tabular}{|c|c|c|c|c|c|c|c|c|c|}
\hline \multirow[b]{2}{*}{ Categorias alimentares } & \multicolumn{3}{|c|}{$\begin{array}{c}\text { Bufo granulosus } \\
(\mathrm{N}=39)\end{array}$} & \multicolumn{3}{|c|}{$\begin{array}{c}\text { Pleurodema diplolistris } \\
(\mathrm{N}=54)\end{array}$} & \multicolumn{3}{|c|}{$\begin{array}{c}\text { Physalaemus albifrons } \\
\mathrm{N}=(48)\end{array}$} \\
\hline & Freqüência & Massa (g) & Ocorrência & Freqüência & Massa (g) & Ocorrência & Freqüência & Massa (g) & Ocorrência \\
\hline Formicidae & $\begin{array}{c}1112 \\
77,31 \% \\
\end{array}$ & $\begin{array}{r}0,3249 \\
68,01 \% \\
\end{array}$ & $\begin{array}{c}39 \\
100,00 \% \\
\end{array}$ & $\begin{array}{c}297 \\
53,56 \% \\
\end{array}$ & $\begin{array}{r}0,6422 \\
47,86 \% \\
\end{array}$ & $\begin{array}{c}47 \\
87,04 \% \\
\end{array}$ & $\begin{array}{c}429 \\
41,92 \% \\
\end{array}$ & $\begin{array}{r}0,0753 \\
23,14 \% \\
\end{array}$ & $\begin{array}{c}40 \\
83,33 \% \\
\end{array}$ \\
\hline Coleoptera & $\begin{array}{c}106 \\
15,21 \% \\
\end{array}$ & $\begin{array}{l}0,1218 \\
24,39 \% \\
\end{array}$ & $\begin{array}{c}29 \\
74,36 \% \\
\end{array}$ & $\begin{array}{c}86 \\
23,38 \% \\
\end{array}$ & $\begin{array}{l}0,2968 \\
31,74 \% \\
\end{array}$ & $\begin{array}{c}39 \\
72,22 \% \\
\end{array}$ & $\begin{array}{c}135 \\
26,12 \% \\
\end{array}$ & $\begin{array}{l}0,1199 \\
42,06 \% \\
\end{array}$ & $\begin{array}{c}42 \\
87,50 \% \\
\end{array}$ \\
\hline Isoptera & $\begin{array}{c}25 \\
3,18 \% \\
\end{array}$ & $\begin{array}{l}0,0173 \\
4,42 \% \\
\end{array}$ & $\begin{array}{c}7 \\
17.95 \% \\
\end{array}$ & $\begin{array}{c}78 \\
9,34 \% \\
\end{array}$ & $\begin{array}{l}0,1520 \\
5,52 \% \\
\end{array}$ & $\begin{array}{c}13 \\
24.07 \% \\
\end{array}$ & $\begin{array}{c}109 \\
12.05 \% \\
\end{array}$ & $\begin{array}{l}0,2000 \\
13,83 \% \\
\end{array}$ & $\begin{array}{c}10 \\
20,83 \% \\
\end{array}$ \\
\hline Chilopoda & $\begin{array}{l}- \\
-\end{array}$ & $\begin{array}{l}- \\
-\end{array}$ & - & $\begin{array}{c}1 \\
0,09 \% \\
\end{array}$ & $\begin{array}{l}0.1419 \\
1,47 \% \\
\end{array}$ & $\begin{array}{c}1 \\
1,85 \% \\
\end{array}$ & $\begin{array}{c}1 \\
2,08 \% \\
\end{array}$ & $\begin{array}{l}0,0014 \\
2,08 \% \\
\end{array}$ & $\begin{array}{c}1 \\
2,08 \% \\
\end{array}$ \\
\hline Orthoptera & - & $\begin{array}{l}- \\
-\end{array}$ & $\begin{array}{l}- \\
-\end{array}$ & $\begin{array}{c}4 \\
0.89 \% \\
\end{array}$ & $\begin{array}{l}0.0730 \\
3.10 \% \\
\end{array}$ & $\begin{array}{c}4 \\
7.41 \% \\
\end{array}$ & $\begin{array}{c}9 \\
1.55 \% \\
\end{array}$ & $\begin{array}{l}0.0196 \\
6,99 \% \\
\end{array}$ & $\begin{array}{c}8 \\
16.67 \% \\
\end{array}$ \\
\hline Larva de Insecta & $\begin{array}{c}8 \\
0,93 \% \\
\end{array}$ & $\begin{array}{l}0.0020 \\
0.46 \% \\
\end{array}$ & $\begin{array}{c}6 \\
15,38 \% \\
\end{array}$ & $\begin{array}{c}15 \\
2.56 \% \\
\end{array}$ & $\begin{array}{l}0.0548 \\
3.33 \% \\
\end{array}$ & \begin{tabular}{|c|}
9 \\
$16,67 \%$ \\
\end{tabular} & $\begin{array}{c}12 \\
4,66 \% \\
\end{array}$ & $\begin{array}{l}0,0112 \\
3,57 \% \\
\end{array}$ & $\begin{array}{c}10 \\
20,83 \% \\
\end{array}$ \\
\hline Araneae & $\begin{array}{c}3 \\
0,17 \% \\
\end{array}$ & $\begin{array}{l}0,0010 \\
0,16 \% \\
\end{array}$ & $\begin{array}{c}2 \\
5,13 \% \\
\end{array}$ & $\begin{array}{c}19 \\
5,52 \% \\
\end{array}$ & $\begin{array}{l}0.0305 \\
4,43 \% \\
\end{array}$ & \begin{tabular}{|c|}
16 \\
$29,63 \%$ \\
\end{tabular} & $\begin{array}{c}16 \\
3,46 \% \\
\end{array}$ & $\begin{array}{l}0,0065 \\
2,63 \% \\
\end{array}$ & $\begin{array}{c}14 \\
29,17 \% \\
\end{array}$ \\
\hline Diplopoda & $\begin{array}{c}1 \\
0,10 \% \\
\end{array}$ & $\begin{array}{l}0,0152 \\
1,24 \% \\
\end{array}$ & $\begin{array}{c}1 \\
2.56 \% \\
\end{array}$ & $\begin{array}{c}1 \\
1,85 \% \\
\end{array}$ & $\begin{array}{l}0,0028 \\
1,85 \% \\
\end{array}$ & $\begin{array}{c}1 \\
1,85 \% \\
\end{array}$ & - & - & - \\
\hline Acari & $\begin{array}{c}23 \\
2,33 \% \\
\end{array}$ & $\begin{array}{l}0,0017 \\
1,18 \% \\
\end{array}$ & $\begin{array}{c}9 \\
23,08 \% \\
\end{array}$ & $\begin{array}{c}6 \\
1,08 \% \\
\end{array}$ & $\begin{array}{l}0,0003 \\
0,17 \% \\
\end{array}$ & $\begin{array}{c}2 \\
3,70 \% \\
\end{array}$ & $\begin{array}{c}40 \\
5,34 \% \\
\end{array}$ & $\begin{array}{l}0,0066 \\
2,36 \% \\
\end{array}$ & $\begin{array}{c}18 \\
37,50 \% \\
\end{array}$ \\
\hline Mollusca & - & - & - & $\begin{array}{c}1 \\
0,10 \% \\
\end{array}$ & $\begin{array}{l}0,0003 \\
0,02 \% \\
\end{array}$ & $\begin{array}{c}1 \\
1,85 \% \\
\end{array}$ & $\begin{array}{c}3 \\
0,43 \% \\
\end{array}$ & $\begin{array}{l}0,0073 \\
2,72 \% \\
\end{array}$ & $\begin{array}{c}3 \\
6,25 \% \\
\end{array}$ \\
\hline Ovo de Arthropoda & - & - & - & $\begin{array}{c}11 \\
1,26 \% \\
\end{array}$ & $\begin{array}{l}0,0037 \\
0,17 \% \\
\end{array}$ & $\begin{array}{c}3 \\
5,56 \% \\
\end{array}$ & $\begin{array}{c}19 \\
0,91 \% \\
\end{array}$ & $\begin{array}{l}0,0017 \\
0,34 \% \\
\end{array}$ & $\begin{array}{c}2 \\
4,17 \% \\
\end{array}$ \\
\hline Thysanura & - & $\begin{array}{l}- \\
-\end{array}$ & - & - & - & - & $\begin{array}{c}2 \\
0,16 \% \\
\end{array}$ & $\begin{array}{l}0,0017 \\
0,04 \% \\
\end{array}$ & $\begin{array}{c}2 \\
4,17 \% \\
\end{array}$ \\
\hline Outros Hymenoptera & - & - & - & - & - & - & $\begin{array}{c}6 \\
0,87 \% \\
\end{array}$ & $\begin{array}{l}0.0013 \\
0,21 \% \\
\end{array}$ & $\begin{array}{c}2 \\
4.17 \% \\
\end{array}$ \\
\hline Scorpionida & $\begin{array}{c}1 \\
0,04 \% \\
\end{array}$ & $\begin{array}{l}0.0003 \\
0,06 \% \\
\end{array}$ & $\begin{array}{c}1 \\
2,56 \% \\
\end{array}$ & $\begin{array}{c}1 \\
0,19 \% \\
\end{array}$ & $\begin{array}{l}0.0006 \\
0,31 \% \\
\end{array}$ & $\begin{array}{c}1 \\
1,85 \% \\
\end{array}$ & $\begin{array}{c}1 \\
0,04 \% \\
\end{array}$ & $\begin{array}{c}0,00001 \\
0,0027 \% \\
\end{array}$ & $\begin{array}{c}1 \\
2,08 \% \\
\end{array}$ \\
\hline Verme & $\begin{array}{c}10 \\
0,73 \% \\
\end{array}$ & $\begin{array}{l}0,0006 \\
0,08 \% \\
\end{array}$ & $\begin{array}{c}3 \\
7.69 \% \\
\end{array}$ & $\begin{array}{l}- \\
-\end{array}$ & - & - & $\begin{array}{c}2 \\
0,05 \% \\
\end{array}$ & $\begin{array}{c}0.00001 \\
0,0019 \% \\
\end{array}$ & $\begin{array}{c}1 \\
2.08 \% \\
\end{array}$ \\
\hline Lepidoptera & - & - & - & $\begin{array}{c}1 \\
0,07 \%\end{array}$ & $\begin{array}{l}0.0004 \\
0,01 \% \\
\end{array}$ & $\begin{array}{c}1 \\
1,85 \% \\
\end{array}$ & - & - & - \\
\hline Ovócito de Anura & - & $\begin{array}{l}- \\
-\end{array}$ & $\begin{array}{l}- \\
-\end{array}$ & $\begin{array}{c}1 \\
0,10 \% \\
\end{array}$ & $\begin{array}{l}0,0003 \\
0,02 \% \\
\end{array}$ & $\begin{array}{c}1 \\
1,85 \% \\
\end{array}$ & $\begin{array}{l}- \\
-\end{array}$ & - & - \\
\hline Homoptera & $\begin{array}{l}- \\
-\end{array}$ & - & - & - & - & - & $\begin{array}{c}1 \\
0,12 \% \\
\end{array}$ & $\begin{array}{l}0,0001 \\
0,01 \% \\
\end{array}$ & $\begin{array}{c}1 \\
2,08 \% \\
\end{array}$ \\
\hline Hemiptera & - & - & - & - & - & - & $\begin{array}{c}1 \\
0,23 \% \\
\end{array}$ & $\begin{array}{c}0,00001 \\
0,0058 \% \\
\end{array}$ & $\begin{array}{c}1 \\
2,08 \% \\
\end{array}$ \\
\hline Total 1 & 1289 & 0,4849 & - & 522 & 1,3996 & - & 786 & 0,4528 & - \\
\hline Arthropoda não-identificado & 9 & 0,0085 & 8 & 26 & 0,0623 & 19 & 38 & 0,0353 & 26 \\
\hline Tecidos Vegetais & 277 & 0,0389 & 28 & 178 & 0,0208 & 31 & 148 & 0,0095 & 27 \\
\hline Miscelânea & - & 0,0163 & & - & 0,0931 & & - & 0,0283 & \\
\hline Total2 & 1575 & 0,5486 & - & 726 & 1,5758 & - & 972 & 0,5259 & - \\
\hline
\end{tabular}


Tabela 3 - Eletividades na dieta das espécies de anuros mais abundantes das dunas de morfologia típica de Ibiraba, Bahia, calculadas pelo índice de Strauss L (1979), com dados de contribuição percentual em massa. "Hymenoptera" exclui Formicidae. Em negrito as maiores eletividade e hachuradas as eletividades importantes.

\begin{tabular}{rrrr}
\hline Categorias alimentares & $\begin{array}{c}\text { Bufo } \\
\text { granulosus }\end{array}$ & $\begin{array}{c}\text { Pleurodema } \\
\text { diplolistris }\end{array}$ & $\begin{array}{r}\text { Physalaemus } \\
\text { albifrons }\end{array}$ \\
\hline Formicidae & $\mathbf{0 , 2 3 4 0 8 1}$ & 0,032637 & $\mathbf{- 0 , 2 1 4 5 6 6}$ \\
\hline Coleoptera & 0,013551 & $\mathbf{0 , 0 8 6 9 8 9}$ & $\mathbf{0 , 1 9 0 2 4 6}$ \\
\hline Isoptera & $-0,113774$ & $\mathbf{- 0 , 1 0 2 8 1 3}$ & $-0,019674$ \\
\hline Chilopoda & $-0,061310$ & $-0,046572$ & $-0,040477$ \\
\hline Orthoptera & $-0,039619$ & $-0,008635$ & 0,030247 \\
\hline Araneae & $-0,014676$ & 0,028068 & 0,010016 \\
\hline Mollusca & $-0,024482$ & 0,004199 & 0,006576 \\
\hline Acari & $-0,003252$ & $-0,003089$ & 0,023979 \\
\hline Darva de Arthropoda & 0,008053 & $-0,002026$ & 0,019876 \\
\hline Arthoda & 0,004672 & 0,010817 & $-0,007701$ \\
\hline Scorpionida & $-0,002319$ & $-0,000624$ & 0,001117 \\
\hline Hymenoptera & 0,000164 & 0,002697 & $-0,000362$ \\
\hline Thysanura & $-0,000560$ & $-0,000560$ & 0,001523 \\
\hline Verme & $-0,000727$ & $-0,000727$ & $-0,000373$ \\
\hline Lepidoptera & 0,000544 & $-0,000265$ & $-0,000246$ \\
\hline Ovócito de Anura & $-0,000171$ & $-0,000083$ & $-0,000171$ \\
\hline Homoptera & $-0,000128$ & 0,000034 & $-0,000128$ \\
\hline Hemiptera & $-0,000043$ & $-0,000043$ & 0,000066 \\
\hline
\end{tabular}


Tabela 4 - Informações disponíveis na literatura sobre eletividades e categorias importantes na dieta de espécies dos gêneros Bufo, Pleurodema e Physalaemus, em vários ambientes. Na coluna das eletividades, o sinal indica se a eletividade é positiva (+ ) ou negativa (-). "Insetos e outros artrópodes pequenos" foi a expressão utilizada por Duellman (1990) para descrever a dieta de al gumas das espécies listadas. * A dieta das duas espécies foi analisada conjuntamente. IRI = Índice de importância relativa.

\begin{tabular}{|c|c|c|c|c|c|c|}
\hline Espécie & Local & Hábitat & $\begin{array}{l}\text { Categorias importantes } \\
\text { na dieta }\end{array}$ & $\begin{array}{l}\text { Eletividades na } \\
\text { dieta }\end{array}$ & $\begin{array}{l}\text { Índice de dieta / } \\
\text { eletividade }\end{array}$ & Referência \\
\hline \multicolumn{7}{|l|}{ Bufo } \\
\hline Bufo alatus & Barro Colorado, Panamá & Floresta úmida & Formicidae & - & $?$ & Duellman (1990) \\
\hline Bufo bufo & $\begin{array}{l}\text { Cercanias de um lago em } \\
\text { Leicestershire, Inglaterra }\end{array}$ & Plantação de Populus sp. & $\begin{array}{l}\text { Diptera adultos, Dermaptera, } \\
\text { Coleoptera }\end{array}$ & - & Freqüência & Cornish et al. (1995) \\
\hline Bufo cognatus & Playas Wetlands, Texas, EUA & $\begin{array}{l}\text { Wetland de uma região } \\
\text { semi-árida }\end{array}$ & Coleoptera & - & $\begin{array}{l}\text { IRI (freqüência, } \\
\text { volume, ocorrência) }\end{array}$ & Anderson et al.(1999) \\
\hline Bufo cognatus & Playas Wetlands, Texas, EUA & $\begin{array}{l}\text { Wetland de uma região } \\
\text { semi-árida }\end{array}$ & Coleoptera & - & Massa & Smith et al. (2004) \\
\hline $\begin{array}{l}\text { Bufo cognatus e Bufo } \\
\text { woodhousii }\end{array}$ & Pradaria na Dakota do Sul, EUA & $\begin{array}{l}\text { Pradaria (prairie pothole } \\
\text { marsh) }\end{array}$ & Coleoptera, Collembola & $\begin{array}{l}\text { Coleoptera }(+), \\
\text { Collembola }(-)\end{array}$ & ? / Índice de Jacobs & Flowers e Grav es (1995) \\
\hline Bufo coniferus & La Selva, Costa Rica & Floresta úmida & $\begin{array}{l}\text { "Insetos e outros artrópodes } \\
\text { pequenos" }\end{array}$ & - & $?$ & Duellman (1990) \\
\hline Bufo coniferus & El Lano-Cartí Road, Panamá & Floresta úmida & Formicidae & $\begin{array}{l}\text { Formicidae }(+), \\
\text { Orthoptera }(-)\end{array}$ & ? / Índice de Jacobs & Toft (1981) \\
\hline Bufo coniferus & Pipeline Road, Panamá & Floresta úmida & Formicidae & $\begin{array}{l}\text { Formicidae (+), } \\
\text { Orthoptera }(-)\end{array}$ & ? / Índice de Jacobs & Toft (1981) \\
\hline Bufo glaberrimus & $\begin{array}{l}\text { Manu, Peru, e Santa Cecilia, } \\
\text { Equador }\end{array}$ & Floresta úmida & $\begin{array}{l}\text { "Insetos e outros artrópodes } \\
\text { pequenos" }\end{array}$ & - & $?$ & Duellman (1990) \\
\hline Bufo granulosus & Barro Colorado, Panamá & Floresta úmida & $\begin{array}{l}\text { "Insetos e outros artrópodes } \\
\text { pequenos" }\end{array}$ & - & $?$ & Duellman (1990) \\
\hline Bufo granulosus & Lençóis, Bahia, Brasil & Floresta semidecidual & Isoptera, Formicidae & Isoptera & $\begin{array}{l}\text { Freqüência / Índice } \\
\text { de Jabocs }\end{array}$ & Silva e Juncá (no prelo) \\
\hline Bufo haematiticus & $\begin{array}{l}\text { Barro Colorado, Panamá, e La } \\
\text { Selva, Costa Rica }\end{array}$ & Floresta úmida & Formicidae & - & $?$ & Duellman (1990) \\
\hline Bufo haematiticus & El Lano-Cartí Road, Panamá & Floresta úmida & Formicidae & $\begin{array}{l}\text { Formicidae }(+), \\
\text { Orthoptera }(-)\end{array}$ & ? / Índice de Jacobs & Toft (1981) \\
\hline
\end{tabular}


Tabela 4 (continuação) - Informações disponíveis na literatura sobre eletividades e categorias importantes na dieta das espécies dos gêneros Bufo, Pleurodema e Physalaemus, em vários ambientes. Na coluna das eletividades, o sinal indica se a eletividade é positiva (+ ) ou negativa (-). "Insetos e outros artrópodes pequenos" foi a expressão utilizada por Duellman (1990) para descrever a dieta de algumas das espécies listadas.

\begin{tabular}{|c|c|c|c|c|c|c|}
\hline Espécie & Local & Hábitat & $\begin{array}{c}\text { Categorias } \\
\text { importantes na dieta }\end{array}$ & $\begin{array}{c}\text { Eletividades } \\
\text { positivas }\end{array}$ & $\begin{array}{l}\text { Índice de dieta / } \\
\text { eletividade }\end{array}$ & Referência \\
\hline \multicolumn{7}{|l|}{ Bufo } \\
\hline Bufo marinus & $\begin{array}{l}\text { Barro Colorado, Panamá, e La } \\
\text { Selva, Costa Rica }\end{array}$ & Floresta úmida & $\begin{array}{l}\text { "Insetos e outros } \\
\text { artrópodes pequenos" }\end{array}$ & - & $?$ & Duellman (1990) \\
\hline Bufo marinus & Venezuela & $\begin{array}{l}\text { Hábitats áridos, semi-áridos, } \\
\text { de savana, florestados e mata } \\
\text { de galeria }\end{array}$ & Coleoptera, Formicidae & - & Massa & Evans e Lampo (1996) \\
\hline Bufo marinus & Alter do Chão, Pará, Brasil & Praias fluviais de areia & Isoptera, Formicidae & $\begin{array}{l}\text { Isoptera (+), } \\
\text { Formicidaes (+) }\end{array}$ & $\begin{array}{l}\text { Freqüência / } \\
\text { Comparação gráfica } \\
\text { dieta-disponibilidade }\end{array}$ & Strüssmann et al. (1984) \\
\hline Bufo marinus & $\begin{array}{l}\text { Trinidade-Tobago e Guiana } \\
\text { Inglesa }\end{array}$ & Floresta úmida & Formicidae & - & Ocorrência & Weber (1938) \\
\hline Bufo marinus & Costa Rica & Áreas abertas e semi-abertas & Hemiptera & - & $?$ & Penã et al. (1995) \\
\hline Bufo marinus & Northern Queensland, Austrália & $\begin{array}{l}\text { Áreas florestadas incluindo } \\
\text { áreas mais abertas }\end{array}$ & Formicidae, Coleoptera & - & Ocorrência & Warren (1993) \\
\hline Bufo paracnemis & Distrito Federal, Brasil & Cerrado & Isoptera, Acari & - & Freqüência & Moreira (1993) \\
\hline Bufo cf. typhonius & $\begin{array}{l}\text { Amazônia central, Reserva Ducke } \\
\text { Brasil }\end{array}$ & 'Floresta úmida & $\begin{array}{l}\text { Acari (pequenos), } \\
\text { Formicidae (adultos) }\end{array}$ & - & Massa & Lima e Magnusson (1998) \\
\hline Bufo typhonius & $\begin{array}{l}\text { Manu, Peru, e Santa Cecilia, } \\
\text { Equador }\end{array}$ & Floresta úmida & Formicidae & - & $?$ & Duellman (1990) \\
\hline Bufo typhonius & Baixo Rio Llullapichis, Peru & Floresta úmida & Formicidae & $\begin{array}{l}\text { Formicidae }(+), \\
\text { Orthoptera }(-)\end{array}$ & $\begin{array}{l}\text { Massa / Índice de } \\
\text { Jacobs }\end{array}$ & Toft (1980) \\
\hline Bufo typhonius & El Lano-Cartí Road, Panamá & Floresta úmida & Formicidae & $\begin{array}{l}\text { Formicidae }(+), \\
\text { Orthoptera }(-)\end{array}$ & ? / Índice de Jacobs & Toft (1981a) \\
\hline Bufo typhonius & Rondônia, Brasil & Floresta úmida & Formicidae, Coleoptera & $\begin{array}{l}\text { Formicidae }(+), \\
\text { Coleoptera }(+)\end{array}$ & $\begin{array}{l}\text { Volume / Índice de } \\
\text { Lawlor }\end{array}$ & Caldwell e Vitt (1994) \\
\hline Bufo variegatus & $\begin{array}{l}\text { Lago del Desierto, Santa Cruz, } \\
\text { Argentina }\end{array}$ & $?$ & $\begin{array}{l}\text { Coleoptera (machos), } \\
\text { Coleoptera (fêmeas), Acari } \\
\text { (jovens) }\end{array}$ & - & $\begin{array}{l}\text { IRI padronizada } \\
\text { (freqüência, volume, } \\
\text { ocorrência) }\end{array}$ & Rappi et al. (2000) \\
\hline
\end{tabular}


Tabela 4 (continuação) - Informaç̃es disponíveis na literatura sobre eletividades e categorias importantes na dieta das espécies dos gêneros Bufo, Pleurodema e Physalaemus, em vários ambientes. Na coluna das eletividades, o sinal indica se a eletividade é positiva (+ ) ou negativa (-). "Insetos e outros artrópodes pequenos" foi a expressão utilizada por Duellman (1990) para descrever a dieta de al gumas das espécies listadas. IRI = Índice de importância relativa.

\begin{tabular}{|c|c|c|c|c|c|c|}
\hline Espécie & Local & Hábitat & $\begin{array}{c}\text { Categorias importantes } \\
\text { na dieta }\end{array}$ & $\begin{array}{l}\text { Eletividades } \\
\text { positivas }\end{array}$ & $\begin{array}{l}\text { Índice de dieta / } \\
\text { eletividade }\end{array}$ & Referência \\
\hline \multicolumn{7}{|l|}{ Physalaemus } \\
\hline $\begin{array}{l}\text { Physalaemuscf. } \\
\text { cicada }\end{array}$ & Lençóis, Bahia, Brasil & Floresta semidecidual & Isoptera, Formicidae & Isoptera & $\begin{array}{l}\text { Freqüência / Índice } \\
\text { de Jabocs }\end{array}$ & Silva e Juncá (no prelo) \\
\hline Physalaemus cuvieri & Distrito Federal, Brasil & Cerrado & Isoptera & - & Freqüência & Moreira (1993) \\
\hline $\begin{array}{l}\text { Physalaemus } \\
\text { ephippifer }\end{array}$ & Roraima, Brasil & $\begin{array}{l}\text { Área de transição entre } \\
\text { floresta úmida e Lavrado }\end{array}$ & Isoptera, Formicidae & - & Volume & Caldwell e Vitt (1999) \\
\hline Physalaemus petersi & $\begin{array}{l}\text { Manu, Peru, e Santa Cecilia, } \\
\text { Equador }\end{array}$ & Floresta úmida & Isoptera & - & $?$ & Duellman (1990) \\
\hline Physalaemus petersi & Rondônia, Brasil & Floresta úmida & Isoptera & Isoptera (+) & $\begin{array}{l}\text { Volume / Índice de } \\
\text { Lawlor }\end{array}$ & Caldwell e Vitt (1994) \\
\hline $\begin{array}{l}\text { Physalaemus } \\
\text { pustulosus }\end{array}$ & Barro Colorado, Panamá & Floresta úmida & Formicidae & - & $?$ & Duellman (1990) \\
\hline \multicolumn{7}{|l|}{ Pleurodema } \\
\hline Pleurodema bufonina & Chile & Áreas de cordilheiras & Formicidae & - & $\begin{array}{l}\text { IRI (freqüência, } \\
\text { ocorrência) }\end{array}$ & Pincheira-Donoso (2002) \\
\hline
\end{tabular}




\section{FIG URAS}




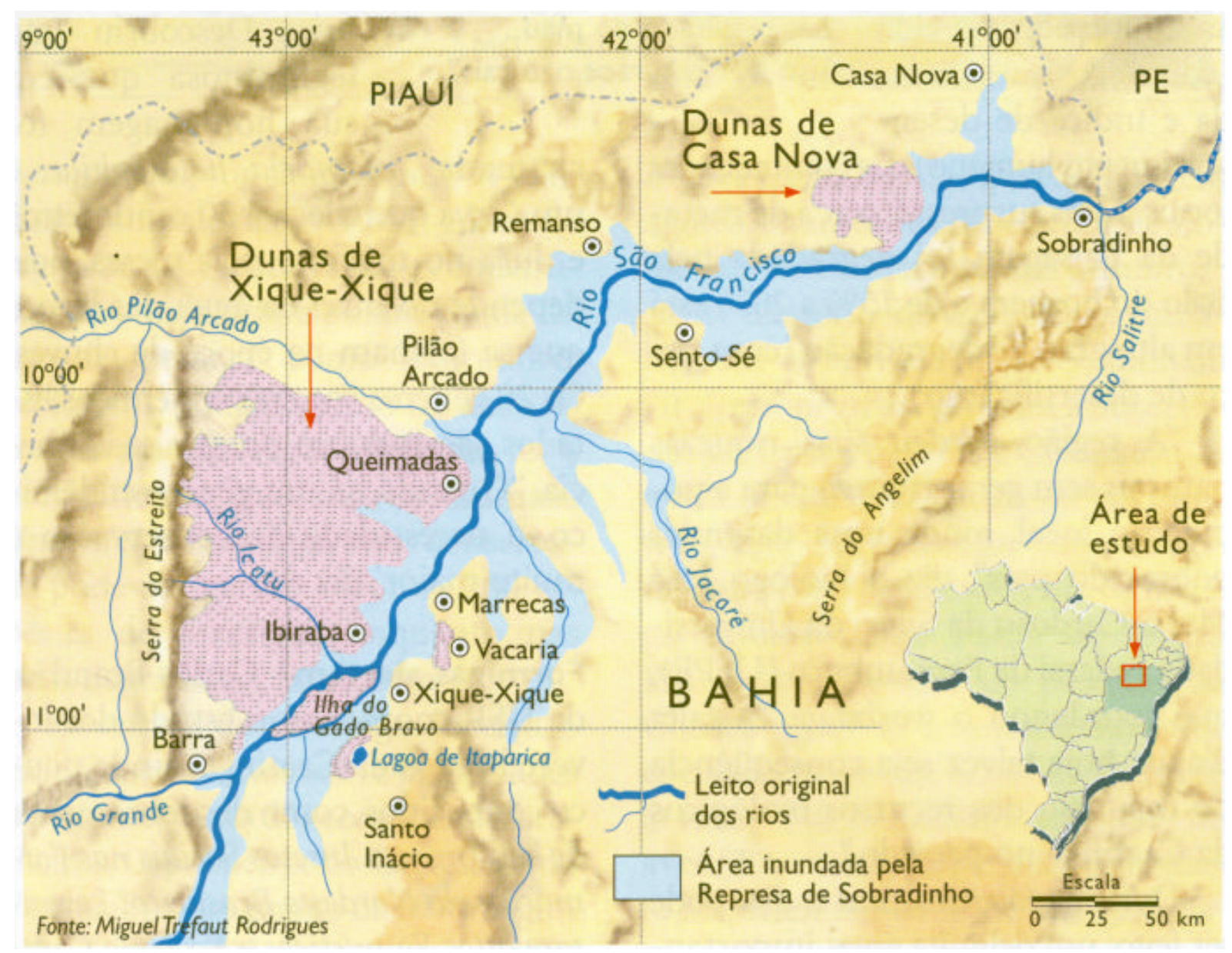

Figura 1: Localização dos mares de areia do médio Rio São Francisco, Bahia. Em rosa, as dunas de Xique-Xique e de Casa Nova e as manchas de areia de Lagoa de Itaparica e Vacaria. Ibiraba foi o local de estudo. Fonte: Revista Pesquisa, FAPESP - Setembro/2000 n 57.

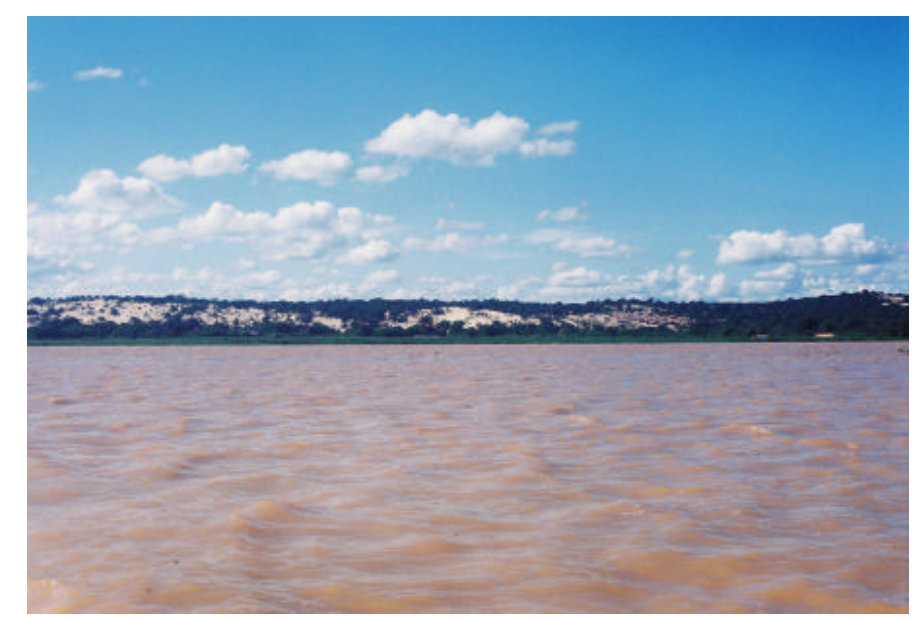

Figura 2: Dunas vistas do Rio São Francisco. 

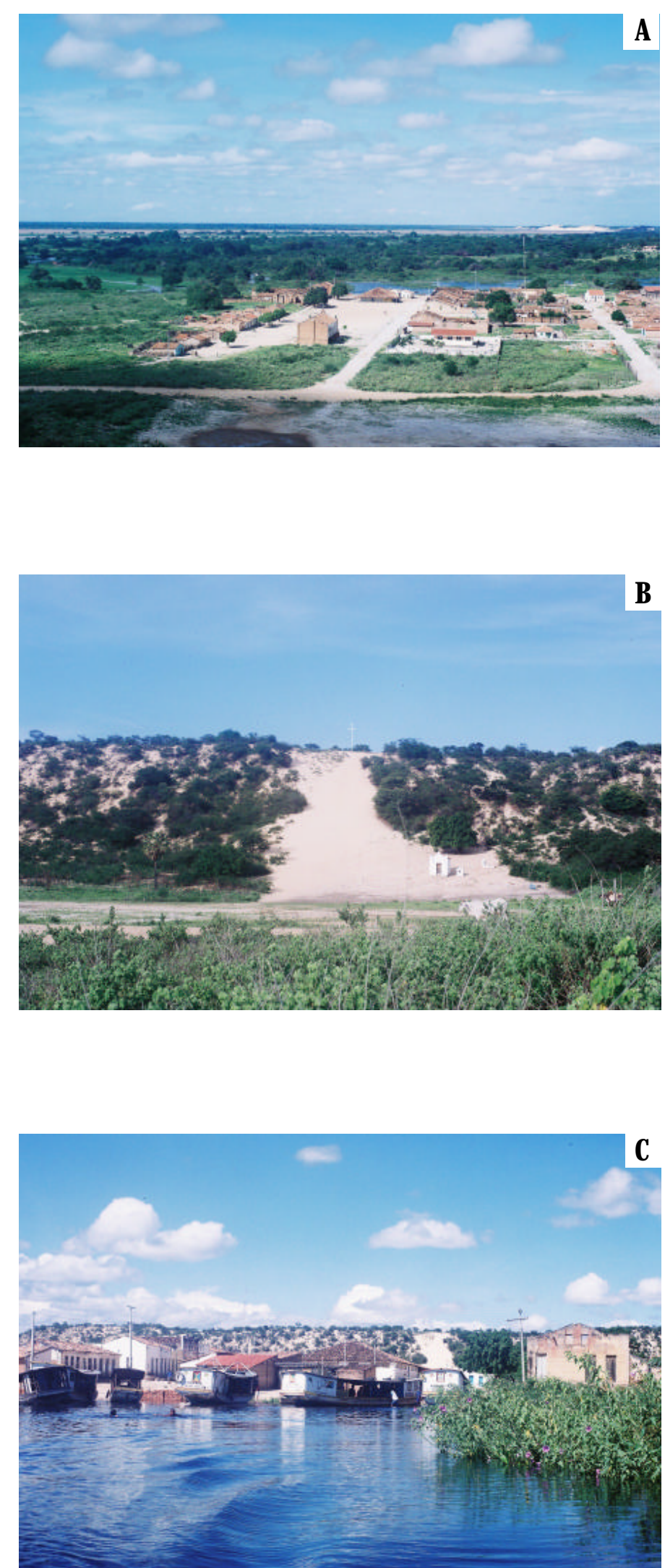

Figura 3: Vila de Ibiraba, Município de Barra, Bahia. Em "A" a vila, em "B" as dunas, em "C" o pequeno porto da vila no período de chuvas. 

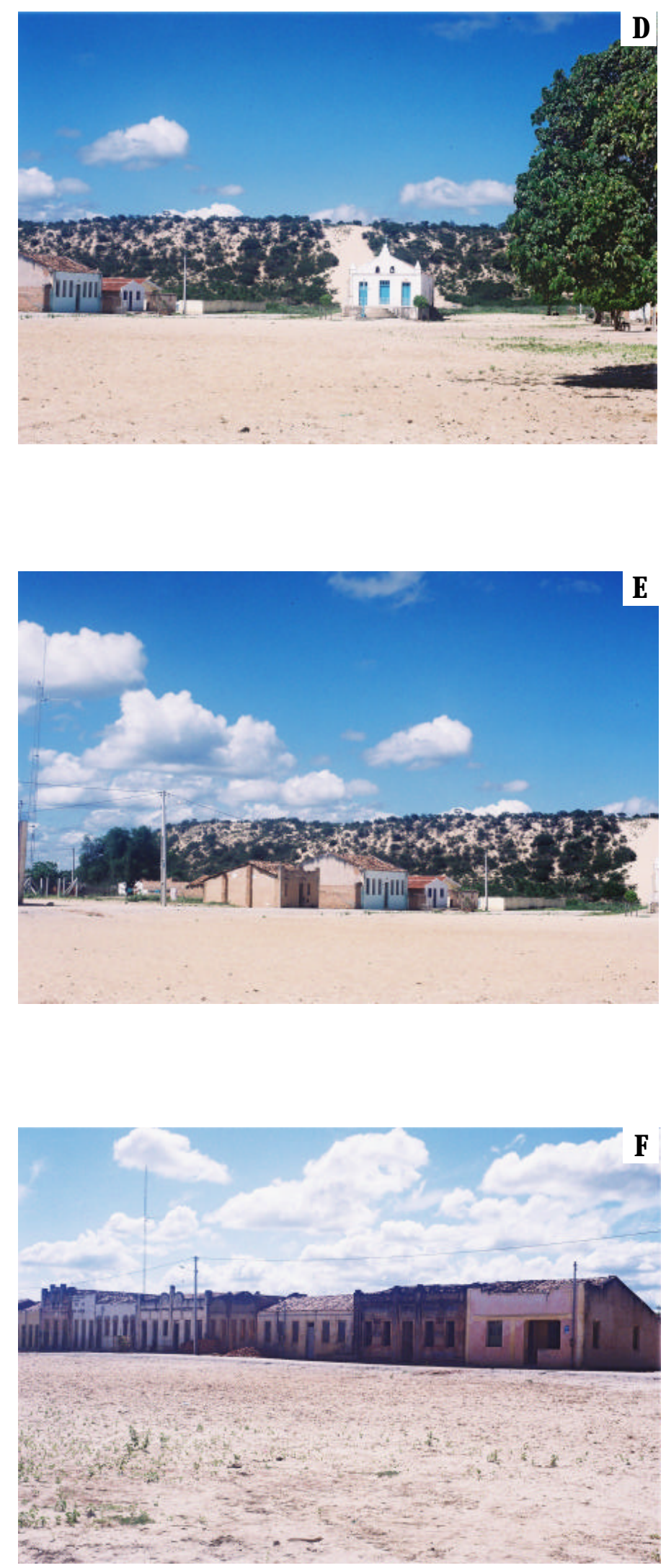

Figura 3 (continuação): Vila de Ibiraba, Município de Barra, Bahia. Em "D", "E" e "F", vista das casas e da Igreja Matriz. 

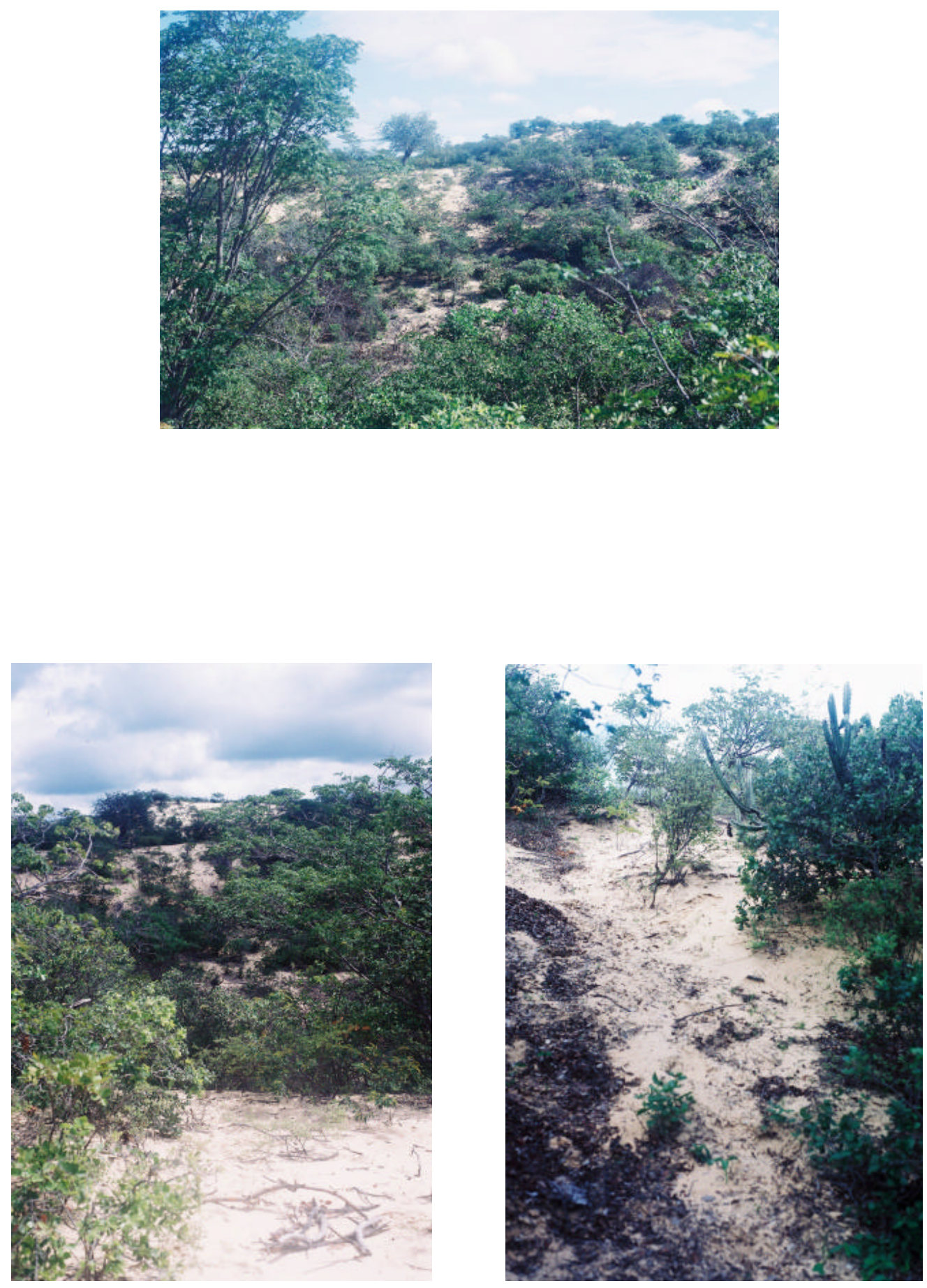

Figura 4: Aspecto da topografia marcada das dunas de Ibiraba. 

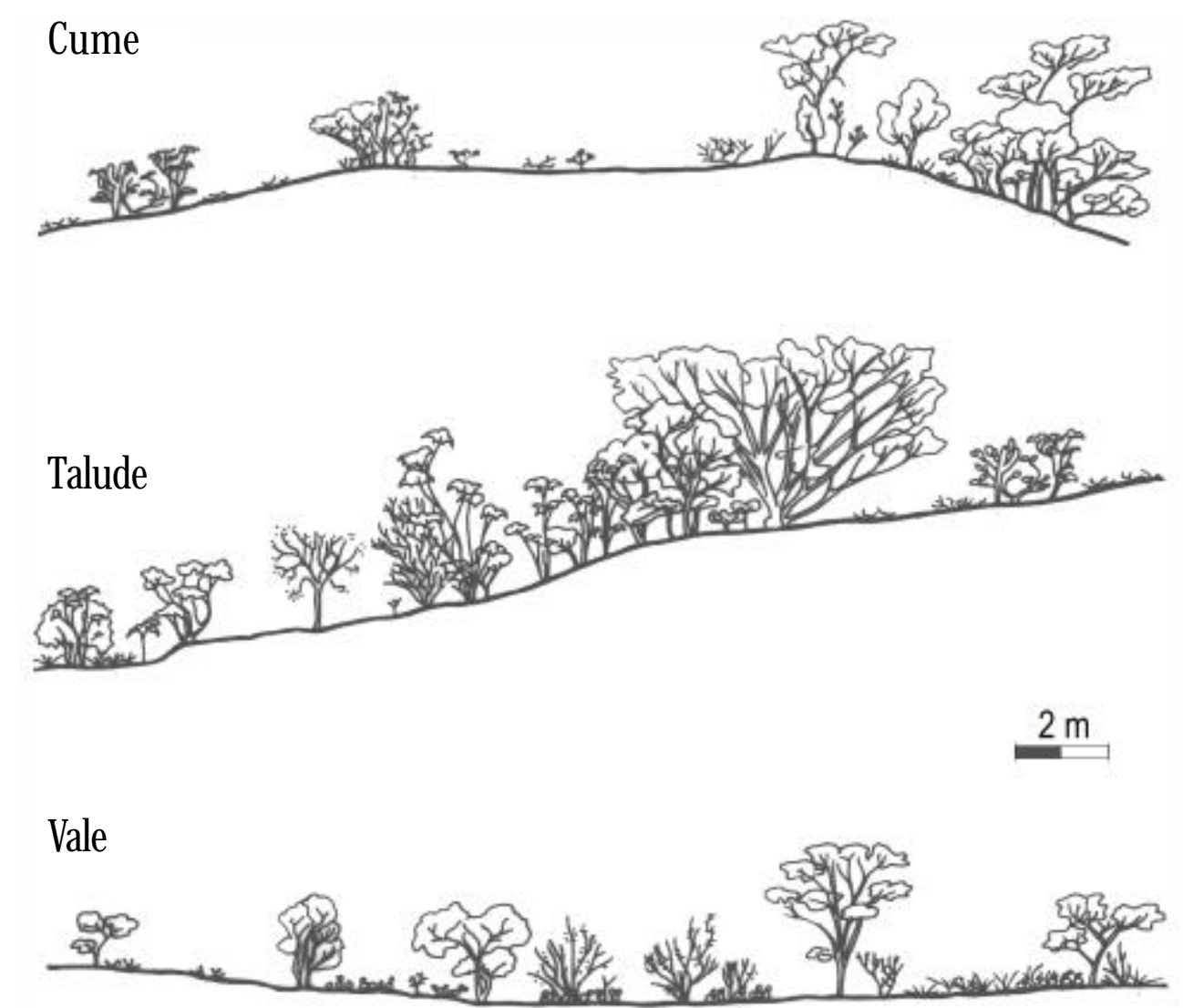

Figura 5: Perfil da vegetação ( profundidade $=2 \mathrm{~m}$ ) nos diferentes setores das dunas (cume, talude e vale). Modificado de Rocha et al., 2004. 

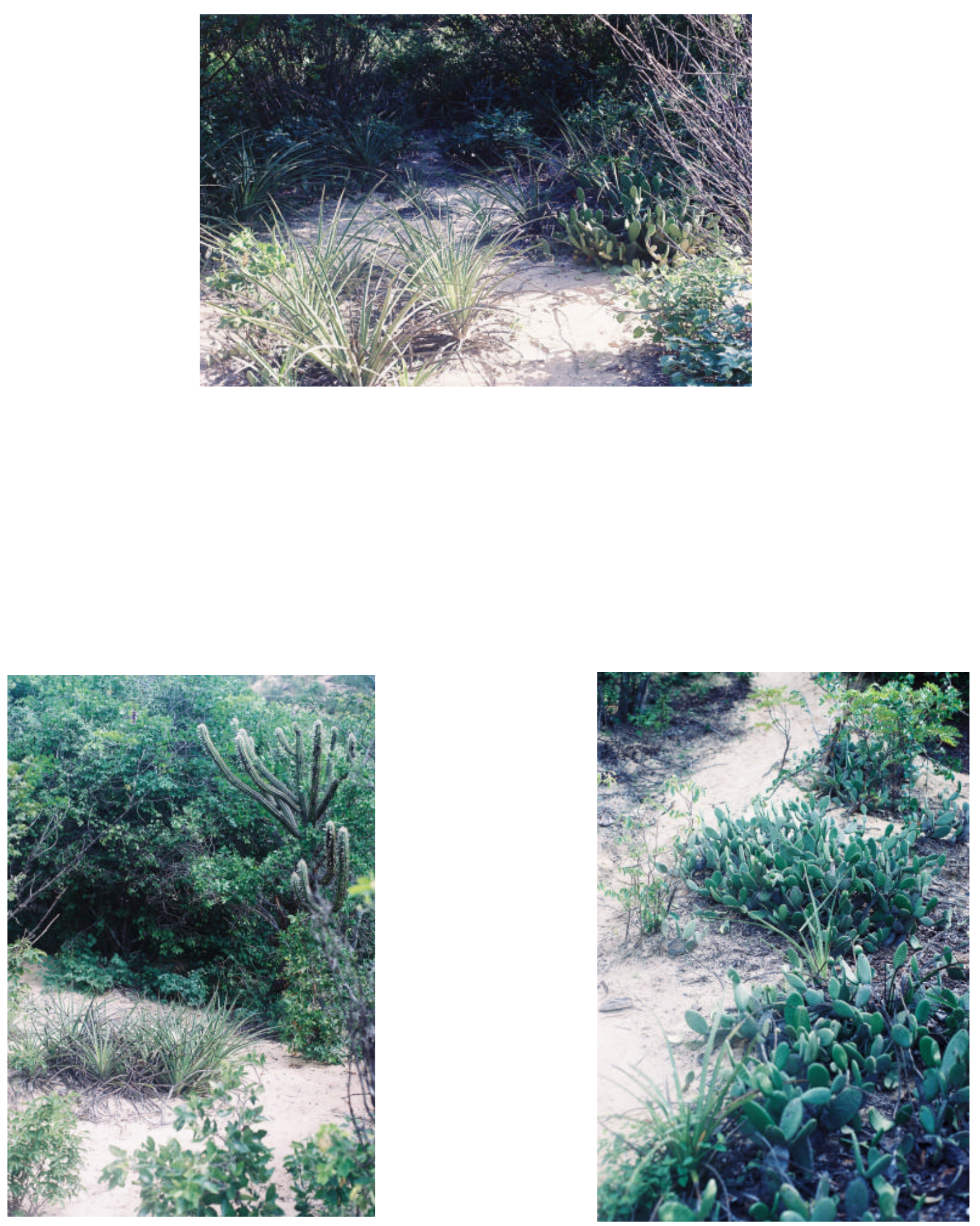

Figura 6: Aspecto da vegetação das dunas com destaque para as touceiras de macambira (Bromelia antiacantha) e quipá (Tacinga inamoena). 

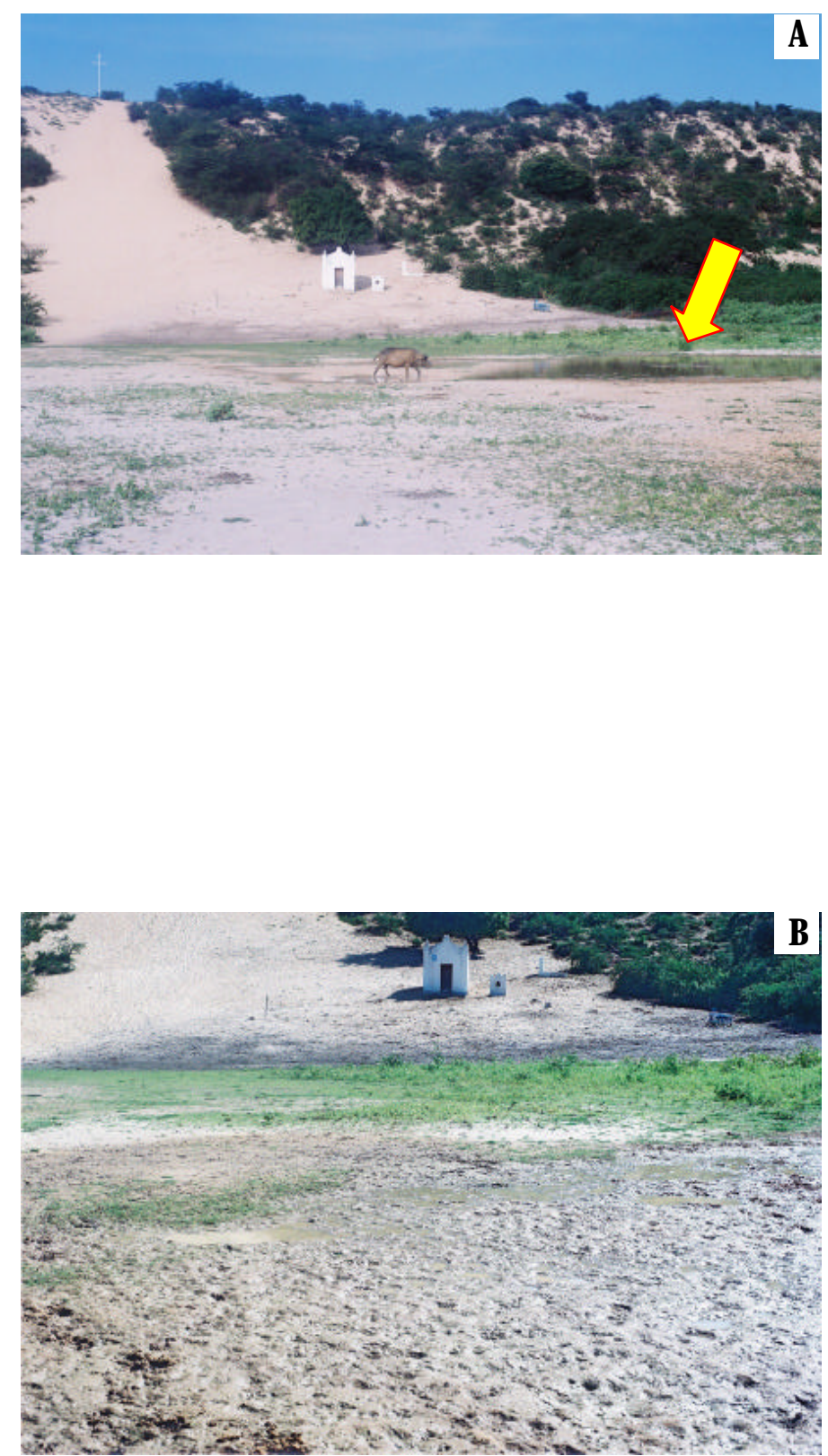

Figura 7: Local mais próximo das dunas de Ibiraba onde se acumula água na época de chuvas. Observou-se atividade reprodutiva de anuros no local (Rocha, comunicação pessoal). Em " $\mathrm{A}$ " a localização da poça e em "B" detalhe do aspecto da poça. 


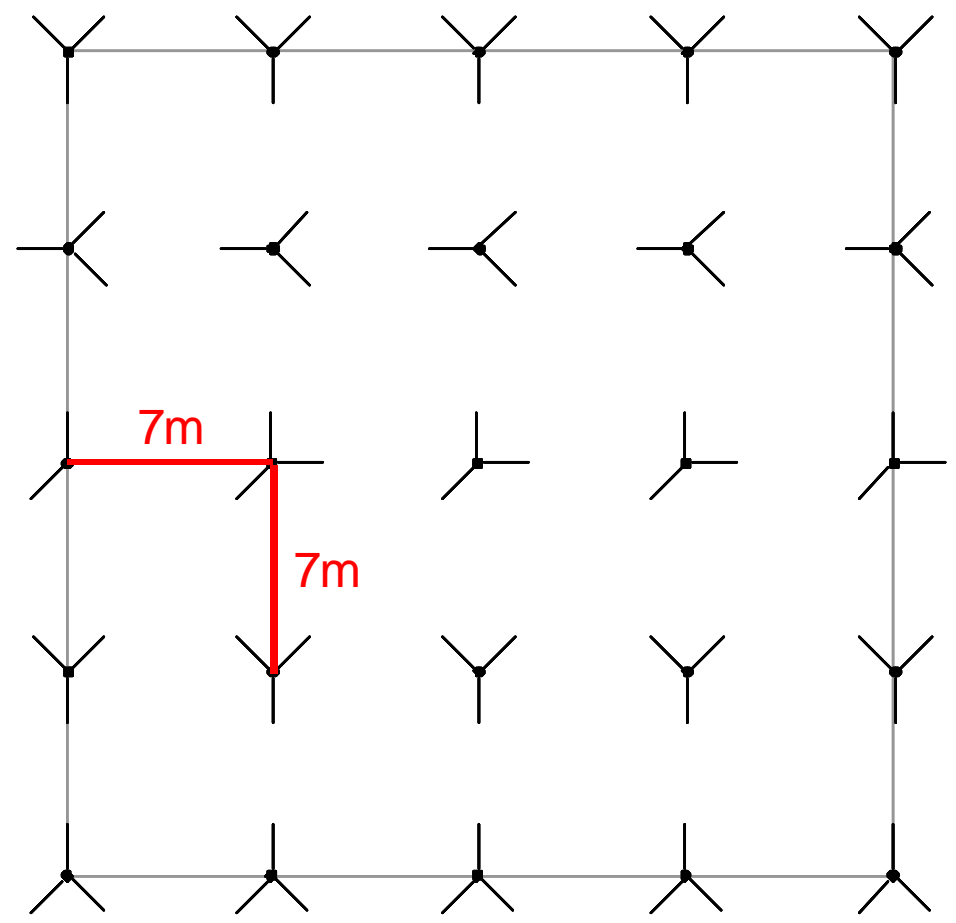

Figura 8: Desenho esquemático em escala da grade das armadilhas de anuros. A posição das cercas de irecionamento no esquema não corresponde exatamente ao que foi montado em campo.
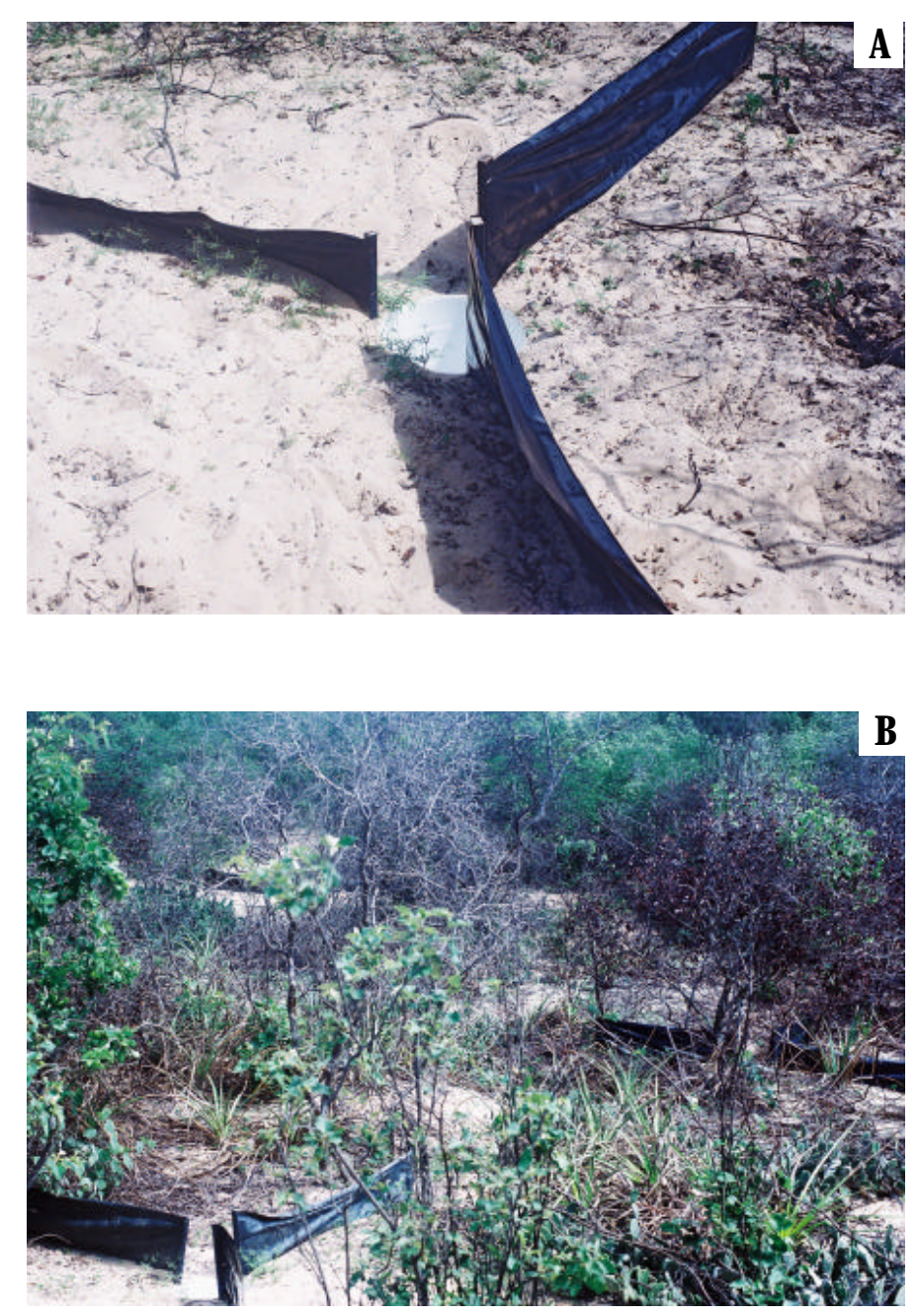

Figura 9: Armadilha de anuros em "A" e parte da grade de armadilhas em "B". 


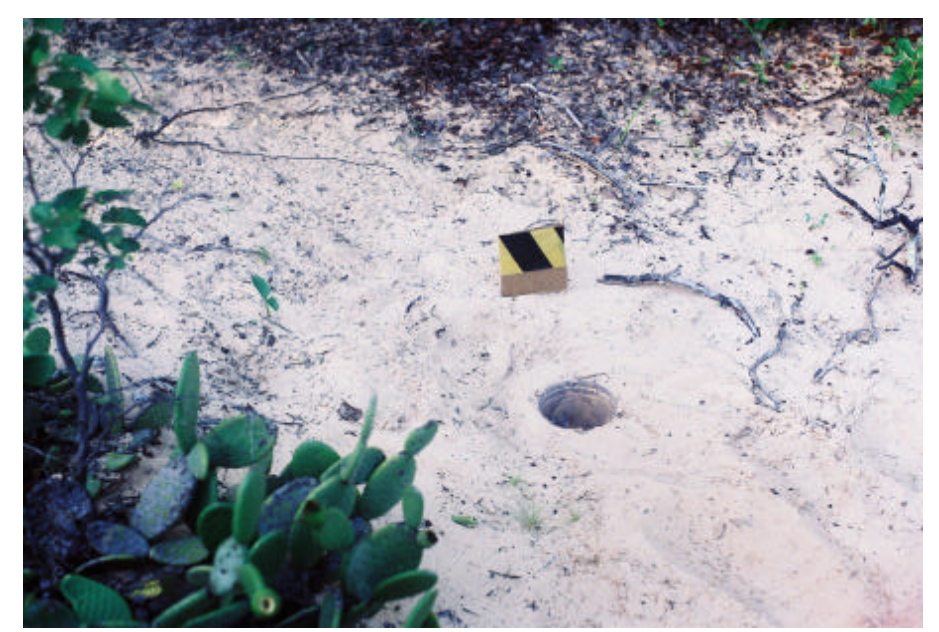

Figura 10: Armadilha de artrópodes.

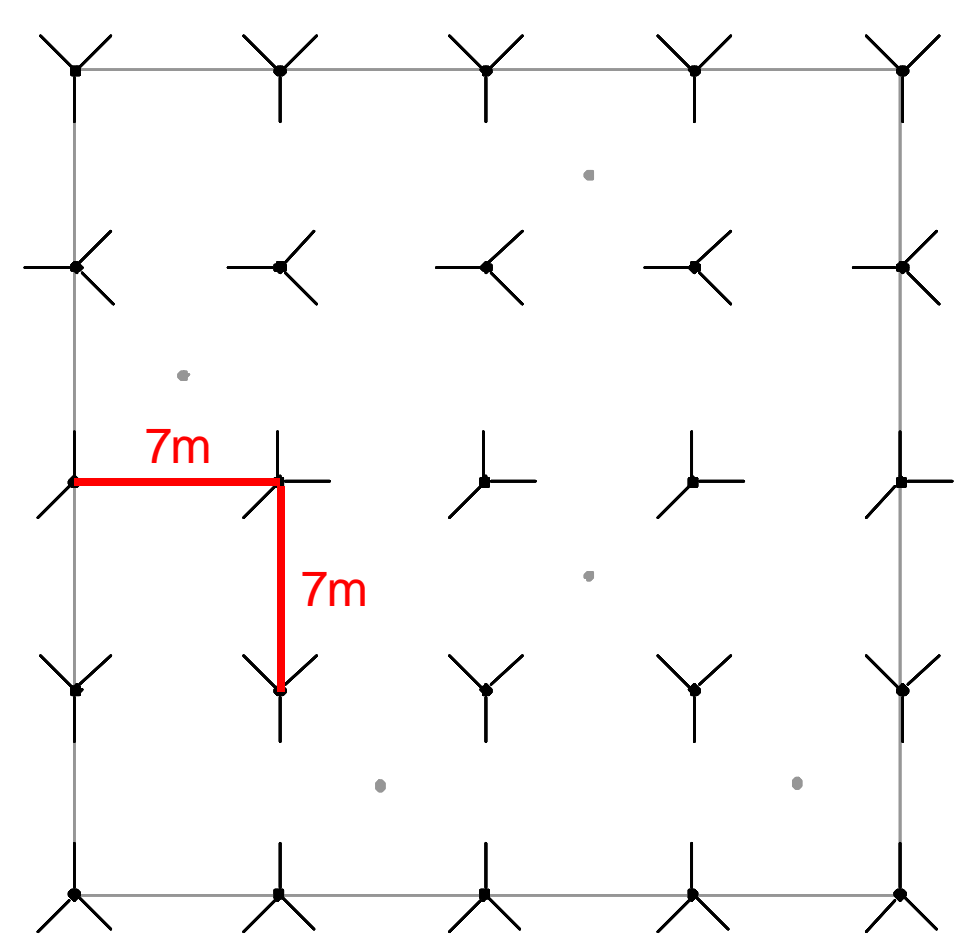

Figura 11: Desenho esquemático da grade das armadilhas de anuros e um exemplo da localização das armadilhas de artópodes (em cinza) na grade. 

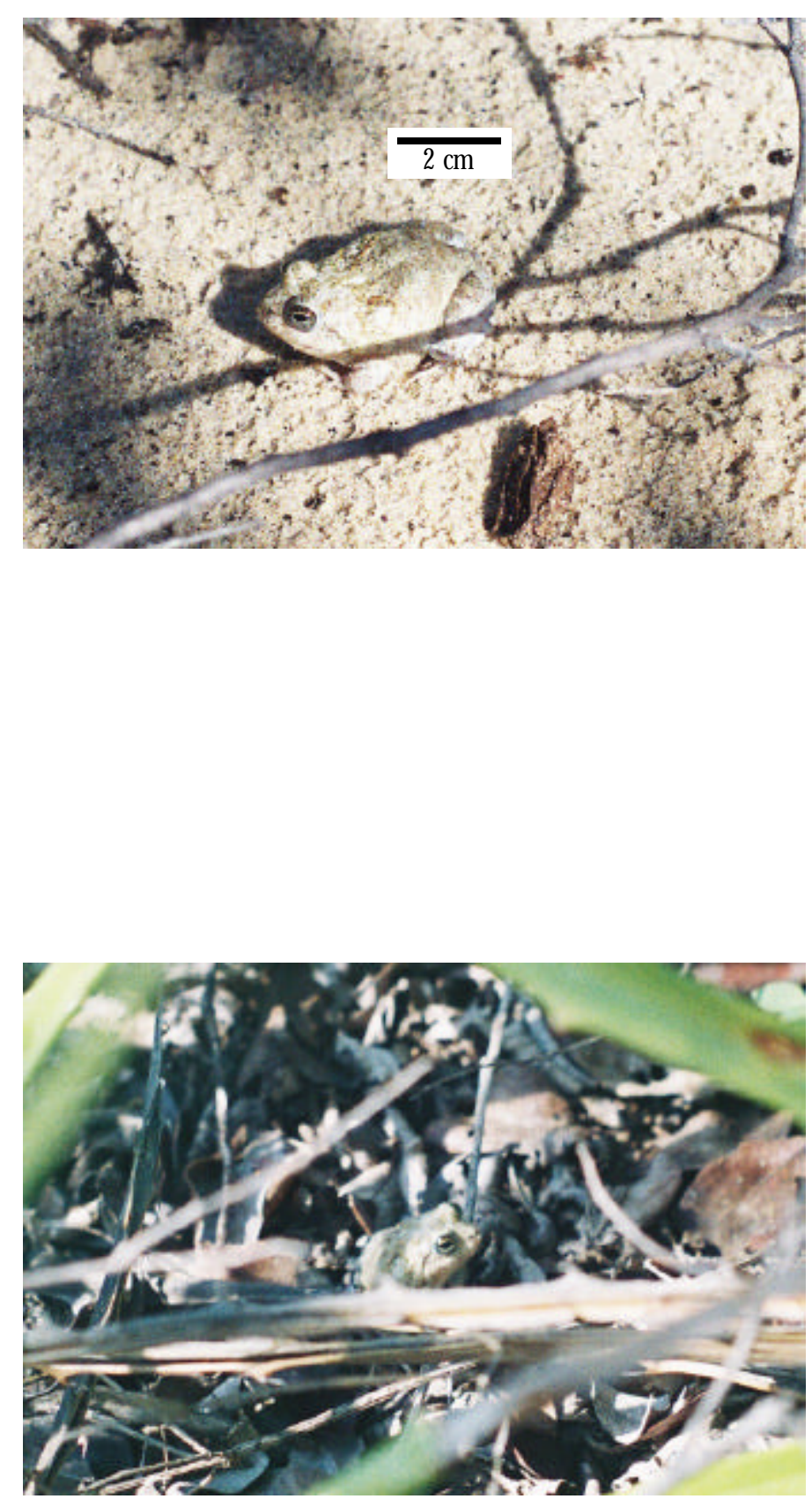

Figura 12: Pleurodema diplolistris (Leptodactylidae), espécie de anuro terrícola mais abundante das dunas de topografia marcada de Ibiraba. 

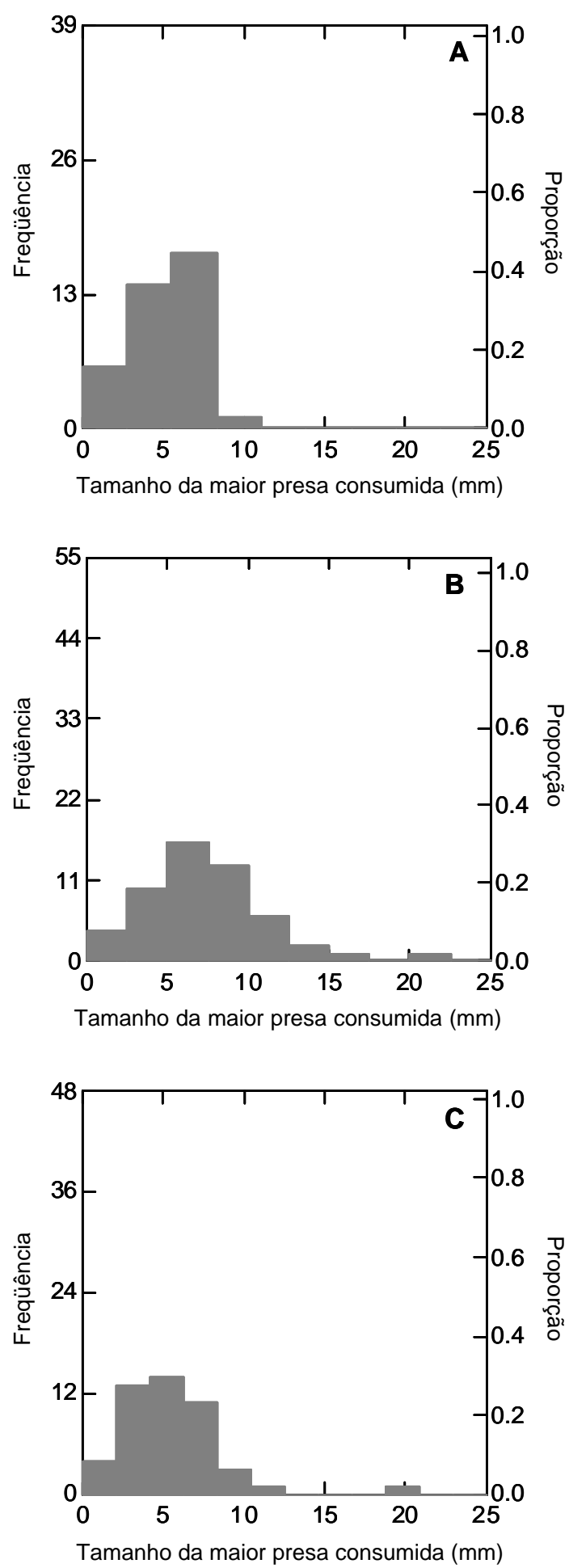

Figura 13 - Histograma de freqüência dos tamanhos das maiores presas consumidas por Bufo granulosus (A), Pleurodema diplolistris (B) ePhysalaemus albifrons (C). 

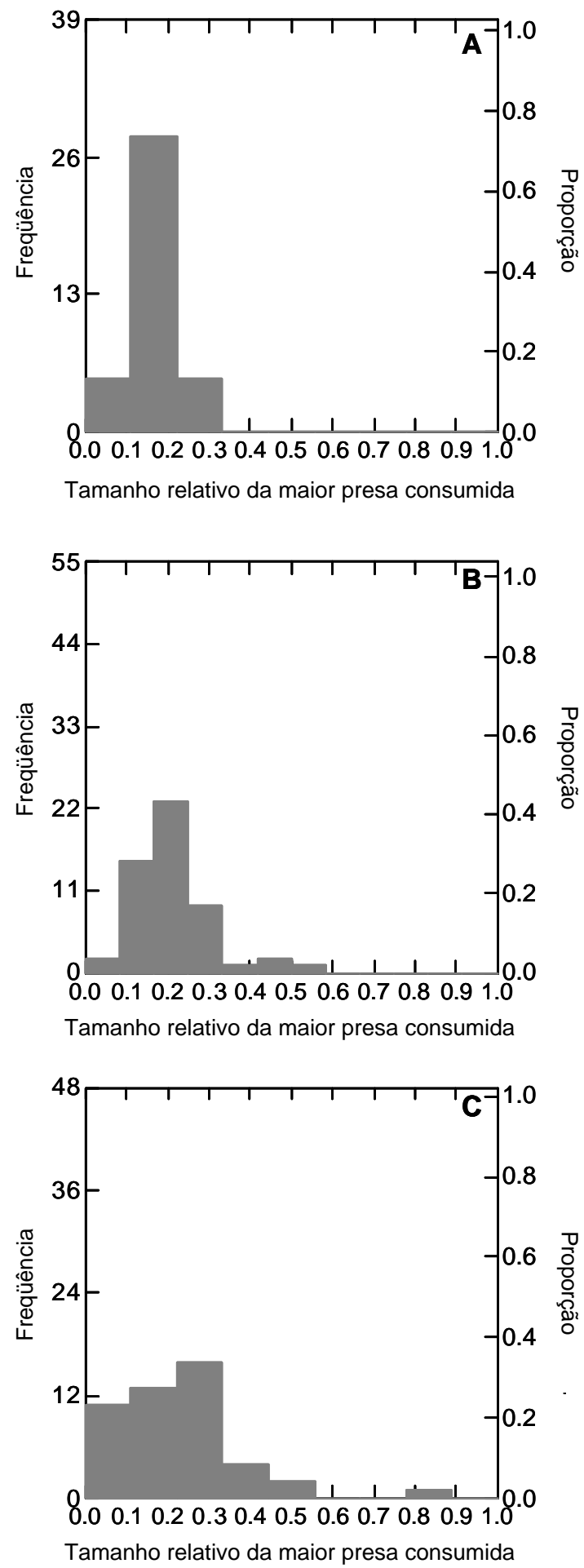

Figura 14 - Histograma de freqüência dos tamanhos relativos das maiores presas consumidas por Bufo granulosus (A), Pleurodema diplolistris (B) e Physalaemus albifrons (C). 0 tamanho relativo da presa é a proporção do tamanho da presa em relação ao tamanho do predador (tamanho das presa/tamanho do predador). 

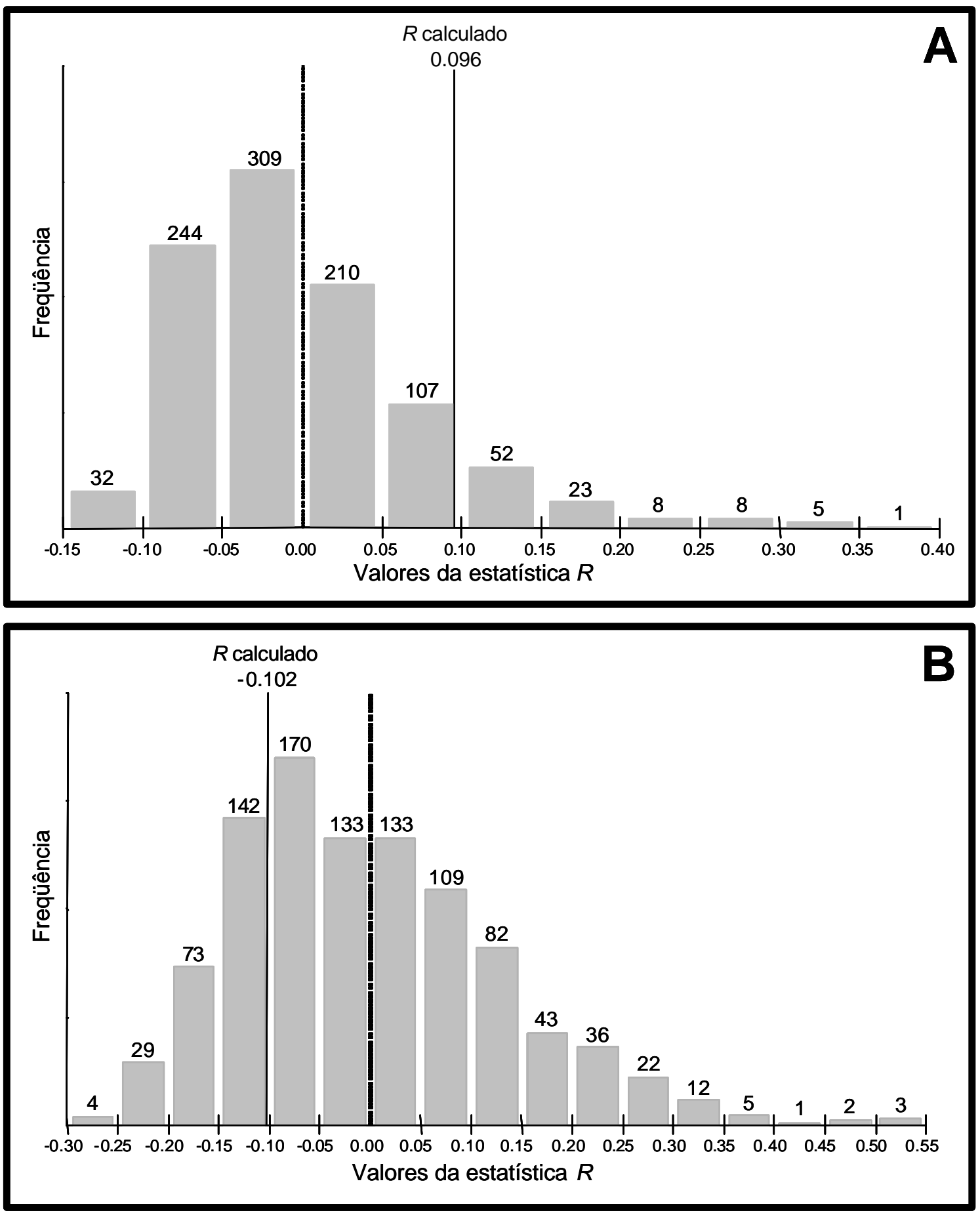

Figura 15 - Distribuições nulas da estatística R e R calculados na análise de similaridade (ANOSIM - Analysis of Similarities) de dois fatores (fator $1=$ método de coleta; fator $2=$ dia de análise) no teste da premissa de que a alimentação dos anuros nas armadilhas de queda não interfere significativamente na sua dieta. Em " $A$ ", 0 resultado da análise sobre diferença na dieta entre Pleurodema di plolistris col etados passivamente (armadilhas de queda) e ativamente. Em " $B$ ", o resultado da análise sobre diferença entre os dias de coleta. A linha pontilhada representa a média das distribuições. 


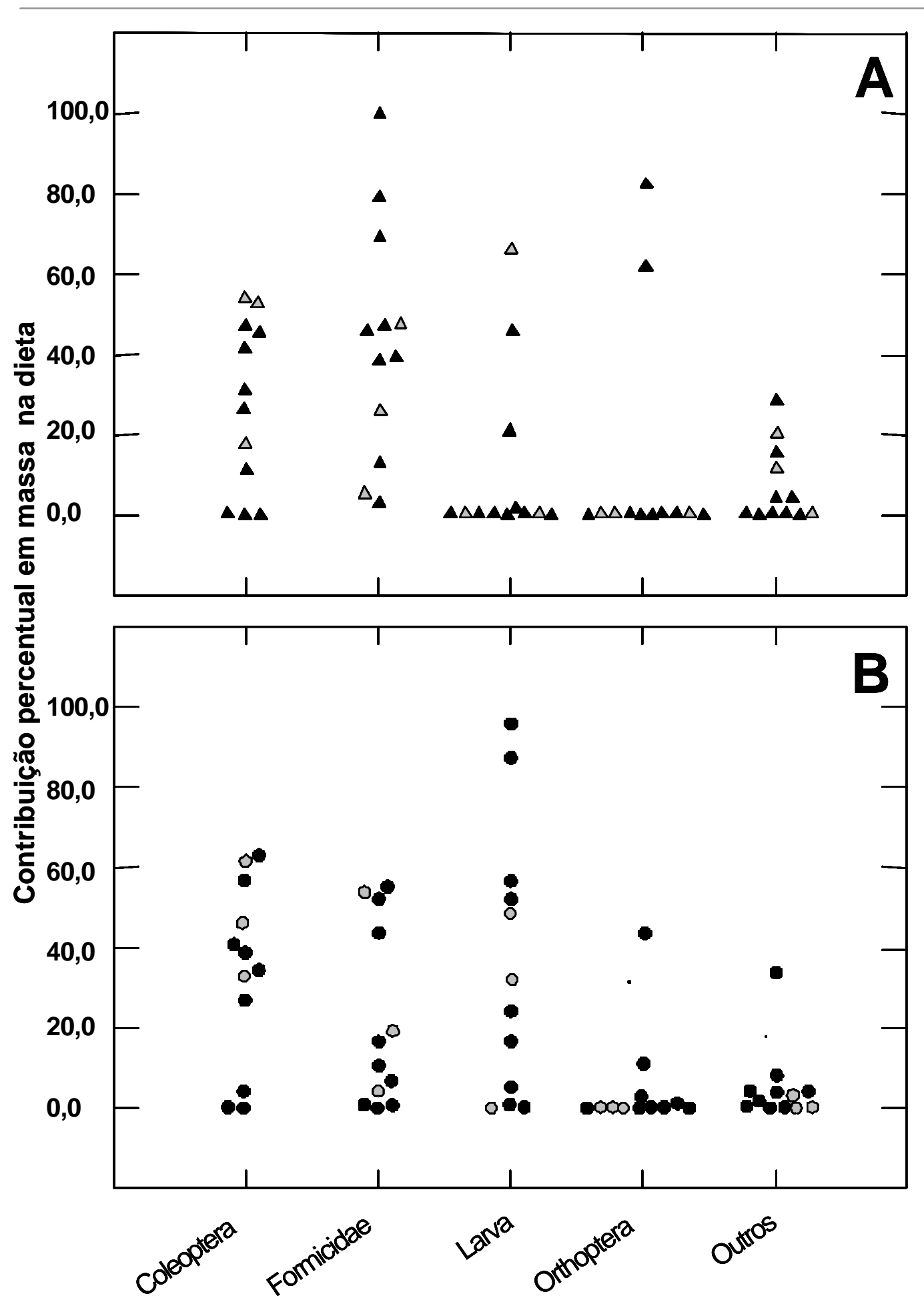

\section{Categorias alimentares}

Figura 16 - Contribuição percentual em massa das categorias alimentares na dieta de Pleurodema diplolistris coletados por armadilhas de queda (A) e por coleta ativa (B). Em preto, animais coletados no dia 18/02/2004 e em cinza, os animais coletados no dia 19/02/2004. Estão representadas apenas as categorias alimentares com contribuição percentual em massa de pelo menos 10\%, que somaram mais de $80 \%$ da massa das estimativas de uso. "Outros" refere-se à soma de todas as outras categorias al imentares não representadas no gráfico. 


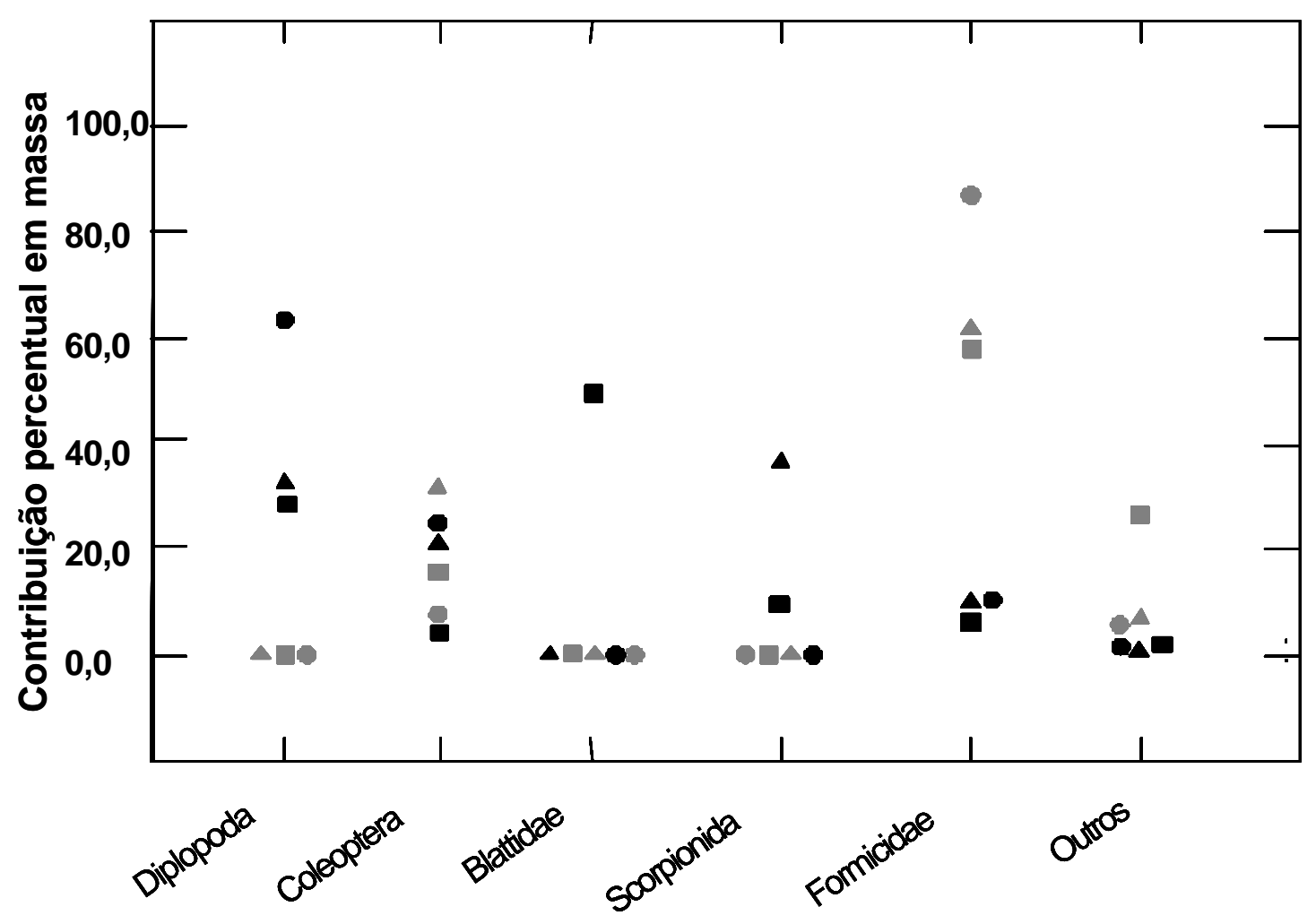

Categorias alimentares

Figura 17 - Contribuição percentual em massa dos artrópodes na estimativa de disponibilidade de alimento no ambiente (em cinza) e na estimativa de abundância (em preto). A disponibilidade foi estimada com base na dieta de B. granulosus e P. diplolistris. Símbolos diferentes representam dias de coleta (quadrado= 18/02; triângul $0=19 / 02$; círcul $0=20 / 02 / 2004$ ). "Outros" refere-se à soma de todas as categorias alimentares que tiveram contribuição percentual menor que $10,0 \%$. Diplopoda, Coleoptera, Blattidae, Scorpionida e Formicidade somaram 89,8\% na estimativa de abundância e 87,7\% na estimativa de disponibilidade. 

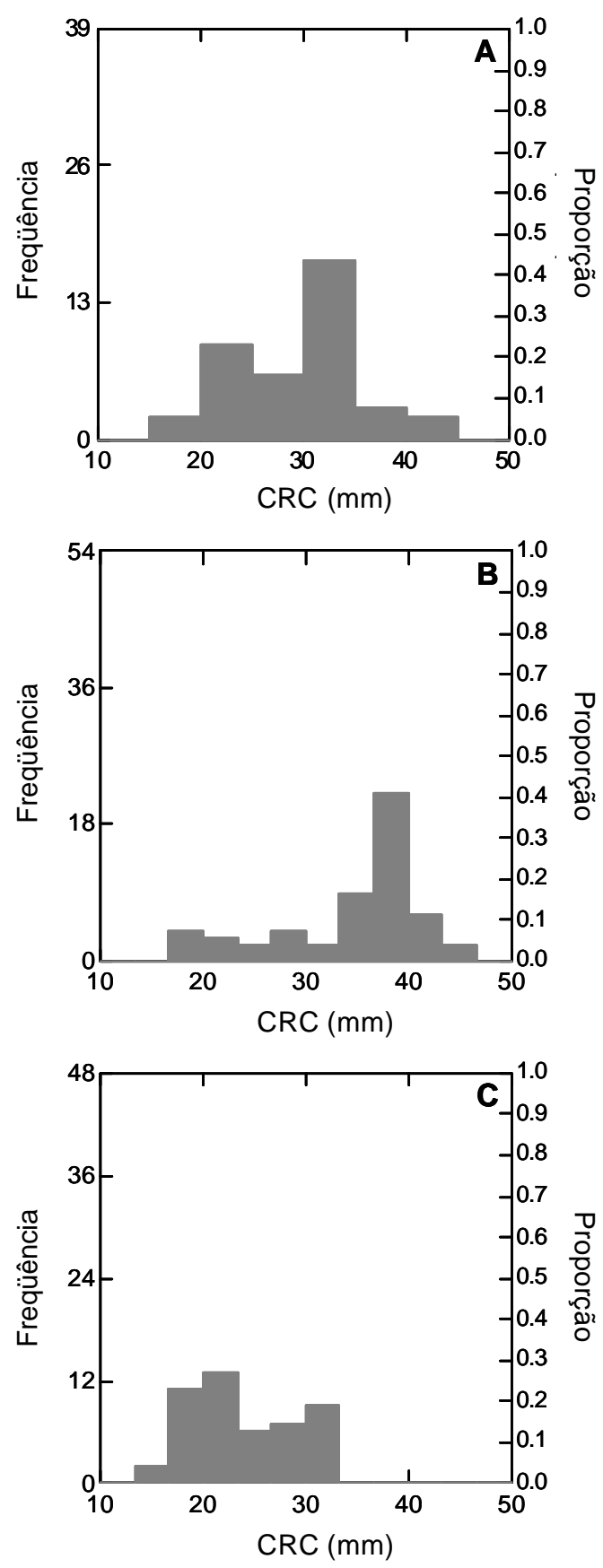

Figura 18 - Histograma de freqüência dos comprimentos rostro-cloacais (CRC) em milímetros dos indivíduos utilizados nas análises de variação ontogenética da dieta. Em " $A$ " as medidas de Bufo granulosus, em " $B$ ", de Pleurodema diplolistris e em " $C$ ", de Physalaemus albifrons. 

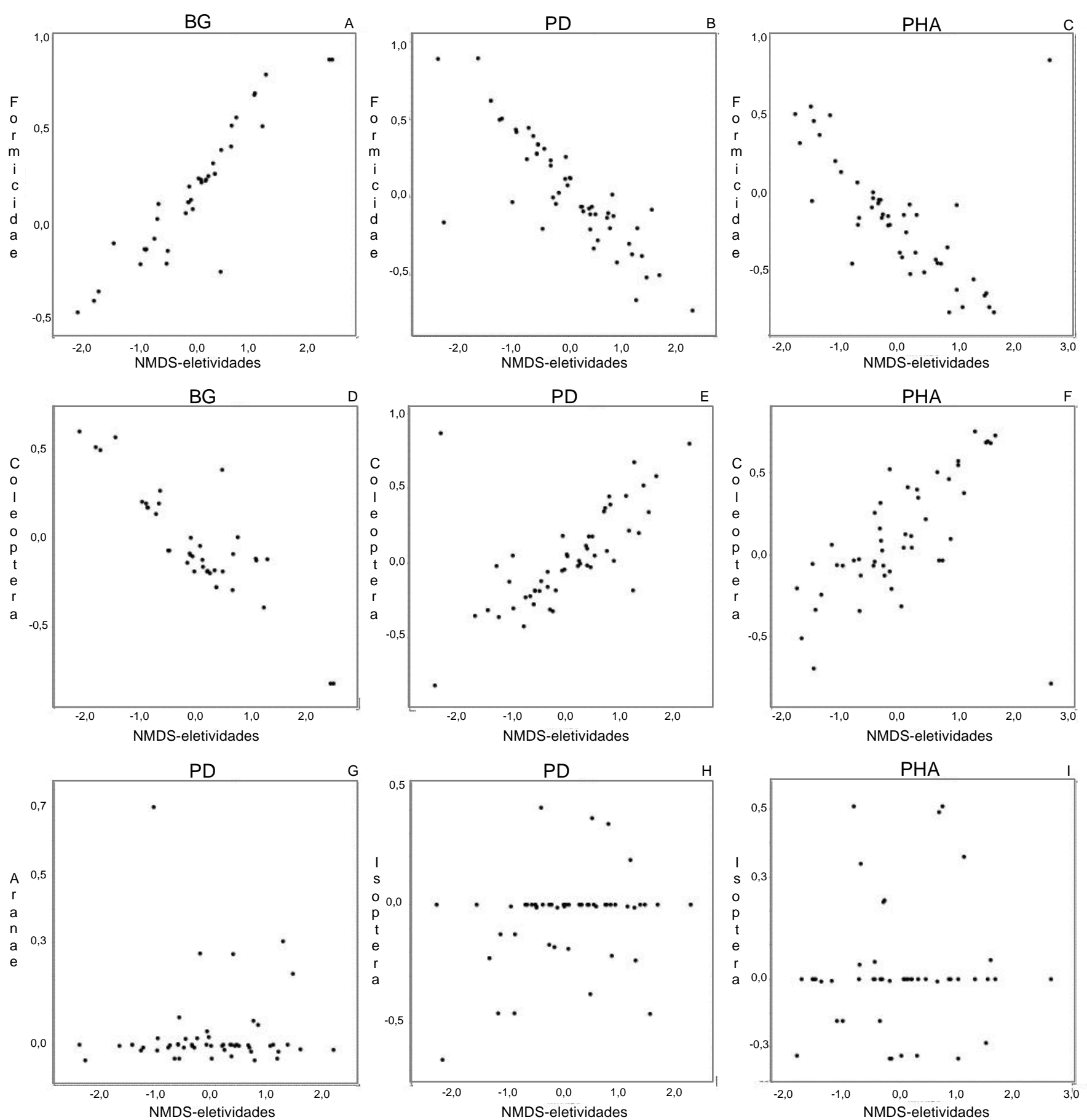

Figura 19: Gráficos de dispersão das eletividades por categorias alimantares e eixo NMDS-eletividades de Bufo granulosus (BG), em "A" e "D", Pleurodema diplolistris (PD), em "B", "E", "G" e "H", e Physalaemus albifrons (PHA), em "C", " $F$ ", "I". Nos gráficos " $A$ ", "B" @ "C", o eixo y representa eletividades por Formicidae; nos gráficos "D", "E" e "F", o eixo y representa eletividades por Coleoptera, no gráfico "G", o eixo y representa eletividade por Aranae e nos gráficos "H" e "I", eletividades por Isoptera. 

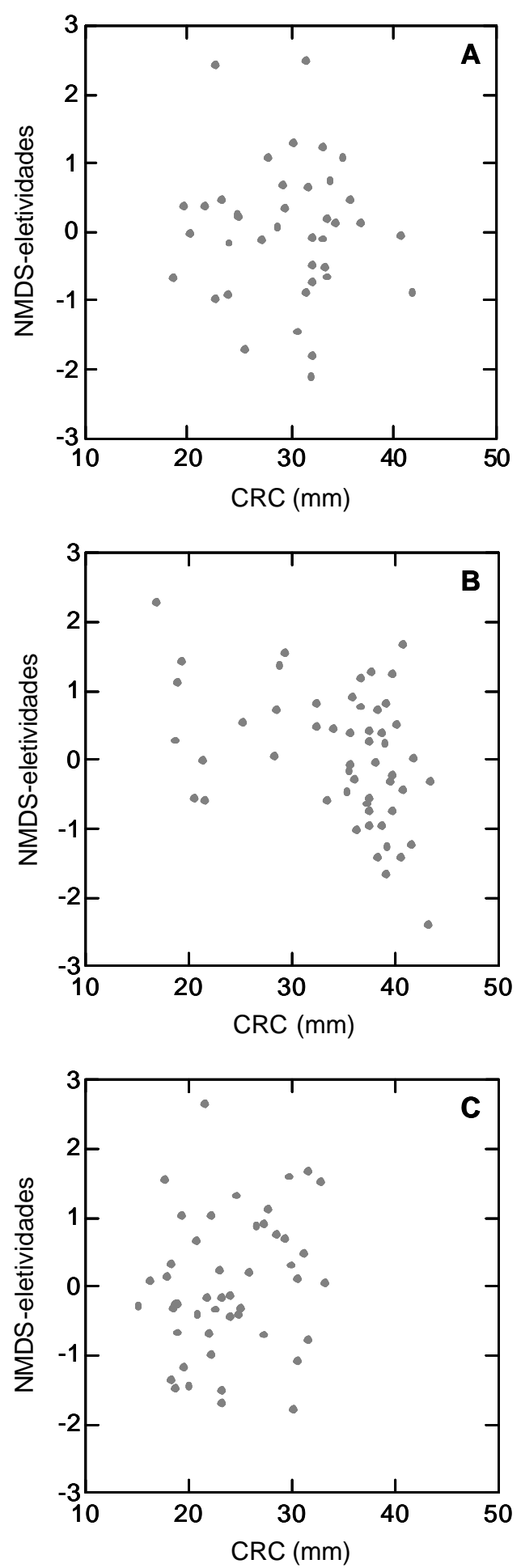

Figura 20 - Gráficos de dispersão do eixo reduzido das eletividades (NMDSeletividades) pelo tamanho rostro-cloacal (CRC), em milímetros, de Bufo granulosus (A), Pleurodema diplolistris (B) e Physalaemus albifrons (C). 

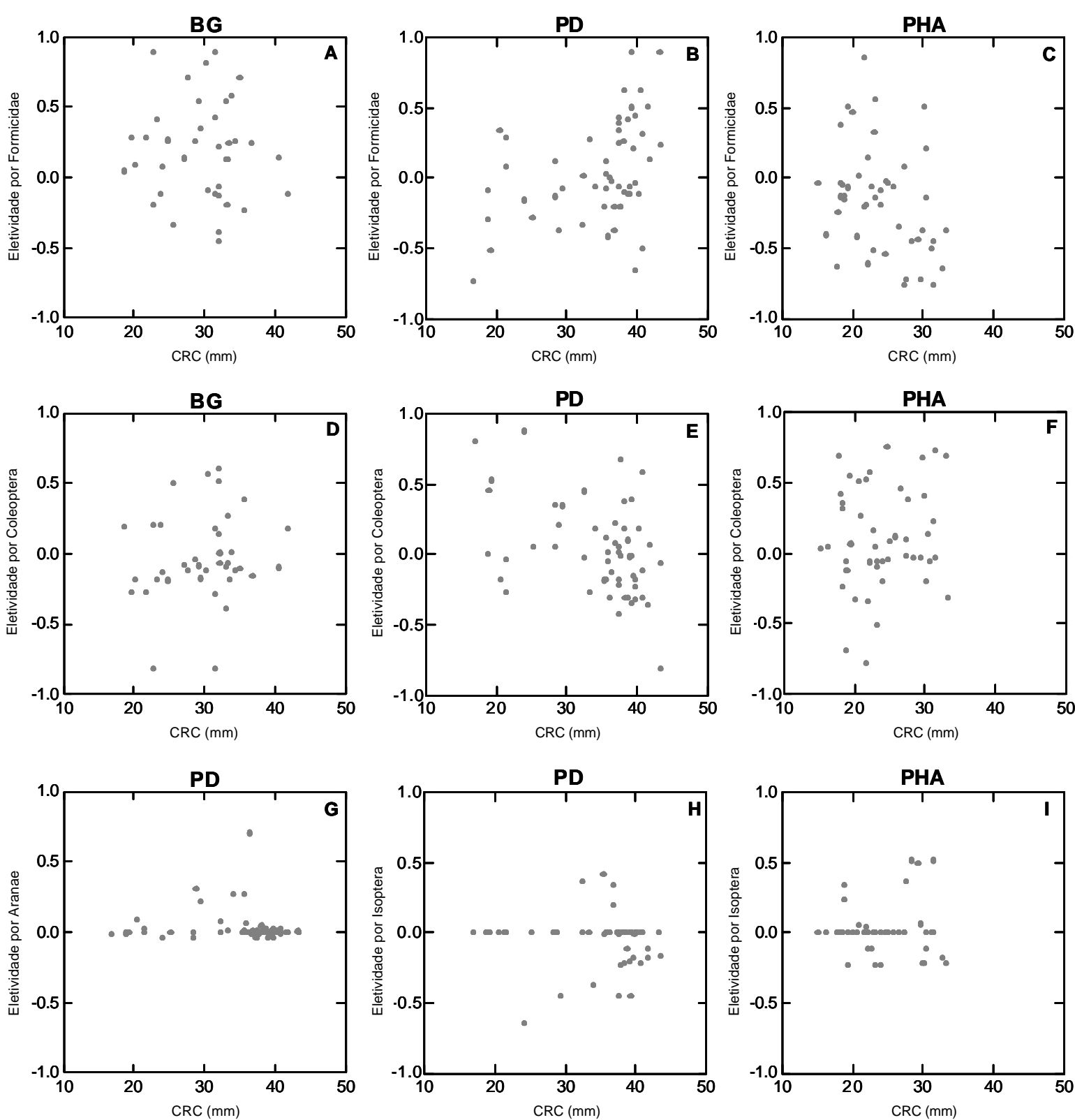

Figura 21 - Gráficos de dispersão das eletividades por categorias alimentares e 0 comprimento rostro-clocal (CRC), em milímetros, de Bufo granulosus (BG), em " $A$ " e "D", Pleurodema diplolistris (PD), em "B", "E", "G" e "H", e Physalaemus albifrons (PHA), em "C", "F", "I". 

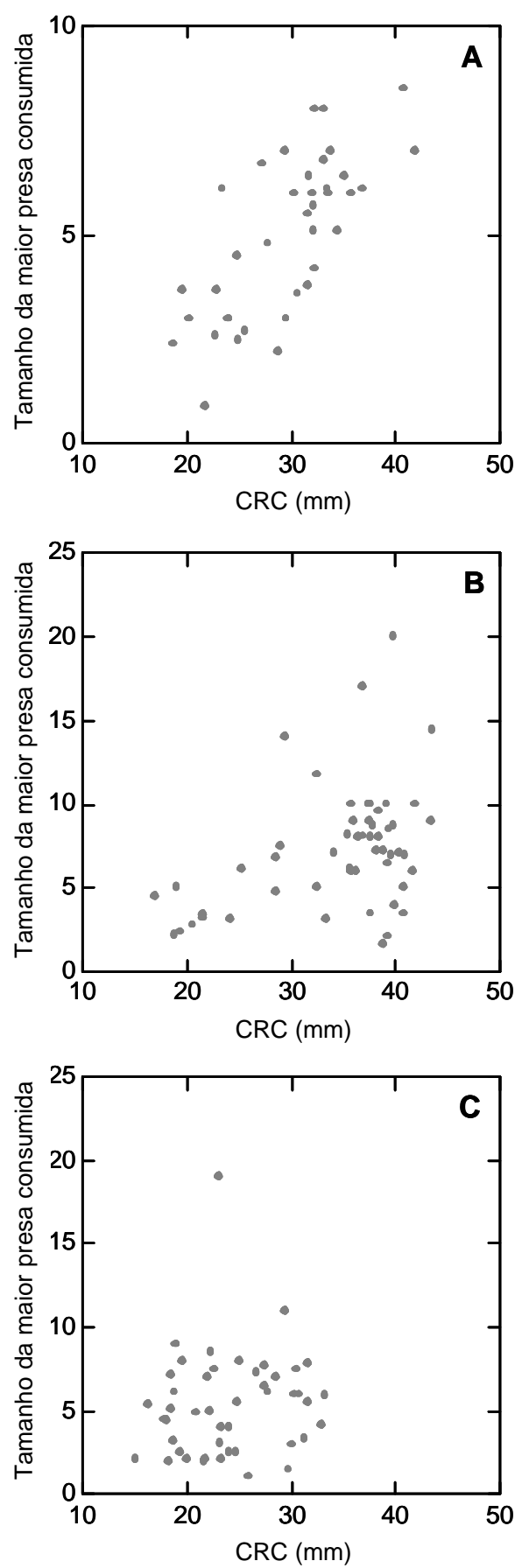

Figura 22 - Gráficos de dispersão do maior tamanho da maior presa consumido pelo tamanho rostro-cloacal (CRC), em milímetros, de Bufo granulosus (A), Pleurodema diplolistris (B) e Physalaemus albifrons (C). 

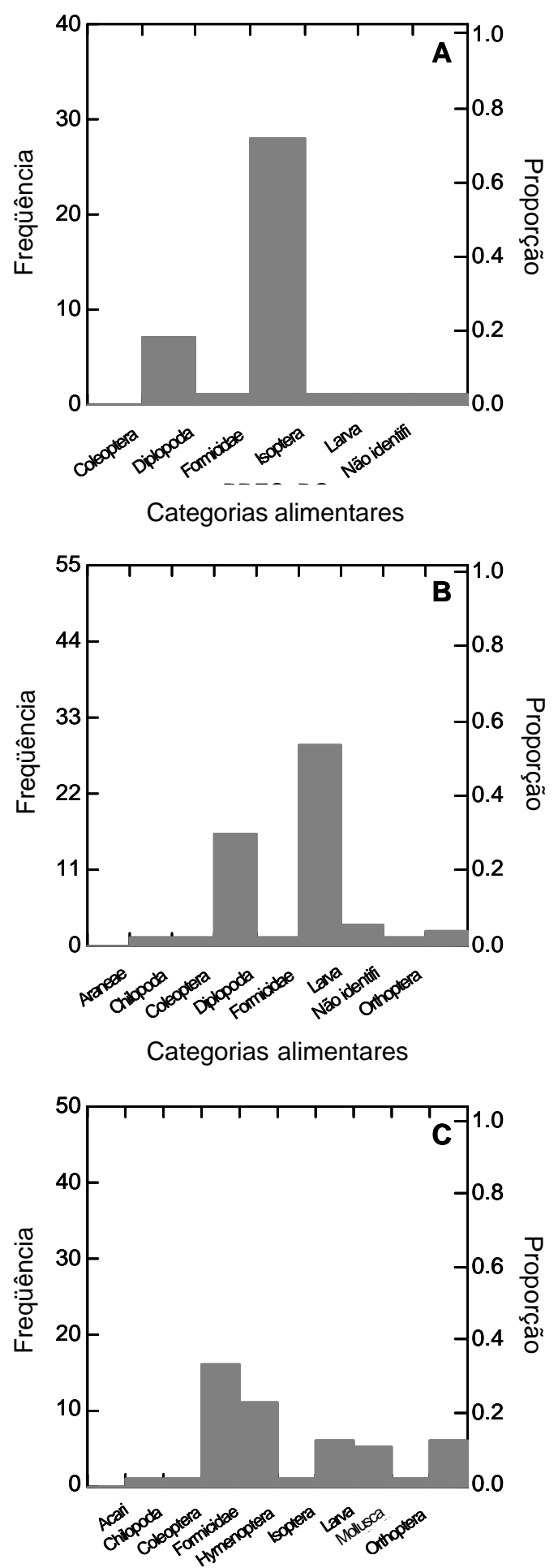

Categorias alimentares

Figura 23 - Histograma de freqüência dos maiores itens consumidos por Bufo granulosus (A), Pleurodema diplolistris (B) e Physalaemus albifrons (C). "Larva" identifica larvas de insetos e "Não identifi" representa reúne artrópodes nãoidentificados. "Hymenoptera" exclui Formicidae. 

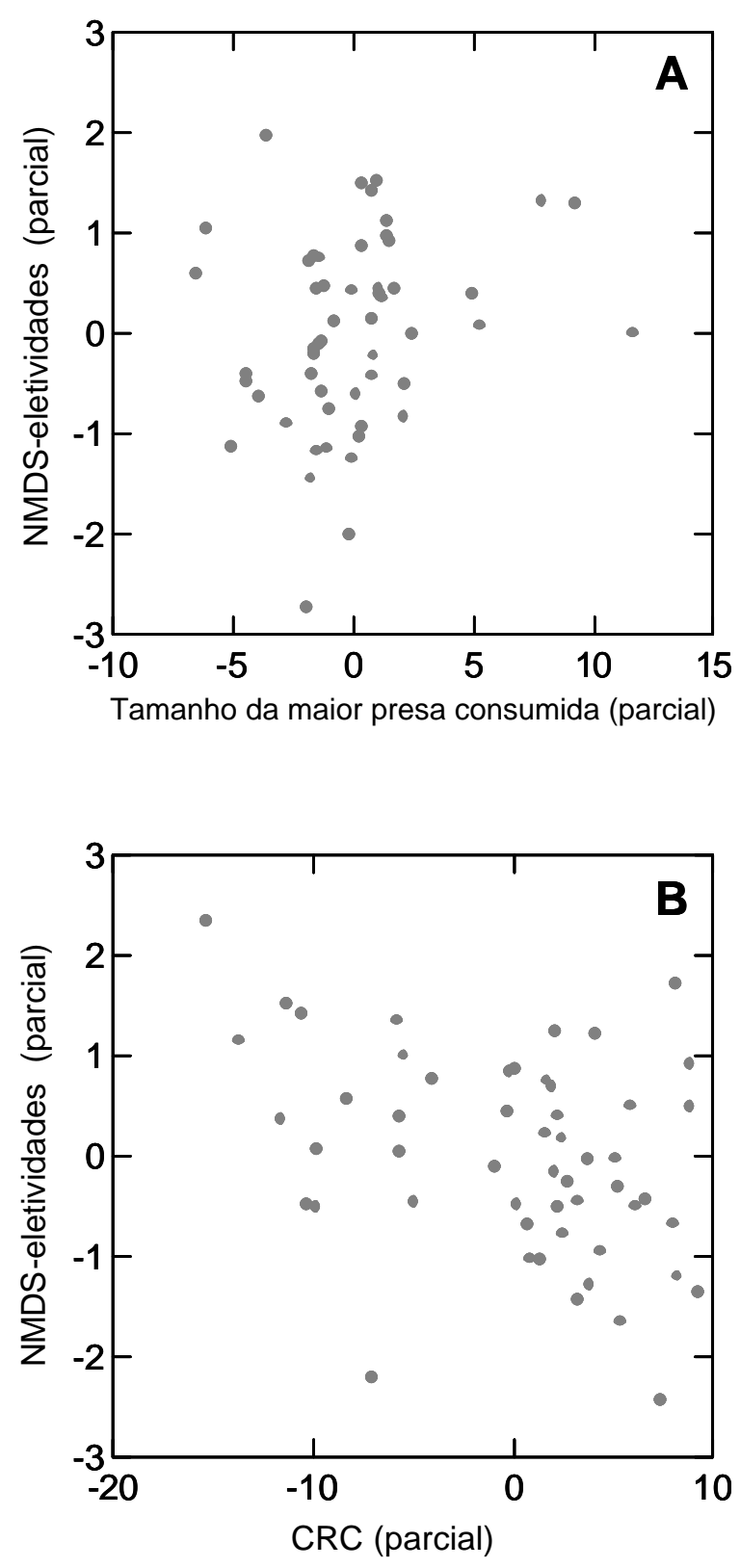

Figura 24 - Gráficos de dispersão parciais resultantes da regressão múltipla entre 0 eixo reduzido das eletividades (NMDS-eletividades) e (A) o maior tamanho das maiores presas consumidas por Pleurodema diplolistris e (B) o comprimento rostro-cloacal (CRC) dos anuros. As medidas de CRC e tamanho da presa estão em milímetros. 


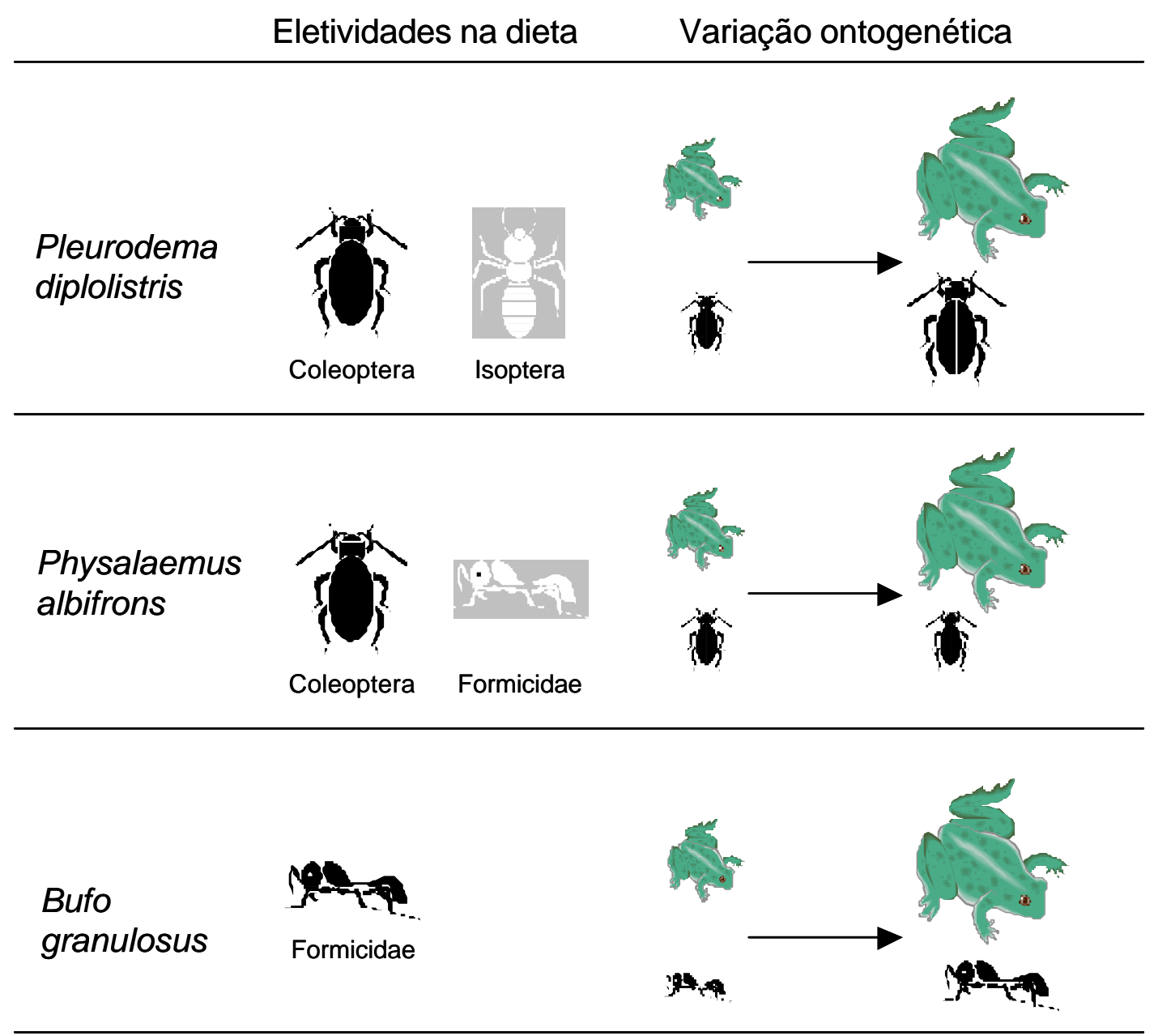

Figura 25 - Resumo esquemático das diferenças nas eletividades da dieta e das variações ontogenéticas das espécies de anuros terrícolas das dunas de topografia marcada de Ibiraba, Bahia. Desenhos pretos indicam eletividades positivas, desenhos brancos com fundo cinza, eletividades negativas. P. diplolistris e B. granulosus apresentaram variação ontogenética no tamanho das presas consumidas e P. albifrons não apresentou modificação ontogenética no tipo nem no tamanho das presas consumidas. 

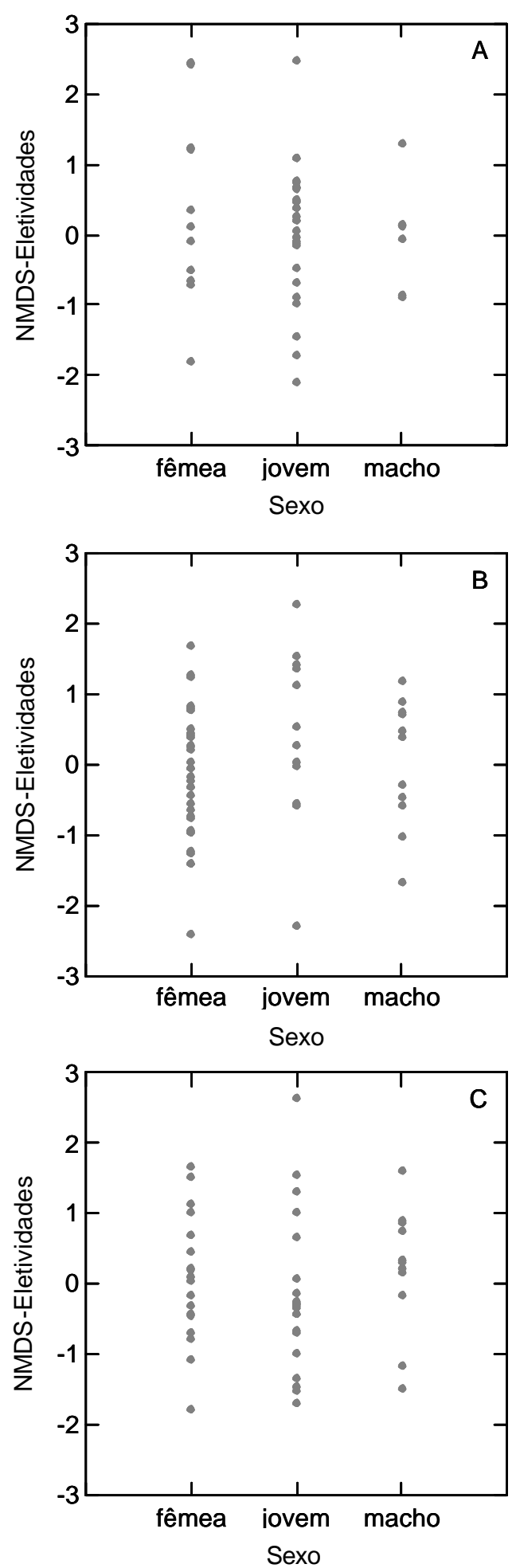

Figura 26 - Gráficos de dispersão do eixo reduzido das eletividades (NMDSeletividades) pelo sexo de Bufo granulosus (A), Pleurodema diplolistris (B) e Physalaemus albifrons (C). 

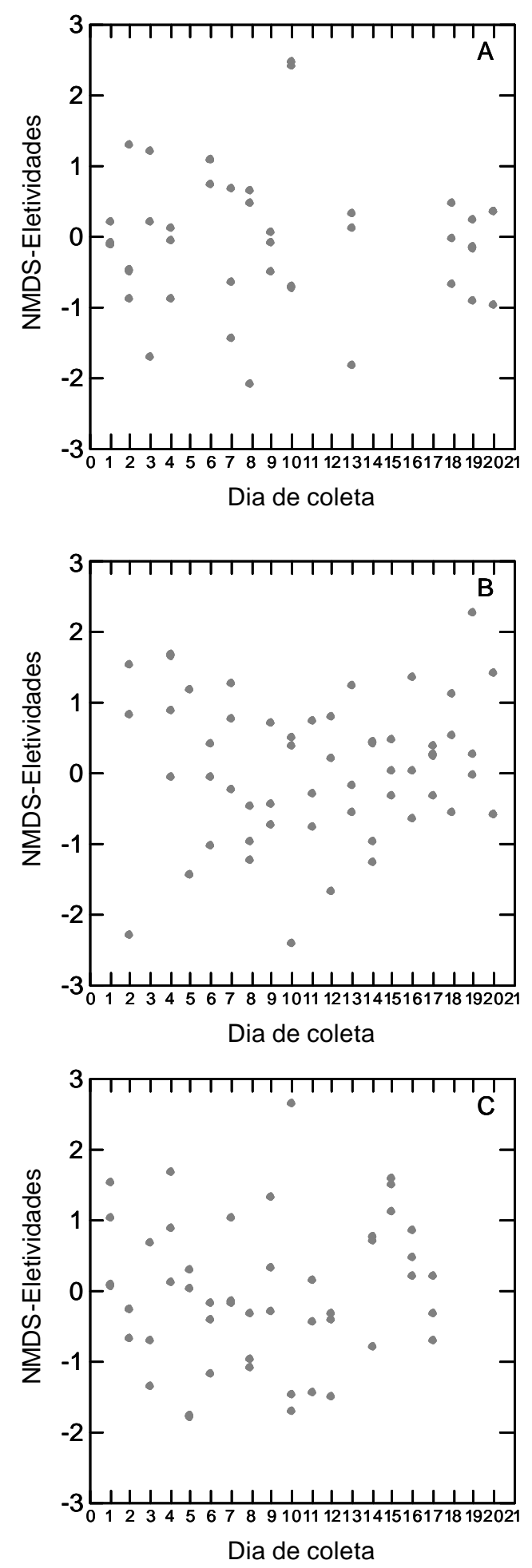

Figura 27 - Gráficos de dispersão do eixo reduzido das eletividades (NMDSeletividades) pelos dias de coleta de Bufo granulosus (A), Pleurodema diplolistris (B) e Physalaemus albifrons (C). 


\section{REFERÊNCIAS BIBLIOGRÁFICAS}

AB'SABER, A.N. Os domínios morfoclimáticos da América do Sul: primeira aproximação. G eomorfologia, v. 52, p.1-22, 1977.

ADIS, J. Problems of interpreting arthropod sampling with pitfall traps. Zoologischer A nzeiger, v. 202, n. 3/ 4, p.177-184, 1979.

ANDERSON, A.N. et al. Diet composition of three anurans from the playa wetlands of northwest Texas. Copeia, v.1999, n.2., p.515-520, 1999.

ARTHUR, S.M. et al. Assessing habitat selection when availability changes. E œlogy, v.77, n.1, p.215-227, 1996.

ARZABE, C. Reproductive activity patterns of anurans in two different altitudinal sites within the brazilian caatinga. Revista Brasileira de Z oologia, v.16, n.3, p. 851-864, 1999.

ARZABE, C.; ALMEIDA, C.C. Life history notes on Leptodadylus troglodytes (Anura, Leptodactylidae) in northeastern Brazil. A mphibia-Reptilia, v.18, p.211-215, 1996.

BAHIA-SE PLANTEC. Atlas do estado da Bahia. Salvador: CEPLAB, 1978. 50 mapas.

BARRETO , A.M. F. Estudo morfológico e sedimentológico da ponção norte do mar de areia fóssil do médio Rio São Francisco, Bahia. 1993. 98 f. Dissertação (Mestrado em Geologia Sedimentar) - Instituto de Geociências, Universidade de São Paulo, São Paulo.

BARRETO , A.M.F. Interpretação paleoambiental do sistema de dunas fixadas do médio Rio São Francisco, Bahia. 1996. 174 f. Tese (Doutoramento em Geologia Sedimentar) - Instituto de G eociências, Universidade de São Paulo, São Paulo

BEUCHAT, C.A. et al. Response to simultaneous dehydration and thermal stress in three species of Puerto Rican frogs. Journal of Comparative Physiology B, v.154, p.579-585, 1984.

BLAIR, W.F. (Ed.) Evolution in the genus Bufo. Austin: University of Texas Press, 1972. 459p.

BREKKE, D .R. et al. Behavior associated with water absorption response by the toad, Bufo punctatus. Copeia, v.1991, p.393-401, 1991.

BRO OKS, D.R.; MCLENNAN, D .A. Phylogeny, Ecology, and Behavior A research program in Comparative Biology. Chicago: The University of Chicago Press, 1991. 434 p. 
BROWN, L.J. An evaluation of some marking and trapping techniques currently used in the study of anuran population dynamics. Journal of H erpetology, v.31, n.3, p.410-419, 1997.

CADLE, J.E.; GREENE, H.W. Phylogenetic patterns, biogeography, and the ecological strucutre of Neotropical snake assemblage. In: RICKLEFS, R. E.; SCHLUTER, D. (Eds.) Species diversity in ecological communities. Chicago: The University of Chicago Press, 1993. p.281-293.

CALDWELL, J.P. The evolution of myrmecophagy and correlates in poison frogs (Family D endrobatidae). Journal of Z oology L ondon, v.240, p.75-101, 1996.

CALDWELL, J.P.; VITT, L.J. D ietary asymmetry in leaf litter frogs and lizards in a transitional northern Amazonian rain forest. 0ik os, v.84, p.383-397, 1999.

CARAMASCHI, U. Manual de técnicas para a preparação de coleções zoológicas. Fascículo 1: Generalidades. Campinas: Sociedade Brasileira de Zoologia. 1987.

CARD O SO , A.J.; ARZABE, C. Corte e desenvolvimento larvário de Pleurodema diplolistris (Anura: Leptodactylidae). Revista Brasileira de Biologia, v.53, p.555-560, 1993.

CARVALHO, A.L.; BAILEY, J.R. Sôbre os hábitos e ecologia de Pleurodema diplolistris (Peters) (Amphibia, Anura). Revista Brasileira de Biologia, v.8, p.261-264, 1948.

CASCON, P. Observações sobre diversidade, ecologia e reprodução da anurofauna de uma área de caatinga. 1987. Dissertação (Mestrado) - Instituto de Biologia, Universidade Federal da Paraíba, João Pessoa.

CHRISTIAN, K.A. Changes in the food niche during postmetamorphic ontogeny of the frog Pseudacris triseriata. Copeia, v.1982, n.1, p. 73-80, 1982.

CLARKE, K.R.; WARWICK, R.M. Change in marine communities: an approach to statistical analysis and interpretation. 2 ed. Plymouth: PRIMER-E, 2001.

CLOUD SLEY-THOMPSON, J.L. Ecophysiology of Desent Arthropods and Reptiles. Berlin: Springer-Verlag, 1991. 203 p.

COLWELL, R.K.; FUTUYMA, D. J. On the measurement of niche breadth and overlap. E cology, v.52, n.4, p.567-576, 1971.

CORNISH, C.A. Comparison of the diet of adult toads (Bufo bufo L.) with pitfall trap catches. H erpetological Journal, v.5, p.236-238, 1995.

CRUZ, L.C. Utilização de recursos espaciais e alimentares por Physalaemus albifrons (Anura: Leptodactilydae) das dunas do Rio São Francisco, Bahia. 2000. 
52 f. Trabalho de Conclusão de Curso (Graduação em Ciências Biológicas) - Instituto de Biologia, Universidade Federal da Bahia, Salvador.

CRUZ, L.C. A prática científica na Ecologia de Comunidades: Um estudo da literatura de ecologia de comunidades de lagartos. 2003. 177 f. Dissertação (Mestrado em Ecologia e Biomonitoramento) - Instituto de Biologia, Universidade Federal da Bahia, Salvador.

DAMASCENO, R.P.; ROCHA, P.L.B. Adaptation versus phylogenetic inertia in resource use: study with vicariant assemblages of fossorial squamates. (em preparação).

DEBRUYN, L. et al. Diet of X enopus freseri (Anura, Pipidae). Journal of H erpetology, v.30, n.1, p. 82-85, 1996.

D ODD , C.K. The effects of drought on population structure, activity, and orientation of toads (Bufo querciaus and B. terrestris) at a temporary pond. E thology E oology \& E volution, v.6, p.331-349, 1994.

DONNELLY, M.A. Feeding patterns of strawbery poison frog, Dendrobates pumilio (Anura: D endrobatidae). C opeia, v. 1991, p.723-730, 1991.

DONNELLY, M.A. Amphibian diversity and natural history. In: McDADE, L.A.; BANA, K.S.; HESPENHEIDE, H.A.; HARTSHO N, G.S. (Eds.) La Selva: Ecology and Natural History of a Neotropical rain forest. Chicago: University of Chicago Press, 1994. 457p.

DUELLMAN, W.E. Amphibians and reptiles of the rainsforests of Southern El Petén, G uatemala. U niversity of Kansas Publications M useum of N atural H istory, v.15, n.5, p.205-249, 1963.

DUELLMAN, W.E. Herpetofaunas in Neotropical Rainforests: Comparative composition, history and resource use. In: Gentry, A. H. (Ed.) Four N eotropical Rainforests. New Haven: Y ale University Press, 1990. 640p.

DUELLMAN, W.E; SCHULTE, R. D escription of a new species of Bufo from Northern Peru with comments on phenetic groups of south american toads (Anura: Bufonidae). Copeia, v.1992, n.1, p.162-172, 1992.

DUELLMAN, W.E.; TRUEB, L. Biology os amphibians. London: Johns Hopkins, 1986. 670p.

DUELLMAN, W.E.; VELO SO , A.M. Phylogeny of Pleurodema (Anura: Leptodactylidae): a biogeographic model. $\mathrm{O}$ casional Papers of the $\mathrm{M}$ useum of $\mathrm{N}$ atural $\mathrm{H}$ istory of the University of Kansas, v.64, p.1-46, 1977. 
ENDLER, J.A. Geographic variation, speciation, and clines. Princeton: Princeton University Press, 1977.

EVANS, M.; LAMPO, M. Diet of Bufo marinus in Venezuela. Journal of H erpetology, v.30, n.1, p. 73-76, 1996.

FLOWERS, M.A.; GRAVES, B.M. Prey selectivity and size-specific diet changes in Bufo cognatus and B. woodhousii during early postmetamorphic ontogeny. Journal of $\mathrm{H}$ erpetology, $\mathrm{v}$. 29, n. 4, p.608-612, 1995.

FONSECA, C.G.; ROCHA, P.L.B. Analysis of phylogenetic inertia in resource use of vicariant species of medium-sized lizard of the ænd dune fields of the São Francisco River, Bahia, Brazil. (em preparação).

FORD, L.S.; CANNATELLA, D.C. The major clades of frogs. H erpetological Monographs, v.7, p.94-117, 1993.

FREITAS, J.N.; EL-HANI, C.N.; ROCHA, P.L.B. Affiliation in the torch tail rat, Trynomys yonenagae (Rodentia: Echymyidae), a sand-dwelling rodent from Brazilian semiarid Caatinga: evolutionary implications. R evista deE tologia, v.5, n.2, p.61-73, 2003.

FROST, D.R. 2004. Amphibian Species of the World: an O nline Reference. Versão 3.0 (22 de Agosto de 2004). Banco de dados eletrônico acessível em: <http:/ / research.amnh.org/ herpetology/ amphibia/ index.html> American Museum of Natural History, Nova York, USA.

GALARDO, J.M. The species Bufo granulosus Spix (Salientia, Bufonidae) and its geographic variation. Bulletin of the Museum of Comparative Zoology, v.134, n.4, p.107-138, 1965.

GALATTI, U. Population biology of the frog Leptodactylus pentadactylus in a Central Amazonian rainforest. Journal of H erpetology, v.26, n.1, p.23-31, 1992.

GIARETTA, A.A. et al. Food habits and ontogenetic diet shifts of the litter dwelling frogs Proceratophrys boidei (Wied). Revista Brasileira deZ oologia, v.15, n.2, p.385-388, 1998.

GIBBONS, J.W.; BENNETT, D.H. D etermination of anuran terrestrial activity patterns by a drift fence method. Copeia, v.1974, n.1, p.236-243, 1974.

GOMES, A.S. Avaliação experimental da ocomência de competição contemporânea entre espécies endêmicas de lagartos das dunas do médio rio São Francisco, BA. 2005. 30 f. Dissertação (Mestrado em Ecologia e Biomonitoramento) Instituto de Biologia, Universidade Federal da Bahia, Salvador. 
GOULD, S.J. The Structure of the Evolutionary Theory. Cambridge: Harvard University Press, 2002. 1433 p.

GOULD , S.J.; VRBA, S. Exaptation - a missing term in the science of form. Paleobiology, v.3, p.23-40, 1982.

GREENBERG, C.H.; NEARY, D.G.; HARRIS, L.D. A comparison of herpetofaunal sampling effectiveness of pitfall, single-ended, and double-ended funnel traps used with drift fences. Journal of H erpetology, v.28, n.3, p.319-324, 1994.

HARVEY, P.H.; PAGEL, M.D. The Comparative Method in Evolutionary Biology. New Y ork: Oxford University Press, 1991. 239 p.

HEYER, W.R.; JUNCÁ, F.A. L eptodactylus caatingae, a new species of frog from eastern Brazil (Amphibia: Anura: Laptodactylidae). Proceedings of the Biological Society of W ashington, v.116, n.2, p. 317-329, 2003.

HEYER, W.R. et al. (Eds.) Measuring and monitoring biological diversity Standard methods for amphibians. Washington: Smithsonian Institution Press, 1994. 364 p.

HÓ D AR, J.A. et al. Tophic ecology of the O cellated lizard L acerta lepida in an arid zone of southern Spain: relationships with availability and daily activity of prey. Journal of A rid E nvironments, v.33, p.95-107, 1996.

HURLBERT, S.H. Pseudoreplication and the design of ecological field experiments. E oological M onographs, v.54, n.2, p.187-211, 1984.

INSTITUTO NACIO NAL DE METEOROLOGIA. (10 de Agosto de 2000) Banco de dados eletrônico acessível em <http:/ / www.inmet.gov.br/ >.

JACOBS, J. Quantitative measurement of food selection: a modification of the forage ratio and Ivlev's electivity index. 0 ecologia, v.14, p.413-417, 1974.

JACO MINE, P.K.T. et al. Levantamento exploratório - Reconhecimento de solos da margem esquerda do Rio São Francisco, Estado da Bahia. Boletim Técnico EMBRAPA, n.38, p.1-404, 1976.

JO HNSON, D.H. The comparison of usage and availability measurements for evaluating resource preference. E ology, v.61, n.1, p.65-71, 1980.

JONGMAN, R.H.G.; TER BRAAK, C.J.F.; VAN TONGEREN, O.F.R. (Eds.) Data analysis in community and landscape ecology. Cambridge: Cambridge University Press, 1995. 299 p. 


\section{KACHIGAN, S.K. Statistical analysis: an interdisciplinary introduction to univariate and multivarate methods. New Y ork: Radius Press,. 1986. 589p.}

LABANICK, G.M. Prey availability, consuption and selection in the cricket frog, A cris creptans (Amphibia, Anura, Hylidae). Journal of H erpetology, v.10, n.4, p.293-298, 1976.

LAWLOR, L.R. Overlap, similarity, and competition coefficients. E ology, v.61, n.2, p.245-251, 1980.

LEAL, A.S. Inventário hidrogeológico básico do Nordeste. Folha 19 - Aracaju - NO. SUD ENE, Série H idrogeologia, v.33, p.1-157, 1970.

LIMA, A.F.B.; ROCHA, P.L.B. Ontogenetic shift in the diet of Tropidurus psammonastes (Tropiduridae: Iguania), alizard endemic from the sand dunes of the São Francisco River, Bahia, Brazil. Phyllomedusa (submetido).

LIMA, A.P. The effects of size on the diets os six sympatric species of postmetamorphic litter anurans in Central Amazonia. Journal of H erpetology, v.32, n.3, p.392-399, 1998.

LIMA, A.P.; MAGNUSSO N, W.E. Partitioning seasonal time: interactions among size, foraging activity and diet in leaf-litter frogs. 0 ecologia, v.116, p.259-266, 1998.

LIMA, A.P.; MOREIRA, G. Effects of prey size and foraging mode on the ontogenetic change in feeding niche of Colostethus stepheni (Anura: D endrobatidae). 0 ecologia, v.95, p.93-102, 1993.

LIMA, A.C.; MAGNUSSO N, W.E.; COSTA, V.L. D iet of the turtle Phrynops rufipes in Central Amazônia. Copeia, v. 1997, n.1, p.216-219, 1997.

LIMA, A.P.; MAGNUSSON, W.E.; WILLIAMS, D.G. Differences in diet among frogs and lizards coexisting in subtropical forests of Australia. Journal of Herpetology, v.34, n.1, p.40-46, 2000.

LO SO S, J.B. Phylogenetic perspectives on community ecology. E ology, v.77, n.5, p.1344$1354,1996$.

MAG NUSSO N, W.E. et al. Use of geometric forms to estimate volume of invertebrates in ecological studies of dietary overlap. Copeia, v. 2003, n.1, p.13-19, 2003.

MANEYRO, R. et al. Diet of the South American frog L eptodactylus oœllatus (Anura, Leptodactylidae) in Uruguay. Iheringia Série Z oologia, v.94, n.1, p.57-61, 2004.

MANLY, B.F. et al. Resource selection by animals Statistical design and analysis for field studies. Londes: Chapman \& Hall, 1993. 177 p. 
MARES, M.A.; WILLIG, M.R.; LACHER, T.E. The Brazilian Caatinga in South American zoogeography: tropical mammals in a dry region. Journal of Biogeography, v.12, p.57-69, 1985.

MCCUNE, B.; GRACE, J.B. Analysis of ecological communities. Gleneden Beach: MjM, 2002. 300 p.

MCKEE, E.D. Sedimentary structures in dunes of the Namib D esert, South West Africa. G eological Society of A merica, Special Papers, n.118, p.1-64, 1982.

MEASY, G.J. D iet of feral X enopus laevis (D audin) in South wales, U.K. Journal of Z oology L ondon, v.2446, p.287-298, 1998.

MENDES, L.A.F. et al. Differences in ingestive balance of two populations of neotropical Thrichomys apereoides (Rodentia, Echimyidae). Comparative Biochemestry and Physiology A , v.138, p.327-332, 2004.

MENGAK, M.T.; GUYNN, D.C. Pitfalls and snap traps for sampling small mammals and herpetofauna. A merican Midland N aturalist, v.118, n.2, p.284-289, 1987.

MOREIRA, G.R.S. Padrões de reprodução, atividade e alimentação de anuros em duas localidades do Brasil central. 1993. 56 f. Dissertação (Mestrado em Ecologia) Instituto de Biologia, Universidade de Brasília, Brasilia.

NARVAES, P. Revisão taxonômica das espécies de Bufo do complexo granulosus (Amphibia, Anura, Bufonidae). 2003. 305 f. Tese (D outorado em Zoologia) - Instituto de Biociências, Universidade de São Paulo, São Paulo.

NAVAS, C.A.; ANTONIAZZI, M.M.; JARED , C. A preliminary assessment of anuran physiological and morphological adaptation to the caatinga, a Brazilian semi-arid encironment. International Congress Series, n.1275, p.298-305, 2004.

NEVES, E.S. Diferenças sexuais do repertório comportamental de Trinomys yonenagae (Rodentia: Echimidae) e seqüências comportamentais exibidas por díades de fêmeas em situação de cativeiro. 2004. $56 \mathrm{f}$. Trabalho de conclusão de curso (Bacharelado em Ciências Biológicas) - Instituto de Biologia, Universidade Federal da Bahia, Salvador.

NIMER, E. 1979. Climatologia do Brasil. Rio de Janeiro: IBG E, 421 p.

PARMELEE, J.R. Trophic ecology of a tropical anuran assemblage. Scientific papers N atural history M useum The U niversity of Kansas, v.11, p.1-59, 1999. 
PEARRE Jr., S. Estimating prey preference by predators: uses of various indices, and a proposal of another based on $\chi^{2}$. Canadian Journal of Fisheries and A quatic Sciences, v.39, p.914-923, 1982.

PEÑA, J.C.; BERRANTES, R.B.; UGALDE, D.R. Feeding habits of Bufo marinus (Anura: Bufonidae) in Costa Rica (SPA). Revista de Biologia Tropical, v.44, 1B, p.702-703, 1997.

PERTRAITIS, P.S. Likelihood measures of niche breadth and overlap. E ology, n.60, v.4, p.703-710, 1979.

PIANKA, E.R. The strucutre of lizard communities. A nnual Review of E cology and Systematic, v.4, p.53-74, 1973.

PIANKA, E.R. Niche relations of desert lizards. In: CODY, M.L.; DIAMO ND, J.M. (Eds.) Ecology and evolution of communities. Cambridge: Harvard University Press, 1975. $545 \mathrm{p}$.

PIANKA, E.R. Ecology and Natural History of desert lizards. Analysis of the Ecological Niche and Community Structure. Princeton: Princeton University Press, 1986. $208 \mathrm{p}$.

PINCHEIRA-DONOSO, D. Nota sobre la alimentación de Pleurodema bufonina Bell, 1843 (Anura - Leptodactylidae). G ayana (C oncecpc.), v.66, n.1, p.77-80, 2002.

PREEST, M.R.; POUGH, F.H. Interactions of temperature and hydration on locomotion of toads. Functional E cology, v.3, p.693-699, 1989.

RAPPI, G.E.; FERNÁNDEZ, S.R.; BASSO, N.G. Alimentación y fecundidad de Bufo variegatus (Anura: Bufonidae) en Santa Cruz, Argentina. C uaderno de H erpetología, v.14, n.1, p.61-70, 2000.

RICKLEFS, R.E.; SCHLUTER, D. (Eds.) Species diversity in ecological communities. Chicago: The University of Chicago Press, 1993.416p.

ROCHA, P.L.B. Proechimys yonenage, a new species of spiny rat (Rodentia: Echimyidae) from fossil sand dunes in Brazilian Caatinga. Mammalia, v.59, n.4, p.537-549, 1995.

ROCHA, P.L.B.; QUEIROZ, L.P.; PIRANI, J.R. Plant species and habitat structure in a sand dune field in the Brazilian Caatinga: a homogeneous habitat harboring an endemic biota. Revista Brasileira de Botânica, v.27, n.4, p.739-755, 2004.

ROCHA, P.L.B.; RODRIGUES, M.T. (no prelo). Electivities and resource use by an assemblage of lizards endemic to the "Brazilian Little Sahara". Papéis A vulsos de Z oologia. 
ROD RIG UES, M.T. Herpetofauna das dunas interiores do Rio São Francisco: Bahia. I. Introdução à área e descrição de um novo gênero de microteiídeo (Calyptommatus) com notas sobre sua ecologia, distribuição e especiação (Sauria, Teiidae). Papéis A vulsos de Z oologia, v.37, n.19, p.285-320, 1991.

RODRIGUES, M.T. Lizards, snakes, and amphisbaenians from the quaternary sand dunes of the middle Rio São Francisco, Bahia, Brazil. Journal of Herpetology, v.30, n.4, p.513-523, 1996.

ROD RIG UE S, M.T. Herpetofauna da Caatinga. In: Leal, I.R.; Tabarelli, M.; Silva, J.M.C. (Eds). E cologia e conservação da Caatinga, Recife: ED UFPE, 2003. 822p.

RODRÍGUEZ-ROBLEZ, J.A.; GREENE, H.W. Food habits of the long-nosed snake (Rhinocheilus lecontei ), a 'specialist' predator? Journal of Z oology L ondon, v.248, p.48-499, 1999.

SANTOS, J.W.A.; DAMASCENO, R.P.; ROCHA, P.L.B. Feeding habits of the frog Pleurodema diplolistris (Anura, Leptodactylidae) in the quaternary sand dunes of the middle Rio São Francisco, Bahia, Brazil. Phyllomedusa, v.2, n.2, p.83-92, 2003.

SANTOS, D.T.V. Estudo do comportamento social do lagarto Tropidurus psammonastes em encontros interespecíficos em experimentos de campo. 2004. 56 f. Trabalho de conclusão de curso (Bacharelado em Ciências Biológicas) - Instituto de Biologia, Universidade Federal da Bahia, Salvador.

SANTOS, J.W.A. Ecologia da socialidade do roedor psamófilo Trinomys yonenagae (Echimyidae) em uma área das dunas do Rio São Francisco na Caatinga. 2004. 119 f. Dissertação (Mestrado em Zoologia) - Instituto de Biociências, Universidade de São Paulo, São Paulo.

SANTOS, S.A. et al. Diets of Caiman croodilus yacare from different habitats in the brazilian pantanal. H erpetological Journal, n.6, p.111-117, 1996.

SEEBACHER, F.; ALFORD, R.A. Movement and microhabitat use of a terrestrial amphibian (Bufo marinus) on a tropical island: Seasonal variation and environmental correlates. Journal of H erpetology, v.33, n.2, p. 208-214, 1999.

SILVA, S.A.; JUNCÁ, F.A. Diet of Physalaemus cf. cicada (Leptodactylidae) and Bufo granulosus (Bufonidae) in a semideciduos forest. Brazilian Journal of Biology, v.67, n.3 (no prelo).

SIMON, M.P.; TOFT, C.A. D iet specialization in small vertebrates: mite-eating in frogs. O ikos, v.61, p.263-278, 1991.

SMITH, L.M.; GRAY, M.J.; QUARLES, A. Diets of newly metamorphosed amphibians in west Texas Playas. The Southwertern N aturalist, v.49, n. 2, p.257-263, 2004. 
STEBBINS, R.C.; COHEN, N.W. A natural history of Amphibians. Princeton: Princeton University Press, 1995. $316 \mathrm{p}$.

STRAUSS, R.E. Reliability estimates for Ivlev's electivity index, the forage ratio, and a proposed linear index of food selection. T ransactions of the A merican Fisheries Society, v.108, p.344-352, 1979.

STRÜSSMAN, C. et al. D iet and foraging mode of Bufo marinus and L eptodadylus ocellatus. Journal of H erpetology, v.18, n.2, p.138-146, 1984.

TINÔCO, M. S. Variação da composição da comunidade de artrópodes das formações florestadas do extremo sul da Bahia: disponibilidade de recursos alimentares para lagartos e sapos de semapilheria. 2004. 92 f. Dissertação (Mestrado em Ecologia e Biomonitoramento) - Instituto de Biologia, Universidade Federal da Bahia, Salvador.

TOFT, C.A. Feeding ecology of thirteen syntopic species of anurans in a seasonal tropical environment. 0 ecologia, v.45, p.131-141, 1980a.

TOFT, C.A. Seasonal variation in populations of Panamanian litter frogs and their prey: a comparison of wetter and drier sites. 0 eoologia, v.47, p.34-38, 1980b.

TOFT, C.A. Feeding ecology of Panamanian litter anurans: Patterns in diet and foraging mode. Journal of H erpetology, v.15, n. 2, p.139-144, 1981.

TOFT, C.A. Resource partitioning in amphibians and reptiles. Copeia, v.1985, n.1, p.1-21, 1985.

TOFT, C.A. Evolution of diet specialization in poison-dart frogs (Dendrobatidae). H erpetologica, v.51, n. 2, p.202-216, 1995.

TRICART, J. Existence de périods sèches au quaternaire en Amazonie et dans les régions voisines. V er. G eomorphologie D ymnamique, n.4, p.61-90, 1974.

VAN DER AART, P.J.M.; SMEENK-ENSERINK, N. Correlations between distributions of hunting spiders (Lycosidae, Ctenidae) and environmental characteristics in a dune area. N etherland Journal of Z oology, v.25, n.1, p.1-45, 1975.

VITT, L.J. An introduction to the ecology of cerrado lizards. Journal of $H$ erpetology, v.25, n.1, p. 79-80, 1991.

VITT, L.J. The ecology of tropical lizards in the caatinga of Northeast Brazil. 0 ccasional Papers of the 0 k lahoma M useum of N atural H istory, n.1, p.1-29, 1995. 
VITT, L.J.; CALDWELL, J.P. Resource utilization and guild structure of small vertebrates in the Amazon forest leaf litter. Journal of Z oology L ondon, v.234, p.463-476, 1994.

VITT, L.J.; ZANI, P.A. Organization of a taxonomic diverse assemblage in Amazonian Ecuador. Canadian Journal of Z oology, v.74, p.1313-1335, 1996.

VITT, L.J.; ZANI, P.A. Prey use among sympatric lizard species in lowland rain forest of Nicaragua. Journal of Tropical E œlogy, v.14, p.537-559, 1998.

VITT, L.J. et al. History and the global ecology of squamate reptiles. A merican N aturalist, v.162, n.1, p.44-61, 2003.

WEATHER, C.P. Prey-size and parasite relationships in the common toad Bufo bufo. H erpetological Journal, v.1, p.62-66, 1986.

WEBB, J.K.; SHINE, R. Dietary habits of australian blindsnakes (Typhlopidae). Copeia, v.3, p.762-770, 1993.

WEBB, J.K. et al. Life-history strategies in basal snakes: reproduction and dietary habits of the african thread snake L eptotyphlops satifrons (Serpentes: Leptotyphlopidae). Journal of Z oology L ondon, v.250, p.321-327, 2000.

WEBER, N.A. The food of the giant toad, Bufo marinus (L.), in Trinidad and British Guiana with special reference to the ants. A nnals of the $E$ ntomological Sodety of A merica, v. 31, p.499-503, 1938.

WERREN, G.L. Size and diet of Bufo marinus in rainforest of Northeastem Queensland. M emoirs of the Q ueensland M useum, v.34, n.1, p.240, 1993.

WHITING, M.J.; DIXON, J.R.; GREENE, B.D. Spatial ecology of the Concho water snake (N erodia harteri paudimaculata) in a large lake system. Journal of H erpetology, v.31, n.3, p.327-335, 1997.

WINEMILLER, K.O.; PIANKA, E.R. Organization in natural assemblages of desert lizards and tropical fishes. E ological M onographs, v.60, n.1, p.27-55, 1990.

ZAR, J.H. Biostatistical analysis. 4 ed. New Jersey: Prentice Hall, 1999. 663 p. 